\title{
Heat Flow in Southernmost California and the Origin of the Salton Trough
}

\author{
Arthur H. Lachenbruch, J. H. Sass, and S. P. Galanis, Jr.
}

U.S. Geological Survey, Menlo Park, California

\begin{abstract}
Heat flow in the Imperial Valley and adjacent crystalline rocks is very high $\left(\sim 140 \mathrm{~mW} \mathrm{~m}^{-2}\right)$. Gravity and seismic studies suggest the crust is about $23.5 \mathrm{~km}$ thick with the lower half composed of gabbro and the upper fourth composed of low-density sediments. Conduction through such a crust resting directly on asthenosphere would give the observed heat flow if there were no extension or sedimentation. However, both processes must have been active, as the Imperial Valley is part of the Salton Trough, a pull-apart sedimentary basin that evolved over the past 4 or $5 \mathrm{~m} . \mathrm{y}$. To investigate the interrelations of these factors, we consider a one-dimensional model of basin formation in which the lower crustal gabbro and upper crustal sediments accumulated simultaneously as the crust extended and sedimentation kept pace with isostatic subsidence. For parameters appropriate for the Salton Trough, increasing the extension rate has little effect on surface heat flow because it increases effects of heating by intrusion and cooling by sedimentation in a compensating manner; it does, however, result in progressively increasing lower crustal temperatures. Analytical results suggest that the average extensional strain rate during formation of the trough was $\sim 20-50 \% / \mathrm{m} . y .\left(\sim 10^{14} \mathrm{~s}^{-1}\right)$; slower rates are inadequate to account for the present composition of the crust, and faster rates would probably cause massive crustal melting. To achieve the differential velocities of the Pacific plate at one end of the trough and North American plate at the other with this strain rate, extension must have, on the average, been distributed (or shifted about) over a spreading region $\sim 150 \mathrm{~km}$ wide. This is about 10 times wider than the present zone of active seismicity, suggesting that the seismic pattern is ephemeral on the time scale for the trough's formation. Narrow spreading zones are typical where sustained spreading is compensated by basaltic intrusion to form the thin oceanic crust, but where such spreading occurs in thicker continental crust, broader zones of distributed extension (with smaller strain rates) may be required for heat balance. The Salton Trough model suggests that distributed extension can be associated with substantial magmatic additions to the crust; their effect on crustal buoyancy has important implications for the relation between crustal extension and subsidence.
\end{abstract}

\section{INTRODUCTION}

Southernmost California is a region of high mountains, deep valleys, active faults, and locally intense geothermal activity. Within it, the central tectonic feature is the Salton Trough, a large complex pull-apart basin that lies astride the Pacific-North American plate boundary over the $300 \mathrm{~km}$ distance between the southern end of the San Andreas fault near the Salton Sea and the northern end of the Gulf of California in Mexico (Figures 1 and 2). Although the principal tectonic motion is shearing between the plates (represented by horizontal velocity differences of several centimeters per year), rapid uplift of rugged mountains nearby [Sharp, 1982] and evidence for rapid sedimentation in the trough indicate substantial vertical rates of motion as well (up to a few millimeters per year). The vertical motions cause mass to move normal to isotherms and convect heat to or from the surface; they are the ones most effective in generating a simple connection between heat flow and crustal tectonic processes.

New measurements in the Salton Trough and surrounding regions reveal that there are large contrasts in heat flow which do indeed correlate with the major tectonic and physiographic features. The most conspicuous anomaly is the broad high heat flow in the Imperial Valley portion of the Salton Trough, one of the hottest known geothermal areas in the world. In this paper, we address the question "Why is the heat flow high in the Salton Trough?" The answer requires an explicit kinematic model of what is, and has been, going on there in the last several million years, i.e., a model of basin formation with rapid sedimentation, subsidence, and, presumably, extension and intrusion in some form. Because of the large local variability of the heat flow values and uncertainty about three-

This paper is not subject to U.S. copyright. Published in 1985 by the American Geophysical Union.

Paper number 4B5194. dimensional details of crustal structure, mainly onedimensional models are considered.

Many recent one-dimensional model studies of basin formation have followed McKenzie [1978] in which the tectonically active extensional stage is treated formally as a (virtually) instantaneous process; this provides an initial condition from which to calculate the slow passive subsidence associated with subsequent cooling and thermal contraction of the crust and mantle. Such studies generally involve basins that formed so long ago that thermal details of their early origin are obscure. The actively forming sedimentary basin in the Salton Trough provides an opportunity to study a basin in its initial stage.

In this paper we attempt to find a kinematic model for the formation of the trough that is consistent with major geologic and geophysical findings, but sufficiently simple and explicit to permit its thermal consequences to be calculated analytically with a few model parameters to be evaluated from observations. The kinematic model is developed in sections $3-5$, following presentation of heat flow results in section 2 ; it rests upon an interpretation of the regional gravity originally made by Biehler [1964] and upon recent seismic refraction measurements and their interpretation by Fuis et al. [1982, 1984]. The two results together suggest that the upper crust in the Imperial Valley is composed largely of young low-density sediments, and the lower crust largely of dense gabbroic material from the mantle, and that they compensate for one another gravitationally with the elevation near sea level. Our kinematic model for the evolution of this configuration is based on the following explicit assumptions which we believe to be consistent with what is known about the region.

1. The lower crustal "basalt" and upper crustal sediments accumulated simultaneously as the basin extended and its surface subsided.

2. Sedimentation maintained the surface near sea level, and isostatic balance prevailed. 


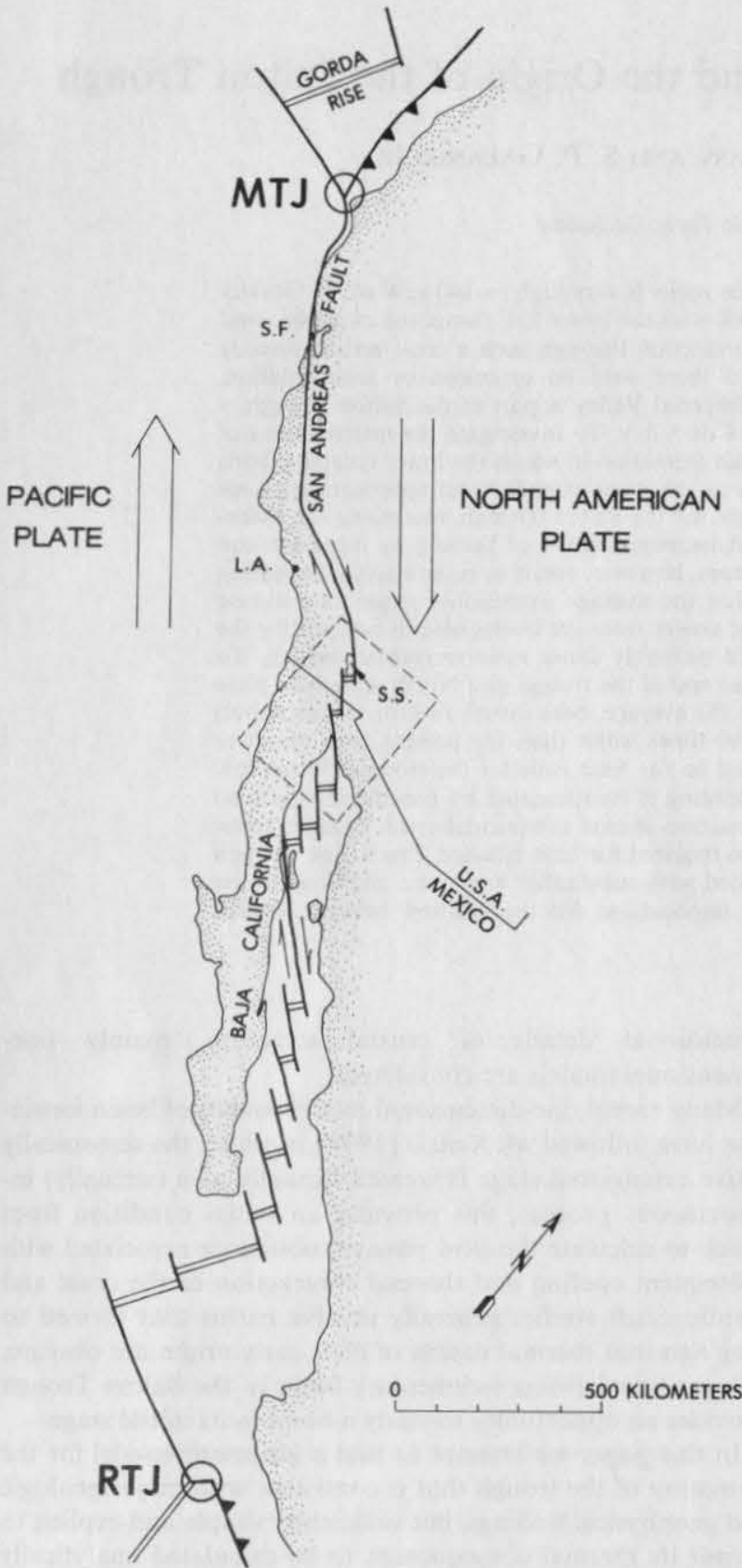

Fig. 1. Boundary between Pacific and North American plates. Abbreviations are MTJ, Mendocino Triple Junction; S.F., San Francisco; L. A., Los Angeles; S.S., Salton Sea; RTJ, Rivera Triple Junction. Rectangle shows location of Figure 2.

3. The crustal additions and extension occurred during opening of the Gulf of California over the past 4 or $5 \mathrm{~m} . \mathrm{y}$.

The important parameters controlling the velocity field in this extending crust are (1) the relative rates of sedimentation and intrusion $(\phi)$ and (2) the extensional strain rate of the crust $(\gamma)$. In section 6 it is shown that with assumption 2 above, $\phi$ is determined by the densities of the accumulating sediment and basalt from which its value can be estimated. This leaves extensional strain rate $\gamma$ as the principal free parameter.

Our original hope was that a thermal analysis of the kinematic model would permit us to evaluate the strain rate from the measured heat flow. However, it is shown in section 9 that although the model correctly "predicts" the measured heat flow, for parameter values appropriate to the Salton Trough, heat flow is insensitive to extension rate. The extension rate can, however, be constrained by considerations of crustal heat balance if deep crustal hydrothermal transport is unimportant and the following additional assumptions are valid.

4. The crust base temperature remained close to the mantle solidus during extension.

5. The crust has remained predominantly solid.

The use of steady state thermal models is justified by assumptions 3 and 4 , and heat balance at the base of the crust yields an upper limit to $\gamma$ from assumption 5 and a lower limit from assumption 4 . The lower limit $(\sim 25 \% / \mathrm{m} . y$. $)$ is consistent with an independent one based on present crustal composition and assumptions 1 and 3 . It is shown that strain rates probably can not be much larger than this minimum without extensive melting of the crust in violation of assumption 5. (The large hot springs that can invalidate these heat balance calculations at ocean ridges do not occur in the Salton Trough.) For reasonable (Pacific-North America) plate separation velocities at the ends of the trough this suggests that extension was, on the average, distributed (or shifted about) over a

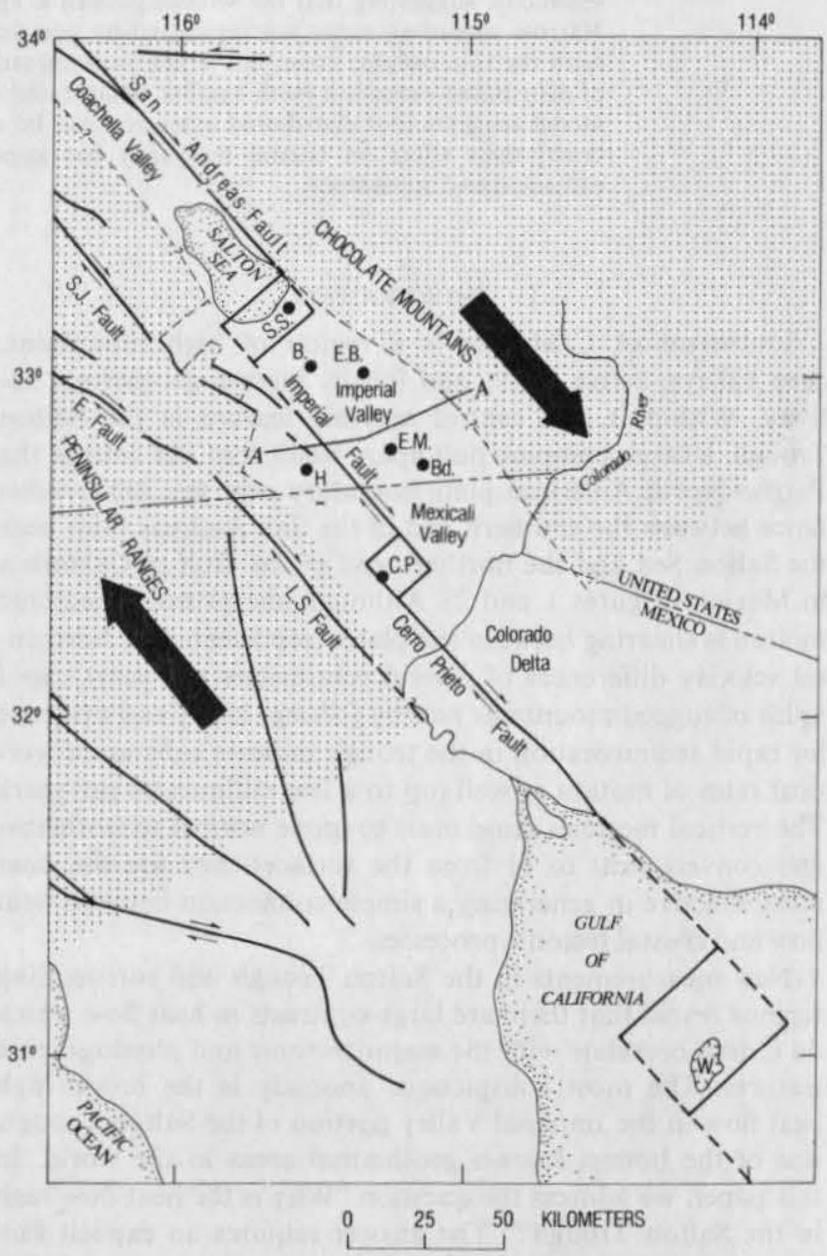

Fig. 2. Schematic structural relations in the Salton Trough adapted from Fuis et al. [1982], Elders et al. [1972], and Lomnitz et al. [1970]. Stippled pattern is extent of crystalline basement inferred by Fuis et al. [1982]; offset pattern of transform faults and spreading centers is from Lomnitz et al. [1970]. AA' denotes location of profile in Figure 9. Dots represent major geothermal areas. Abbreviations are S.S., Salton Sea; B, Brawley; E.B., East Brawley; E.M., East Mesa; Bd., Border; H, Heber; C.P., Cerro Prieto; W., Wagner Basin; S.J., San Jacinto; E, Elsinore; L.S., Laguna Salada. Heavy arrows indicate relative plate motion. 


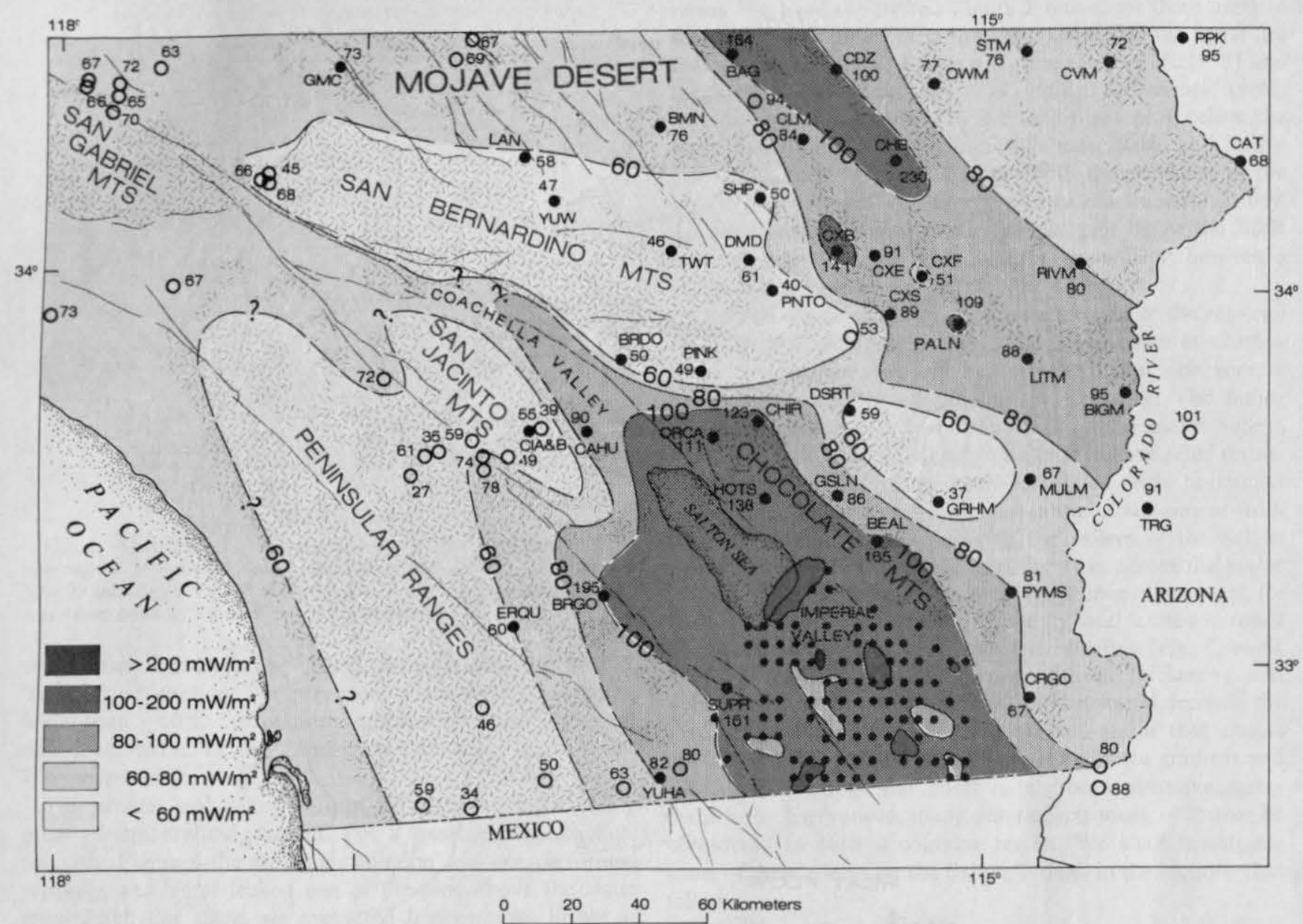

Fig. 3. Heat flow map of southernmost California. Solid circles represent data from Tables 1 and 2; open circles represent previously published values. Small dots show midpoints of rectangles ( 3 arc min latitude by 3 arc min longitude) for which average heat flows were calculated.

region $\sim 150 \mathrm{~km}$ wide, an order of magnitude wider than the present zone of active seismicity. This leads to our conclusion that the Salton Trough probably formed by distributed extension, not by ocean-type extension confined exclusively to the present seismic zone. It is important to emphasize that the inference is based largely on one-dimensional steady state results, but this is probably all that is warranted until more is known of the heat flow, crustal structure, and hydrology throughout the entire trough.

\section{HeAT FLOW}

The present status of regional heat flow measurements in southernmost California is summarized in Figure 3, the location of which is shown by the rectangle on the regional heat flow map of the western United States in Figure 4. Open circles in Figure 3 represent previously published heat flows; the solid circles and dots represent new measurements to be discussed below. The northeastern third of Figure 3 is part of the Basin and Range physiographic province [Fenneman, 1946] where the heat flow is generally high $\left(\sim 80 \mathrm{~mW} / \mathrm{m}^{2}\right)$; the western portion contains the Peninsular Ranges for which relatively low heat flow ( $\lesssim 60 \mathrm{~mW} \mathrm{~m} \mathrm{~m}^{-2}$ ) is well documented [Roy et al., 1972; Smith et al., 1979]. The central part of Figure 3 is a complex region associated with the San Andreas fault zone that includes the Salton Trough (Coachella Valley, Salton Sea, Imperial Valley) and surrounding mountain ranges. The Salton Trough can be viewed tectonically as a northwestward continuation of the Gulf of California where high heat flow has been measured by Von Herzen [1963], Lawver and Williams [1979], and Henyey and Bischoff [1973].

Three hundred and twenty-two heat flow estimates were obtained from unconsolidated sediments in the upper $\sim 150 \mathrm{~m}$ of the Imperial Valley. These results consist of (1) 26 independent determinations using a combination of conventional measurements and an in situ technique [Sass et al., 1981], 15 in the Glamis-east Brawley area [Mase et al., 1981], and 11 west of the known geothermal fields [Sass et al., 1984], (2) 34 sites for which heat flows, published originally by Swanberg [1974], were reevaluated using the least squares gradient below $60 \mathrm{~m}$ and the mean of 93 in situ determinations of thermal conductivity in the Imperial Valley, (3) temperaturegradient data from 260 holes deeper than $60 \mathrm{~m}$ in the Imperial Valley obtained from R. W. Rex (personal communication, 1983), which were also combined with the mean in situ thermal conductivity to produce estimates of conductive heat flux, and (4) estimates from two deep geothermal exploration wells in the Imperial Valley. Details of the data acquisition are presented in Appendix A.

For the purposes of the present discussion we found it convenient to group the data in the areas of densest coverage, and we based our contours on the average heat flow within 3 arc $\min \times 3 \operatorname{arc} \min (\sim 5 \mathrm{~km} \times 5 \mathrm{~km})$ elements (small dots, Figure 3). (For individual heat flow values, see Sass et al. [1984].) The resulting contours (Figure 3) indicate a back- 


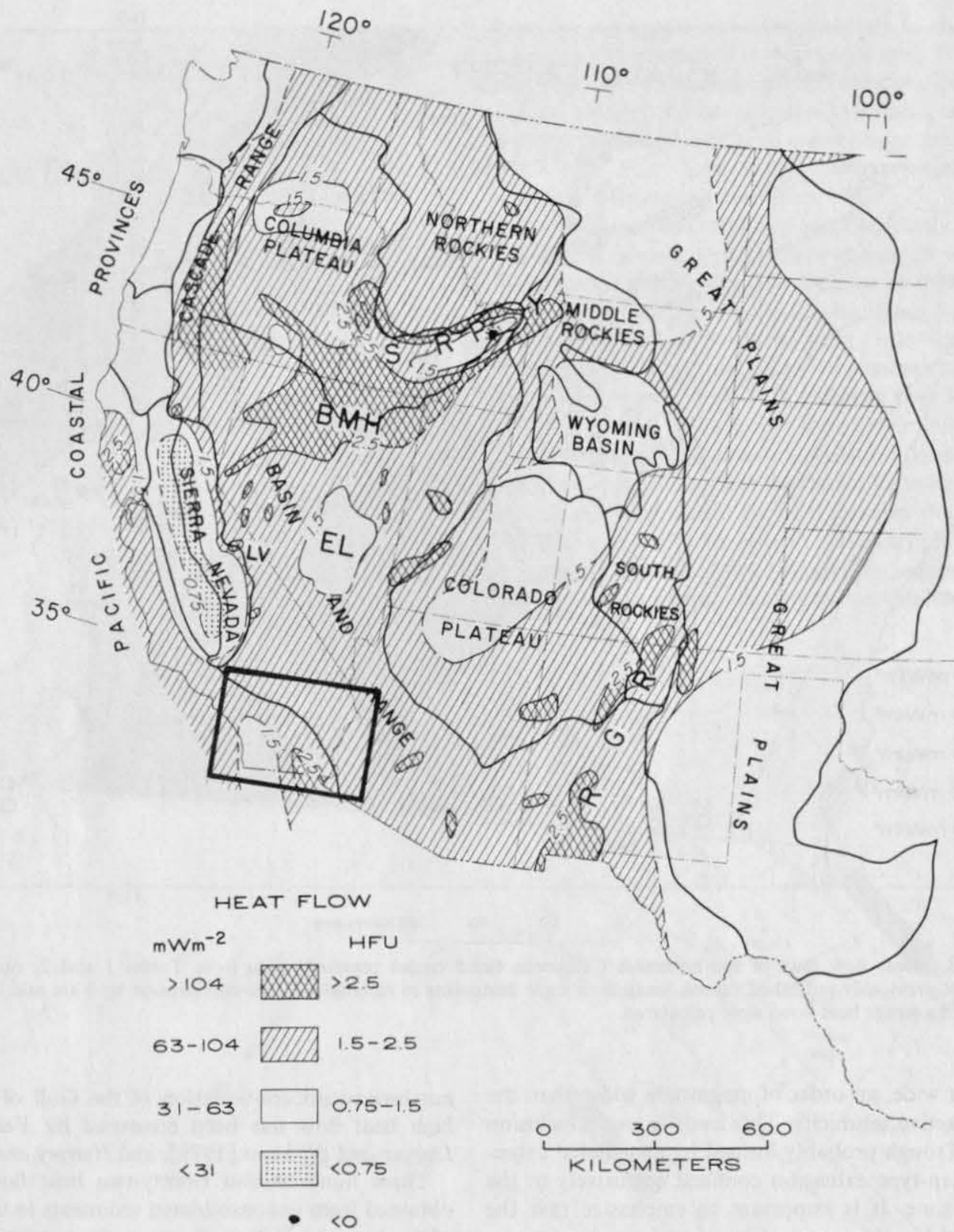

Fig. 4. Heat flow map of western United States with rectangle showing location of Figure 3. Contours in heat flow units (HFU). Abbreviations are SRP, Snake River Plain; Y, Yellowstone; BMH, Battle Mountain High; E.L., Eureka Low: LV, Long Valley Caldera; RGR, Rio Grande Rift.

ground heat flux between 100 and $200 \mathrm{~mW} \mathrm{~m}^{-2}$. Higher values $\left(>200 \mathrm{~mW} \mathrm{~m}^{-2}\right.$ ) all correspond to known geothermal fields which are generally associated with upward water flow and, in one instance (S.S., Figure 2), local late Pleistocene volcanism. Zones of relatively lower heat flow $(<100 \mathrm{~mW}$ $\mathrm{m}^{-2}$ ) probably represent downward water movement. In fact, the variability of the heat flow suggests a complex pattern of hydrothermal flow, a meaningful analysis of which probably requires more and better data. However, unlike at oceanic ridges and most other geothermal areas, advective heat discharge to surface springs and aquifers is negligible in the Imperial Valley and consequently the average of the heat flows is probably a good estimate of mean crustal heat loss. The formal mean for all $993 \mathrm{arcmin} \times 3$ arc min average heat flows within the valley is $166 \mathrm{~mW} \mathrm{~m}^{-2}$ (Figure 5), but with the exception of 10 very high values associated with geothermal areas that might have been oversampled (crosshatched, Figure
5) they are distributed normally about a mean and modal value of about $140 \mathrm{~mW} \mathrm{~m}^{-2}$. We prefer the latter value, although the distinction between them is not very important to the analysis. Allowing about $15 \mathrm{~mW} \mathrm{~m}^{-2}$ for the contribution from crustal radioactivity (equation (B4a) of Appendix B and Table 7 of Sass et al. [1984]), we estimate the modal reduced heat flow for the Imperial Valley to be $\sim 125 \mathrm{~mW} \mathrm{~m}^{-2}(\sim 3$ $\mathrm{HFU}$ ). This value is adopted as a basis for the discussion that follows.

New measurements of heat flow were obtained also at 43 sites in regions of crystalline rock surrounding the Salton Trough (solid circles, Figure 3, and Tables 1 and 2). The holes were sited so as to minimize the uncertainties resulting from topography, refraction, and hydrologic disturbances (see Appendix A). They range in depth from 60 to $256 \mathrm{~m}$ and with few exceptions (usually the result of adverse drilling conditions) are deeper than $100 \mathrm{~m}$. Except for the shallowest wells $(<100$ 


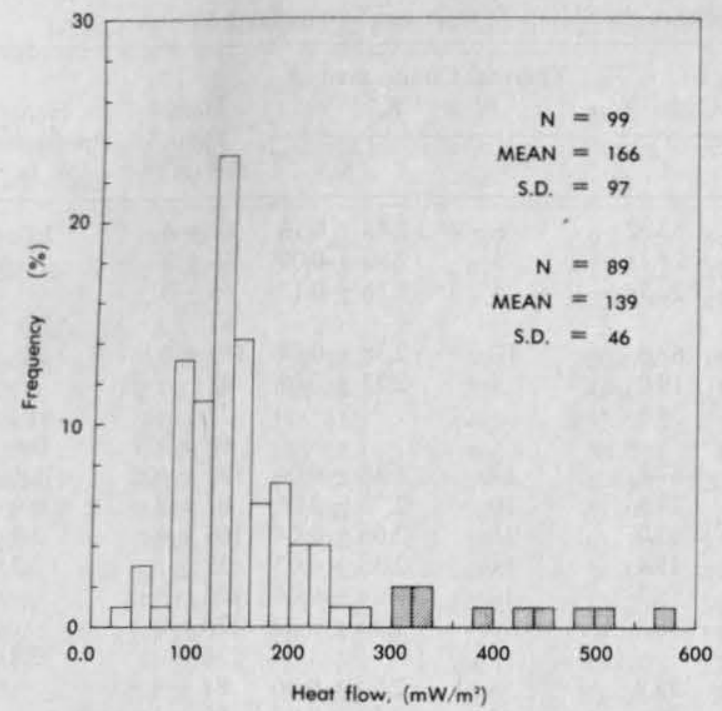

Fig. 5. Distribution of average heat flows from $3 \mathrm{arc} \min \times 3 \mathrm{arc}$ min regions in Imperial Valley (small dots of Figure 3). Statistics for $N=99$ include all values; statistics for $N=89$ exclude regions with mean heat flows $\geqq 300 \mathrm{~mW} \mathrm{~m} \mathrm{~m}^{-2}$ (crosshatched).

$\mathrm{m}$ ) and two with hydrologic disturbance (HOTS and BRGO, Table 1) we consider the precision of the heat flows to be better than $\pm 10 \%$. Temperature profiles corresponding to the data presented in Tables 1 and 2 are shown in Figures 6 and 7 , respectively.

The profiles are arranged from left to right in ascending order of temperature gradient. For a number of wells illustrated in Figure 6 the casing installation was not performed properly, and water leaked out of the pipe above the static water level. For these, we measured temperatures in air at discrete intervals of $8 \mathrm{~m}$ (shown as discrete symbols in Figure 6).

The new values in crystalline rock help to clarify the heat flow distribution in the region. High heat flow values, comparable to those in the sediments of the Imperial Valley, occur in bordering crystalline rocks on both sides, suggesting that the Imperial Valley anomaly is not a superficial feature associated with the sediments or local hydrology. Near the Mexican border, new sites confirm the transition [Roy et al., 1972] from low to high heat flow between the Peninsular Ranges and the Salton Trough. Farther north, we have obtained reliable redundant measurements at CIA and CIB in the Pinyon Flat Observatory (University of California, San Diego). They lie near the eastern end of Lee's [1983] heat flow profile across the San Jacinto fault and confirm his finding of low-to-normal heat flow in the San Jacinto-Santa Rosa Mountains. Taken with the site CAHU (Figure 3), they indicate a rapid transition to high values at the western edge of the Coachella Valley. Low heat flows reappear across the valley at the edge of the San Bernardino Mountains (BRDO, PINK, Figure 3), and in fact, the entire San Bernardino Mountain Range can now be contoured as a region of low-to-normal heat flow.

Radiogenic heat production $A_{0}$ is listed for individual sites in Tables 1 and 2. A plot of heat flow $q$ versus $A_{0}$ (Figure 8) shows a similar range and scatter to that reported by Lachenbruch and Sass [1977, 1978] for the Basin and Range province. Apart from the Salton Trough, three distinct tectonic provinces are represented in the study area: the eastern Mojave subprovince of the Basin and Range (B\&R), the Peninsular Ranges (PR), and the eastern and central Transverse Ranges (ETR) (San Gabriel, San Bernardino, and Chuckwallah moun- tains). We have subdivided Figure 8 into these three units to search for patterns of variation. Also shown on the figure are the original Basin and Range $q-A_{0}$ line [Roy et al., 1968] and the Sierra Nevada line [Roy et al., 1968; Lachenbruch, 1968]. All sites for the eastern Transverse Ranges plot below the Basin and Range reference line, while most Basin and Range points plot near or above the line. With the exception of the sites in the western boundary region of the Imperial Valley, values from the Peninsular Ranges also plot below the $B \& R$ reference line; however, no correlation seems likely between $q$ and $A_{0}$ for any easily identifiable tectonic unit.

Detailed discussion of the $q-A_{0}$ relation and of the regional data shown in Figure 3 is deferred to a later paper in which a larger geographic area will be considered, but one general observation seems worth making at this time. The major mountain ranges have low heat flow and the major valleys have high heat flow. It is likely that much of the relief results from large vertical strain rates associated with horizontal compression and crustal thickening in the mountains or from extension and crustal thinning in the valleys of the Salton Trough. Because of the large shearing rates across the major plate boundary direction $\left(\sim \mathrm{N} 45^{\circ} \mathrm{W}\right)$, minor departures (of either sign) from this master direction by local faults can result in such rapid and locally variable vertical strain [e.g., Crowell, 1974a]. Vertical strain that causes crustal thickening and uplift will separate isotherms, an effect that would decrease the thermal gradient and heat flow; vertical strain that causes crustal thinning and subsidence tends to increase gradient and heat flow. Although this effect is in gross qualitative agreement with observations, many other effects must, of course, be considered in such a complex region. We shall investigate some of these effects for the Salton Trough in the sections that follow.

\section{Other Geophysical Measurements and the Crustal Model}

Biehler [1964] noted that "The Imperial Valley, with over $5.5 \mathrm{~km}$ of sediments, is anomalously associated with a broad gravity high." From this relation, he inferred that anomalous extra mass was present at "intracrustal" depths, either from an anomalously thin crust (he estimated $21 \mathrm{~km}$ relative to $29 \mathrm{~km}$ at San Diego) or widespread crustal intrusion beneath the Imperial Valley (see also Kovach et al. [1962]). Biehler's inference was confirmed in an extensive seismic refraction study by Fuis et al. [1982], who showed that the entire lower crust (beneath $12 \pm \mathrm{km}$ ) has an anomalously high compressional wave velocity. This is seen in the Fuis et al. [1982] crustal profile along the line $\mathrm{AA}^{\prime}$ (Figure 2), which we present in modified form as Figure 9. Their seismically determined boundaries are shown as solid lines; compressional wave velocities are in parentheses. A broad trough of sediments $\left(v_{p} \lesssim\right.$ $4.5 \mathrm{~km} / \mathrm{s}$ ) up to $5 \mathrm{~km}$ deep is bounded on the west by a steep scarp in the basement; on the east the sediments taper off more gradually toward the Chocolate Mountains. Beneath the sediments in the central trough, the basement has an anomalously low velocity $\left(v_{p} \cong 5.65 \mathrm{~km} / \mathrm{s}\right)$ and extends to a depth of about $12 \mathrm{~km}$, beneath which a high-velocity "subbasement" material $\left(v_{p} \sim 7.2 \mathrm{~km} / \mathrm{s}\right)$ extends to undetermined depth. Fuis et al. $[1982,1984]$ suggest that the basement material in the central trough represents basin sediments metamorphosed to the greenschist facies [see also Muffler and White, 1969], although the possibility that some of it represents original (prebasin) crust probably cannot be ruled out. They identify the subbasement with mafic intrusive rock, and we note that the 
TABLE 1. Heat Flow and Heat Production for Crystalline Rocks of the Salton Trough and Surrounding Region

\begin{tabular}{|c|c|c|c|c|c|c|c|c|c|c|}
\hline \multirow{2}{*}{$\begin{array}{c}\text { Well } \\
\text { Designation }\end{array}$} & \multirow{2}{*}{$\begin{array}{l}\text { Latitude } \\
\quad \mathrm{N}\end{array}$} & \multirow{2}{*}{ Longitude } & \multirow{2}{*}{$\begin{array}{l}\text { Elevation, } \\
\mathrm{m}\end{array}$} & \multirow{2}{*}{$\begin{array}{c}\text { Depth } \\
\text { Range, } \\
\text { m }\end{array}$} & \multicolumn{2}{|c|}{ Gradient, ${ }^{\circ} \mathrm{C} \mathrm{km}^{-1}$} & \multicolumn{2}{|c|}{$\begin{array}{l}\text { Thermal Conductivity, } \uparrow \\
\qquad \mathbf{W} \mathbf{m}^{-1} \mathbf{K}^{-1}\end{array}$} & \multirow{2}{*}{$\begin{array}{c}\text { Heat } \\
\text { Flow, } \\
\mathrm{mW} \mathrm{m}^{-2}\end{array}$} & \multirow{2}{*}{$\begin{array}{c}\text { Heat } \\
\text { Production } \\
\mu \mathrm{W} \mathrm{m}^{-3}\end{array}$} \\
\hline & & & & & $\Gamma_{m}$ & $\Gamma_{c}$ & $N$ & $\langle K\rangle$ & & \\
\hline YUHA & $32^{\circ} 41.9^{\prime}$ & $116^{\prime} 00.4^{\prime}$ & 256 & $30-104$ & $33.32 \pm 0.03$ & 33.32 & 6 & $2.45 \pm 0.13$ & $82 \pm 4$ & 1.1 \\
\hline CRGO & $3255.2^{\prime}$ & $114^{\prime} 50.8^{\prime}$ & 194 & $\begin{array}{r}61-122 \\
122-180\end{array}$ & $\begin{array}{l}24.11 \pm 0.03 \\
20.19 \pm 0.06\end{array}$ & $\begin{array}{l}24.11 \\
20.79\end{array}$ & $\begin{array}{l}5 \\
5\end{array}$ & $\begin{array}{l}2.80 \pm 0.09 \\
3.16 \pm 0.13\end{array}$ & $\begin{array}{l}68 \pm 2 \\
66 \pm 3\end{array}$ & \\
\hline Mean & & & & & & & & & $67^{-}$ & 2.0 \\
\hline SUPR & $32^{\prime} 56.6^{\prime}$ & $11547.9^{\prime}$ & 137 & $61-164$ & $57.88 \pm 0.05$ & 63.5 & 12 & $2.38 \pm 0.04$ & $151 \pm 5$ & 1.2 \\
\hline ERQU & $33^{\circ} 05.3^{\prime}$ & $116^{\circ} 29.6^{\circ}$ & 807 & $\begin{array}{l}38-59 \\
56-59\end{array}$ & $\begin{array}{l}17.7 \pm 0.5 \\
31.6 \pm 0.8\end{array}$ & $\begin{array}{l}19.2 \\
34.6\end{array}$ & 5 & $2.22 \pm 0.08$ & $\begin{array}{l}43^{-1} \\
77\end{array}$ & \\
\hline Mean & & & & & & & & & $60 \pm 17$ & 0.4 \\
\hline BRGO & $33^{\circ} 10.8^{\prime}$ & $116^{\prime} 12.1^{\prime}$ & 192 & $30-91$ & $70.5 \pm 0.1 \ddagger$ & 67.8 & 12 & $2.88 \pm 0.04$ & $195 \pm 10 \ddagger$ & 1.4 \\
\hline PYMS & $33^{\prime} 11.7^{\prime}$ & $114^{\prime} 54.3^{\prime}$ & 318 & $46-161$ & $29.5 \pm 0.1$ & 29.5 & 10 & $2.73 \pm 0.06$ & $81 \pm 2$ & 0.8 \\
\hline BEAL & $33^{\prime \prime} 19.8^{\prime}$ & $115^{\prime} 20.2^{\prime}$ & 414 & $61-239$ & $63.3 \pm 0.2$ & 62.0 & 15 & $2.66 \pm 0.04$ & $165 \pm 4$ & 2.9 \\
\hline GRHM & $33^{2} 26.5^{\prime}$ & $11508.3^{\prime}$ & 482 & $107-179$ & $15.8 \pm 0.03$ & 15.4 & 11 & $2.38 \pm 0.03$ & $37 \pm 1$ & 1.3 \\
\hline HOTS & $33^{\circ} 27.3^{\prime}$ & $115^{\prime} 41.5^{\prime}$ & 134 & $\begin{array}{r}91-160 \\
198-234\end{array}$ & $\begin{array}{r}55.5 \pm 0.1 \\
46.75 \pm 0.1\end{array}$ & $\begin{array}{l}55.3 \\
46.3\end{array}$ & $\begin{array}{r}10 \\
4\end{array}$ & $\begin{array}{l}3.07 \pm 0.04 \\
2.98 \pm 0.03\end{array}$ & $\begin{array}{l}170 \pm 3 \\
138 \pm 2\end{array}$ & \\
\hline Best value§ & & & & & & & & & 138 & 2.8 \\
\hline GSLN & $33^{\circ} 27.4^{\prime}$ & $115^{\prime} 28.4^{\prime}$ & 573 & $\begin{array}{r}46-145 \\
152-239\end{array}$ & $\begin{array}{c}36.6 \pm 0.2 \\
37.79 \pm 0.03\end{array}$ & $\begin{array}{l}33.2 \\
35.6\end{array}$ & $\begin{array}{l}8 \\
7\end{array}$ & $\begin{array}{l}2.52 \pm 0.06 \\
2.50 \pm 0.02\end{array}$ & $\begin{array}{l}84 \pm 3 \\
89 \pm 3\end{array}$ & \\
\hline Mean & & & & & & & & & $86^{1-}$ & 2.3 \\
\hline MULM & $33^{\prime} 29.8^{\prime}$ & $114^{\prime} 50.3^{\prime}$ & 232 & $\begin{array}{r}30-100 \\
104-146\end{array}$ & $\begin{array}{r}25.6 \pm 0.03 \\
22.88 \pm 0.02\end{array}$ & $\begin{array}{l}24.5 \\
22.5\end{array}$ & $\begin{array}{l}5 \\
4\end{array}$ & $\begin{array}{l}2.86 \pm 0.09 \\
2.85 \pm 0.02\end{array}$ & $\begin{array}{l}70 \pm 4 \\
64 \pm 2\end{array}$ & \\
\hline $\begin{array}{l}\text { Mean } \\
\text { ORCA }\end{array}$ & & & & & $333+0.9$ & 333 & 4 & $3.27+0.15$ & $\begin{array}{c}67 \\
109+5\end{array}$ & 0.6 \\
\hline ORCA & $33^{\circ} 35.8^{\prime}$ & $115^{\prime} 52.8^{\prime}$ & 347 & $\begin{array}{l}30-69 \\
70-122\end{array}$ & $36.80 \pm 0.06$ & 36.8 & 5 & $3.03 \pm 0.07$ & $\begin{array}{l}112 \pm 2 \\
112 \pm 2\end{array}$ & \\
\hline $\begin{array}{l}\text { Mean } \\
\text { CIB }\end{array}$ & & & & $122 \cdot 244$ & & & & & 111 & 1.8 \\
\hline $\begin{array}{l}\text { CIB } \\
\text { CIA }\end{array}$ & $\begin{array}{l}33^{\prime} 36.6^{\prime} \\
33^{\circ} 36.8^{\prime}\end{array}$ & $\begin{array}{l}116^{\prime} 27.2^{\prime} \\
116^{\prime} 27.5^{\prime}\end{array}$ & $\begin{array}{l}1280 \\
1280\end{array}$ & $\begin{array}{r}122 \cdot 244 \\
76-229\end{array}$ & $21.82 \pm 0.01$ & $\begin{array}{l}22.7 \\
21.8\end{array}$ & 6 & $2.45 \pm 0.04$ & $56 \pm 1$ & 3.0 \\
\hline $\begin{array}{l}\mathrm{ClA} \\
\text { Mean }\end{array}$ & $33^{-} 36.8^{\prime}$ & & 1280 & & & 21.8 & 6 & $2.45 \pm 0.04$ & $\begin{array}{l}53 \pm 1 \\
55\end{array}$ & $\begin{array}{l}3.5 \\
3.2\end{array}$ \\
\hline CAHU & $33^{\circ} 36.8^{\prime}$ & $116^{\prime \prime} 16.1^{\prime}$ & 52 & $\begin{array}{r}76-152 \\
152-255\end{array}$ & $\begin{array}{c}40.0 \pm 0.1 \\
36.77 \pm 0.02\end{array}$ & $\begin{array}{l}38.4 \\
36.2\end{array}$ & $\begin{array}{r}7 \\
11\end{array}$ & $\begin{array}{l}2.36 \pm 0.07 \\
2.45 \pm 0.06\end{array}$ & $\begin{array}{l}91 \pm 4 \\
89 \pm 3\end{array}$ & \\
\hline Mean & & & & & & & & & 90 & 1.8 \\
\hline CHIR & $33^{\circ} 39.1^{\prime}$ & $115^{\circ} 43.1^{\prime}$ & 585 & $61-177$ & $40.98 \pm 0.01$ & 40.5 & 11 & $30.4 \pm 0.03$ & $123 \pm 2$ & 3.3 \\
\hline DSRT & $33^{\circ} 41.0^{\prime}$ & $115^{\circ} 25.6^{\prime}$ & 402 & $\begin{array}{l}46-85 \\
85-162\end{array}$ & $\begin{array}{l}17.45 \pm 0.04 \\
19.50 \pm 0.03\end{array}$ & $\begin{array}{l}17.45 \\
19.5\end{array}$ & $\begin{array}{l}4 \\
7\end{array}$ & $\begin{array}{l}3.26 \pm 0.03 \\
3.15 \pm 0.08\end{array}$ & $\begin{array}{l}57 \pm 1 \\
61 \pm 2\end{array}$ & \\
\hline Mcan & & & & & & & & & & 1.7 \\
\hline BIGM & $33^{\circ} 43.8^{\prime}$ & $114^{\prime} 31.5^{\prime}$ & 128 & $46-111$ & $25.91 \pm 0.07$ & 25.91 & 8 & $3.66 \pm 0.08$ & $95 \pm 3$ & 6.6 \\
\hline LITM & $33^{\prime} 49.1^{\prime}$ & $11451.0^{\prime}$ & 293 & $76-143$ & $35.88 \pm 0.08$ & 35.5 & 9 & $2.47 \pm 0.04$ & $88 \pm 2$ & 1.7 \\
\hline PAIN & $3354.8^{\prime}$ & $115^{\circ} 04.7^{\prime}$ & 373 & $\begin{array}{r}61-122 \\
128-177\end{array}$ & $\begin{array}{c}25.6 \pm 0.1 \\
28.14 \pm 0.03\end{array}$ & $\begin{array}{l}24.8 \\
27.5\end{array}$ & $\begin{array}{l}7 \\
4\end{array}$ & $\begin{array}{l}4.26 \pm 0.17 \\
4.07 \pm 0.49\end{array}$ & $\begin{array}{l}106 \pm 5 \\
112 \pm 16\end{array}$ & \\
\hline Mean & & & & & & & & & 109 & 1.9 \\
\hline $\begin{array}{l}\text { RIVM } \\
\text { Mean }\end{array}$ & $3404.0^{\prime}$ & $114^{\prime} 40.9^{\prime}$ & 378 & $\begin{array}{r}46-114 \\
122-175\end{array}$ & $\begin{array}{c}28.3 \pm 0.1 \\
30.06 \pm 0.01\end{array}$ & $\begin{array}{l}28.3 \\
30.06\end{array}$ & $\begin{array}{l}6 \\
5\end{array}$ & $\begin{array}{l}2.62 \pm 0.09 \\
2.84 \pm 0.02\end{array}$ & $\begin{array}{l}74 \pm 3 \\
85 \pm 1 \\
80\end{array}$ & 1.1 \\
\hline
\end{tabular}

${ }^{*} \Gamma_{m}$. gradient calculated over stipulated depth range (plus or minus standard error); $\Gamma_{\mathfrak{c}}$, corrected for steady state topography.

$+N$, number of specimens; $\langle K\rangle$, harmonic mean thermal conductivity (plus or minus standard error).

tThis represents a conductive cap overlying a hydrothermal convective system.

The uppermost value of flux represents a conductive cap on a small convective system between 168 and $190 \mathrm{~m}$. From $198 \mathrm{~m}$ to total depth, heat flow is conductive.

high velocity might imply a significant ultramafic component. Other profiles in this study show that the depth to the highvelocity subbasement shows no local anomaly at the "spreading center" linking the San Andreas and Imperial faults near Brawley (Figure 2); the subbasement depth increases northwestward toward the Salton Sea but remains relatively uniform southward to the Mexican border [Fuis et al., 1982, Figure 17]

To extend the implications of their crustal seismic information in the Salton Trough, Fuis et al. [1982] constructed a gravity model. They found that the simplest way to account for the absence of low gravity over the sedimentary trough was to extend the dense subbasement downward as an exaggerated mirror image of the sediments (see Figure 9). This configuration suggests a simple model for crustal evolution wherein the extending crust is intruded or underplated by the "basaltic" subbasement material, while subsidence is accompanied by rapid sedimentation to keep the surface near sea level and isostatic balance is maintained. As the sedimentation must occur over an extended period, this suggests a continuous process, which judging from the high heat flow, seismicity, and gcomorphic evidence must still be in progress [e.g., Sharp, 1982; Crowell and Sylvester, 1979].

This sequence suggests that magma is being supplied from below at a rapid rate (of the same order as sediments are being supplied from above), and this, in turn, suggests a warm lowdensity mantle beneath the extending crust of the trough. Figure 9 differs from the corresponding model by Fuis et al. [1982] by the introduction of such a low-density mantle (density $3.20 \mathrm{~g} / \mathrm{cm}^{3}$, Figure 9) to show that it need not violate the constraints imposed by observations of gravity or seismic velocity. (It is worth noting that teleseismic $P$ delay contours by Hadley and Kanamori [1977] bear some resemblance to the heat flow contours (Figure 3); they suggest a high-velocity body in the mantle beneath the Transverse Ranges and a low velocity beneath the Salton Trough.) 
TABLE 2. Heat Flow and Heat Production for Crystalline Rocks of the San Bernardino Mountains and Eastern Mojave Region

\begin{tabular}{|c|c|c|c|c|c|c|c|c|c|c|}
\hline \multirow{2}{*}{$\begin{array}{c}\text { Well } \\
\text { Designation }\end{array}$} & \multirow[b]{2}{*}{$\begin{array}{l}\text { Latitude } \\
\quad \mathrm{N}\end{array}$} & \multirow{2}{*}{$\underset{W}{\text { Longitude }}$} & \multirow{2}{*}{$\begin{array}{l}\text { Elevation, } \\
\text { m }\end{array}$} & \multirow{2}{*}{$\begin{array}{c}\text { Depth } \\
\text { Range, } \\
\text { m }\end{array}$} & \multicolumn{2}{|c|}{ Gradient, ${ }^{\circ} \mathrm{C} \mathrm{km}{ }^{-1}$} & \multicolumn{2}{|c|}{$\begin{array}{l}\text { Thermal Conductivity, } † \\
\qquad \mathrm{~W} \mathrm{~m}^{-1} \mathrm{~K}^{-1}\end{array}$} & \multirow{2}{*}{$\begin{array}{c}\text { Heat } \\
\text { Flow, } \\
\mathrm{mW} \mathrm{m}^{-2}\end{array}$} & \multirow{2}{*}{$\begin{array}{c}\text { Heat } \\
\text { Production, } \\
\mu \mathrm{W} \mathrm{m}^{-3}\end{array}$} \\
\hline & & & & & $\Gamma_{m}$ & $\Gamma_{c}$ & $N$ & $\langle K\rangle$ & & \\
\hline TRG & $33^{\circ} 25.5^{\prime}$ & $114^{\prime} 28.2^{\prime}$ & 262 & $91-160$ & $34.66 \pm 0.02$ & 34.66 & 9 & $2.63 \pm 0.16$ & $91 \pm 6$ & 0.8 \\
\hline \multirow{2}{*}{ PINK } & $33^{\circ} 46.7^{\prime}$ & $115^{\prime \prime} 55.9^{\prime}$ & 975 & $73-113$ & $27.99 \pm 0.04$ & 23.7 & 8 & $1.87 \pm 0.03$ & $44 \pm 2$ & \\
\hline & & & & $122-198$ & $19.99 \pm 0.02$ & 17.7 & 6 & $3.08 \pm 0.14$ & $54 \pm 3$ & \\
\hline Mean & & & & & & & & & $49 \pm 5$ & 1.4 \\
\hline BRDO & $33^{\circ} 48.8^{\prime}$ & $116^{\circ} 10.3^{\prime}$ & 301 & $100-132$ & $19.75 \pm 0.03$ & 18.25 & 9 & $2.72 \pm 0.07$ & $50 \pm 2$ & 2.3 \\
\hline CXS & $33^{\circ} 55.4^{\prime}$ & $115^{\circ} 18.2^{\prime}$ & 375 & $46-67$ & $35.0 \pm 0.3$ & 34.6 & 6 & $2.58 \pm 0.04$ & $89 \pm 2$ & 0.8 \\
\hline PNTO & $33^{\circ} 59.3^{\prime}$ & $115^{\prime} 41.3^{\prime}$ & 488 & $152-186$ & $14.5 \pm 0.2$ & 14.0 & 14 & $2.84 \pm 0.04$ & $40 \pm 1$ & 2.6 \\
\hline CXF & $34^{\circ} 02.6^{\prime}$ & $115^{\prime} 12.2^{\prime}$ & 466 & $30-101$ & $17.5 \pm 0.1$ & 17.5 & 7 & $2.90 \pm 0.07$ & $51 \pm 2$ & 1.0 \\
\hline DMD & $3404.3^{\prime}$ & $115^{\prime} 45.6^{\prime}$ & 530 & $47-102$ & $20.41 \pm 0.01$ & 20.6 & 7 & $2.94 \pm 0.08$ & $61 \pm 2$ & 3.2 \\
\hline TWT & $3405.4^{\prime}$ & $116^{\prime} 00.7^{\prime}$ & 786 & $61-91$ & $16.61 \pm 0.05$ & 14.6 & 5 & $3.16 \pm 0.17$ & $46 \pm 3$ & 1.4 \\
\hline CXE & $34^{\circ} 06.1^{\prime}$ & $115^{\prime} 21.1^{\prime}$ & 363 & $61-101$ & $33.42 \pm 0.08$ & 34.0 & 7 & $2.67 \pm 0.08$ & $91 \pm 3$ & 1.0 \\
\hline $\mathrm{CXB}$ & $3406.5^{\prime}$ & $115^{\circ} 28.6^{\prime}$ & 686 & $37-92$ & $49.18 \pm 0.06$ & 49.1 & 15 & $2.88 \pm 0.03$ & $141 \pm 2$ & 0.8 \\
\hline YVW & $34^{\circ} 13.5^{\prime}$ & $116^{\circ} 24.2^{\prime}$ & 1025 & $115-256$ & $16.39 \pm 0.13$ & 16.4 & 9 & $2.86 \pm 0.09$ & $47 \pm 2$ & 2.7 \\
\hline SHP & $34^{\circ} 14.4^{\prime}$ & $115^{\prime \prime} 43.4^{\prime}$ & 725 & $68-101$ & $17.21 \pm 0.04$ & 17.21 & 7 & $2.92 \pm 0.02$ & $50 \pm 1$ & 1.1 \\
\hline LAN & $34^{2} 20.4^{\prime}$ & $116^{\circ} 29.8^{\prime}$ & 1024 & $46-102$ & $22.61 \pm 0.04$ & 22.61 & 13 & $2.57 \pm 0.04$ & $58 \pm 1$ & 2.6 \\
\hline \multirow[t]{2}{*}{ CAT } & $34^{\circ} 21.1^{\prime}$ & $114^{\prime} 10.1^{\prime}$ & 145 & $91-114$ & $24.5 \pm 0.03$ & 23.5 & 5 & $3.15 \pm 0.20$ & $74 \pm 6$ & \\
\hline & & & & $118-124$ & $29.5 \pm 0.2$ & 28.7 & 3 & $2.15 \pm 0.13$ & $62 \pm 4$ & \\
\hline Mean & & & & & & & & & $68 \pm 6$ & 1.4 \\
\hline $\mathrm{CHB}$ & $3421.9^{\prime}$ & $115^{\prime} 17.2^{\prime}$ & 309 & $38-67$ & $99.2 \pm 0.3$ & 103.0 & 4 & $2.23 \pm 0.09$ & $230 \pm 12$ & 1.2 \\
\hline BMN & $34^{\circ} 24.7^{\prime}$ & $116^{\prime \prime} 04.1^{\prime}$ & 725 & $76-128$ & $25.19 \pm 0.04$ & 24.3 & 13 & $3.11 \pm 0.05$ & $76 \pm 2$ & 2.3 \\
\hline CLM & $3425.3^{\prime}$ & $115^{\wedge} 33.3^{\prime}$ & 210 & $79-99$ & $28.62 \pm 0.03$ & 28.62 & 4 & $2.93 \pm 0.07$ & $84 \pm 2$ & 2.1 \\
\hline OWM & $3432.7^{\prime}$ & $115^{\prime \prime} 09.5^{\prime}$ & 1222 & $84-102$ & $25.9 \pm 0.2$ & 25.0 & 5 & $3.09 \pm 0.05$ & $77 \pm 2$ & 1.5 \\
\hline GMC & $34^{\circ} 34.1^{\prime}$ & $117^{\circ} 06.4^{\prime}$ & 1030 & $61-152$ & $23.41 \pm 0.02$ & 23.2 & 18 & $3.16 \pm 0.13$ & $73 \pm 4$ & 2.3 \\
\hline $\mathrm{CDZ}$ & $34^{\circ} 34.2^{\prime}$ & $115^{\circ} 29.4^{\prime}$ & 381 & $46-102$ & $29.84 \pm 0.05$ & 31.0 & 7 & $3.24 \pm 0.03$ & $100 \pm 1$ & 5.5 \\
\hline CVM & $34^{\circ} 37.4^{\prime}$ & $114^{\prime \prime} 35.8^{\prime}$ & 713 & $30-49$ & $26.23 \pm 0.08$ & 25.7 & 8 & $2.82 \pm 0.04$ & $72 \pm 1$ & 1.5 \\
\hline BAG & $34^{\circ} 37.6^{\prime}$ & $115^{\circ} 49.6^{\prime}$ & 424 & $61-102$ & $50.30 \pm 0.03$ & 50.3 & 7 & $2.83 \pm 0.07$ & $142 \pm 4$ & 2.9 \\
\hline STM & $34^{\prime} 39.0^{\prime}$ & $114^{\circ} 52.2^{\prime}$ & 671 & $46-107$ & $24.74 \pm 0.06$ & 24.74 & 14 & $3.08 \pm 0.04$ & $76 \pm 1$ & 1,1 \\
\hline PPK & $34^{\prime} 40.8^{\prime}$ & $114^{\prime} 21.4^{\prime}$ & 430 & $122-175$ & $28.41 \pm 0.07$ & 28.41 & 5 & $3.36 \pm 0.14$ & $95 \pm 4$ & 3.7 \\
\hline
\end{tabular}

${ }^{*} \Gamma_{m}$, gradient calculated over stipulated depth range (plus or minus standard error); $\Gamma_{c}$, corrected for steady state topography.

$+N$, number of specimens; $\langle K\rangle$, harmonic mean thermal conductivity (plus or minus standard error).

In what follows, we shall refer to the crustal configuration of Figure 9 as the "geophysical model" to distinguish it from formal kinematic and thermal models needed to discuss the crustal processes. It is important that the geophysical model, though empirically based, is uncertain; e.g., the crustal thick- ness in the trough $(23.5 \mathrm{~km}$ according to Figure 9) has not been confirmed seismically, the local upper mantle velocity has not been determined, and the proportion of melt in the lower half of the crust cannot be estimated with confidence. We shall generally assume that the lower crust is mostly solid,

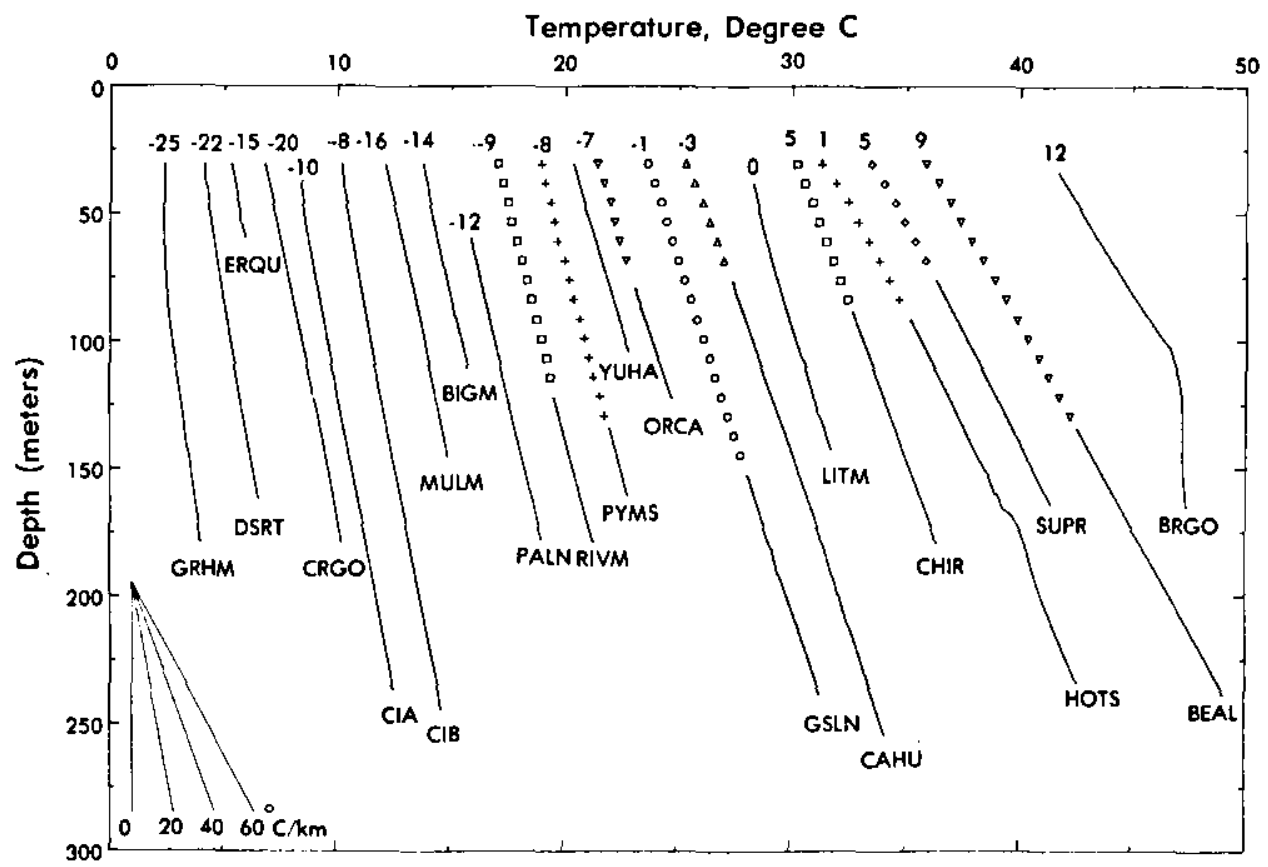

Fig. 6. Temperature profiles in crystalline rocks of the Salton Trough and surrounding regions (see Table 1). Number above each curve represents amount curve has been shifted relative to abscissal scale for plotting purposes. Discrete symbols represent temperature measurements made in air. 


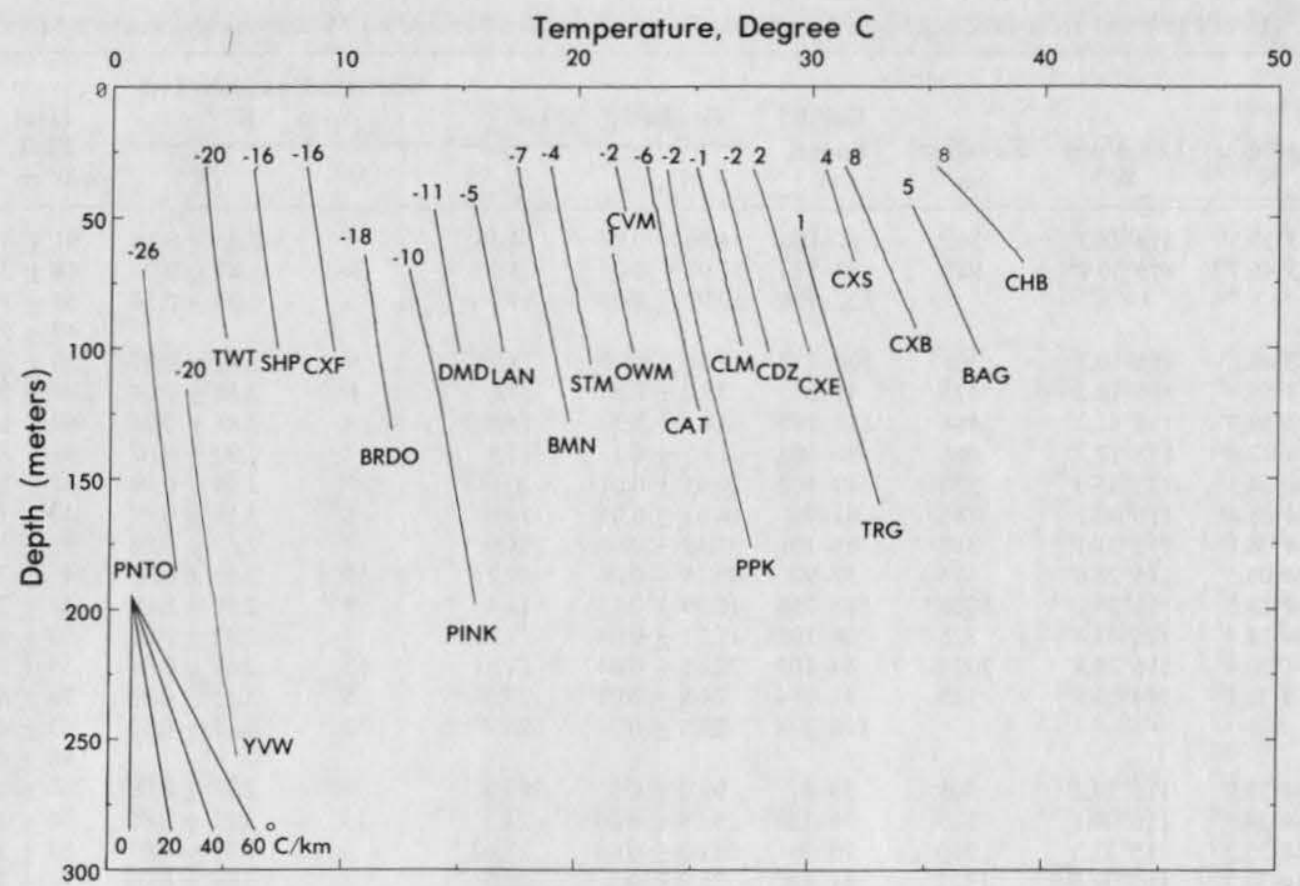

Fig. 7. Temperature profiles in crystalline rocks of the San Bernardino Mountains and Eastern Mojave Region (see Table 2). Number above each curve represents amount curve has been shifted relative to abscissal scale.

but if it is not, inferences based on heat balance will have to be modified. At the margins of the basin at least, it is likely that strain rate varies with depth and that detachment-type features may be forming, but details of crustal structure at the margins of the basin remain to be explored. Because of these uncertainties we shall consider only the simplest models.

\section{Geometry of Crustal Extension in the Salton Trough}

The Salton Trough lies on the plate boundary that cuts off a sliver of the North American continent between the Men-

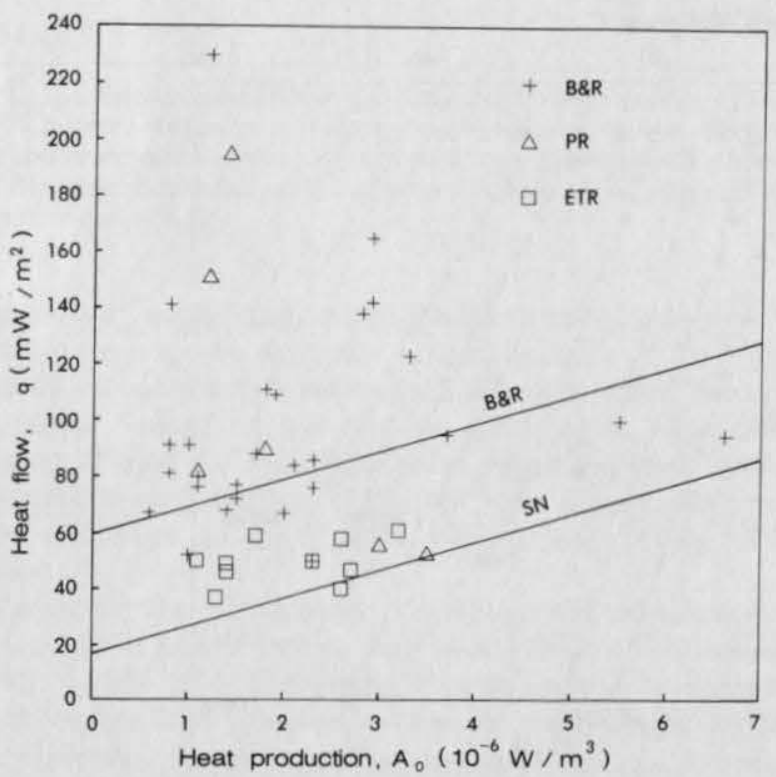

Fig. 8. Plot of measured heat flow $q$ versus mean radioactivity $A_{0}$ of drill samples for sites in crystalline rock listed in Tables 1 and 2 . Abbreviations are B\&R, Basin and Range province; P.R., Peninsular Ranges; ETR, Eastern Transverse Ranges; SN, Sierra Nevada Province. Lines labeled B\&R and SN represent respective province norms (see text). docino and Rivera triple junctions (Figures 1 and 2) [Atwater, 1970; Larson et al., 1968; Lomnitz et al., 1970; Elders et al., 1972]. The northern half of the boundary is the San Andreas right-lateral transform fault system; the southern half is the Gulf of California, which contains a series of right-stepping en echelon right-lateral transform faults offset by small spreading centers or basins. The Salton Trough is a pull-apart basin that occupies a region of transition between the northern and
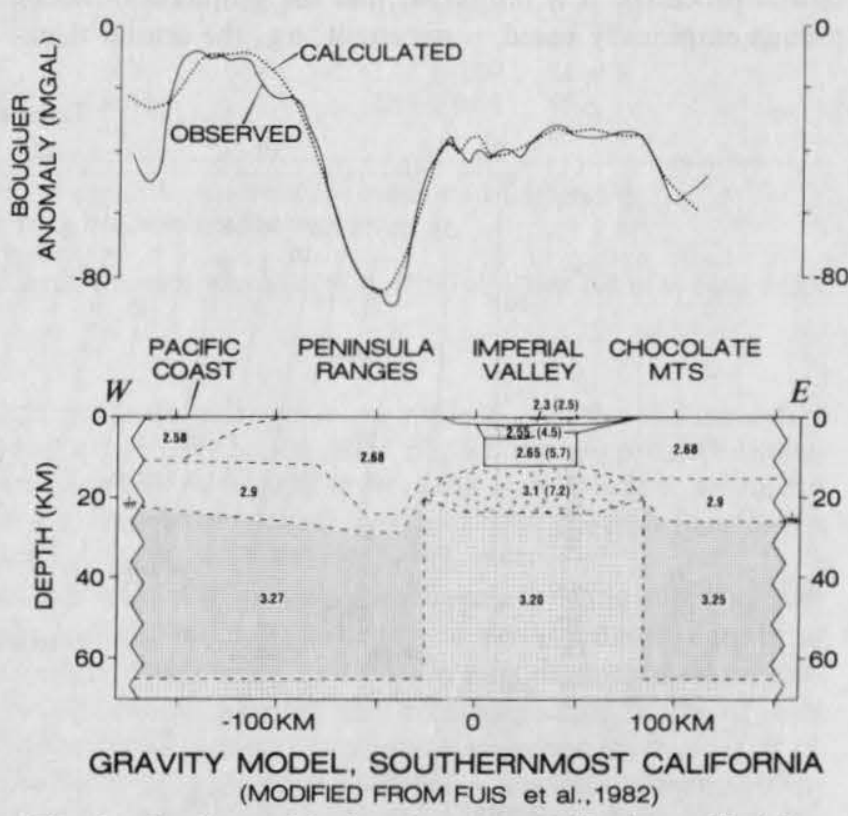

Fig. 9. Gravity model of southernmost California modified from Fuis et al. [1982, 1984] by addition of hot low-density mantle $(3.20$ $\mathrm{g} / \mathrm{cm}^{3}$ ) beneath Imperial Valley. Solid lines represent seismically determined boundaries and values in parentheses are approximate compressional wave velocities in kilometers per second determined by Fuis et al. [1982]. Numbers not in parentheses are densities in grams per cubic centimeter. Location of profile is line AA' (Figure 2) extended westward to the Pacific Coast. 


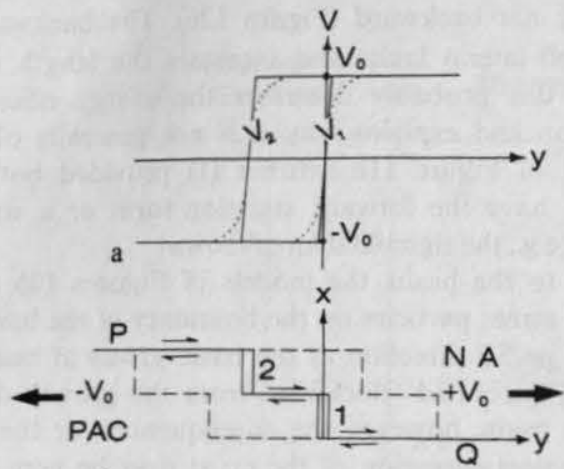

b
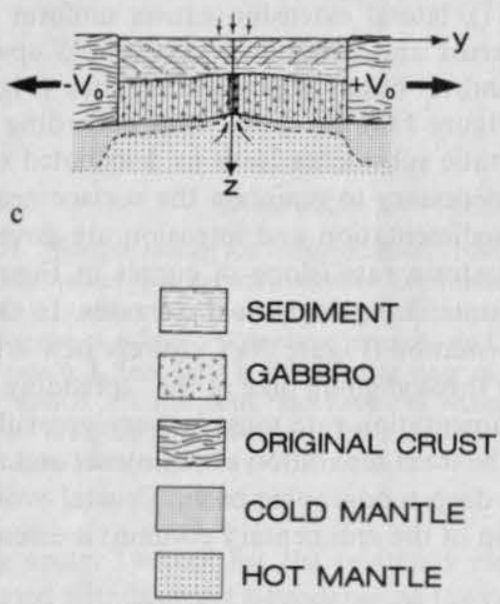

Fig. 10. Idealized model of localized (ocean type) extension with sedimentation and intrusion. (a) Velocity profiles $v_{1}$ and $v_{2}$ normal to the offsetting spreading centers 1 and 2 of Figure $10 b$. (b) Dashed lines show extent of basin created by spreading at the localized centers. (c) Section through basin crust created by central dike intrusion and rapid sedimentation in center of basin.

southern halves; it contains the Coachella Valley, Salton Sea, Imperial Valley, Mexicali Valley, and Colorado Delta (Figure 2) [Sharp, 1982; Garfunkel, 1972a, b; Crowell and Sylvester, 1979]. It can be viewed as a landward extension of the great structural and topographic trough occupied by the Gulf of California [e.g., Biehler, 1964]. The subsidence along this feature (evidenced by oceanic water depths in the southern gulf giving way northward to deep accumulations of recent sediments) is generally attributed to an increase in area of the crust associated with opening of the gulf during the past 4 or 5 m.y. [Hamilton, 1961; Harrison and Mathur, 1964]. This dilation is required because the trend of the trough $\left(\sim \mathrm{N} 30^{\circ} \mathrm{W}\right)$ departs $\sim 15^{\circ}$ from the trend of the transform faults $\left(\sim \mathrm{N} 45^{\circ} \mathrm{W}\right)$ identified by geologic and geophysical mapping and constrained by plate tectonic considerations [Sharman et al., 1976; Fuis et al., 1982].

We need a simple model for the thermal state of the Salton Trough, and this requires a simple but explicit model for its deformation. Because of the small departure of the trough axis from the transform fault direction, most of the deformation is represented by (horizontal) shearing not extension. However, the shearing involves particle motion parallel to isotherms, and its principal thermal effect, frictional heating, is probably unimportant, at least in the upper crust [e.g., Lachenbruch and Sass, 1980, 1981]. On the other hand, the stretching implies vertical motion perpendicular to isotherms (by ductile thinning, normal faulting, subsidence, sedimentation, and intrusion) and the possibility for advecting large amounts of heat [e.g., Lachenbruch and Sass, 1978]. Thus thermal models of pull-apart structures require sufficient attention to the kinematics of extension to identify the associated vertical transport throughout the crust, but structural details of the extension process are probably unimportant. The model should also specify the size and shape of the deforming region in such a way that it can be shown realistically on the geologic map. Several comprehensive discussions of pull-apart structures have been published [e.g., Crowell, 1974b; Mann et al., 1983; Garfunkel, 1972a, b; Aydin and Nur, 1982], but we shall need to consider only two idealized extremes: one in which the extending region is small relative to crustal thickness (Figure $10 b$ ) and one in which it is large (Figure $11 b$ ).

The most convenient representation of the deformation in the structural trough is that suggested by Larsen et al. [1968], Lomnitz et al. [1970], and Elders et al. [1972] of rightstepping transform faults offset by spreading centers shown by the lines and boxes, respectively, in Figures 1 and 2 . In the simple form of this representation generally applied to the

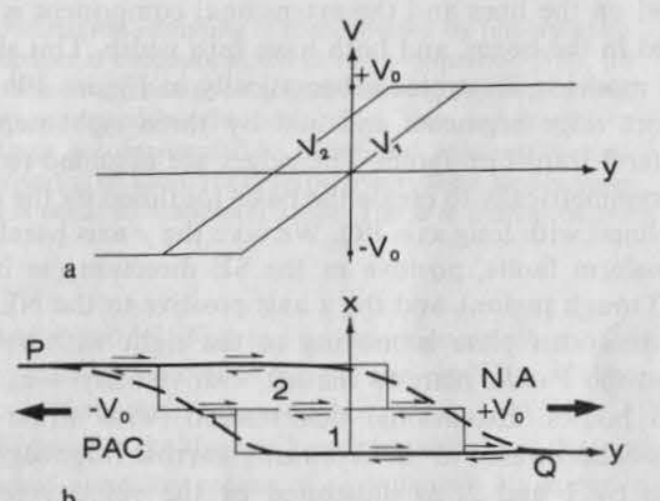

b

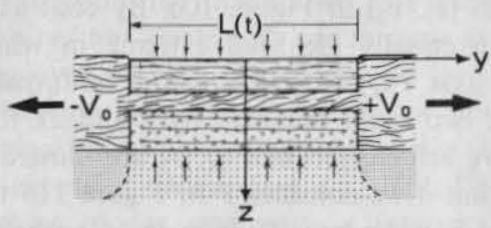

c
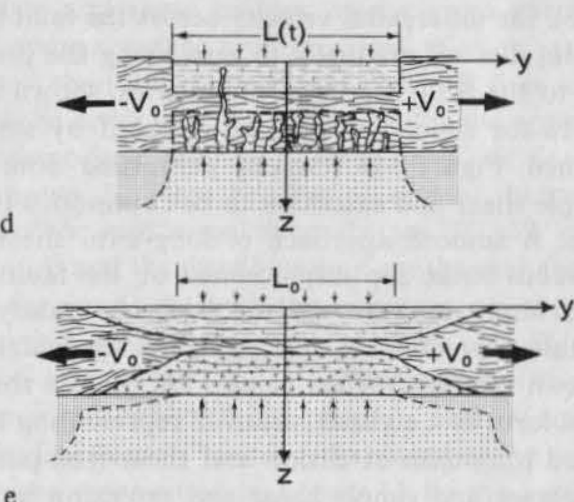

Fig. 11. Idealized models of distributed extension with sedimentation and intrusion. Figure $11 a$ is velocity profiles $v_{1}$ and $v_{2}$ through uniformly extending strips 1 and 2 of Figure $11 \mathrm{~b}$. Dashed curves of Figure $11 \mathrm{~b}$ represent an alternative to stepped basin boundaries. Figures $11 \mathrm{c}$ and $11 \mathrm{e}$ represent crustal cross sections in which gabbroic material is added to lower crust by underplating and in Figure $11 d$ by distributed dike and sill intrusion. In Figures $11 c, 11 d$, and $11 e$ extension, magmatic accumulation, subsidence, and sedimentation are distributed uniformly over length $L$. In Figures $11 c$ and $11 d, L$ increases (and extensional strain rate decreases) as basin grows at rate $2 v_{0}$. In Figure $11 e$, length of the active region $L_{0}$ (and strain rate) remains constant. 


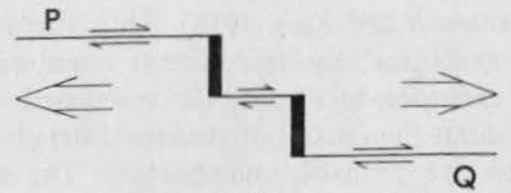

a

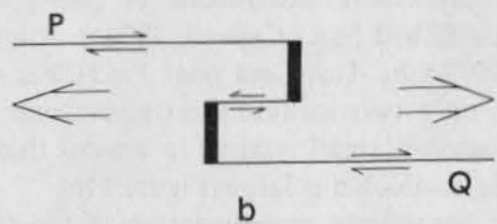

Fig. 12. Geometric alternatives for localized extension between right-stepping right-lateral master transforms: $(a)$ "forward stepping" which does not increase the rectilinear plate boundary length between $P$ and $Q$, and $(b)$ "backward stepping" which does.

ocean basins the shearing component of deformation is concentrated on the lines and the extensional component is concentrated in the boxes, and both have zero width. This simple oceanic model is illustrated schematically in Figure $10 b$ with two short ridge segments enclosed by three right-stepping, right-lateral transform faults. The ridges are assumed to have spread symmetrically to create the basin (outlined by the offset dashed lines) with long axis PQ. We take the $y$ axis parallel to the transform faults, positive in the SE direction (as in the Salton Trough region), and the $x$ axis positive to the NE. The North American plate is moving to the right with velocity $+v_{0}$ and the Pacific plate to the left with velocity $-v_{0}$, both as rigid bodies. Extensional deformation (with strain rate, $\partial v / \partial y$ ) is concentrated in the arbitrarily narrow ridge segments (denoted by 1 and 2 ) as illustrated by the velocity profiles through each $\left(v_{1}, v_{2}\right)$ in Figure $10 a$. By contrast, Figure $11 b$ illustrates an equally idealized extreme in which the same basin (with axis PQ) is generated by uniformly distributed extension in two strips (denoted by 1 and 2), through which the respective velocity profiles $v_{1}, v_{2}$ are illustrated in Figure 11a. (Note that if we consider $\mathrm{P}$ in Figure $11 b$ to represent a point on the San Andreas fault in the Coachella Valley (see Figure 13$)$, the differential velocity across the fault $\left(v_{0}-v_{2}\right.$ in Figure $11 a$ ) dies off gradually to zero along the projection of the fault to the SE.) The basin boundaries, shown stepped in Figure $11 b$ for simplicity, may be replaced by smooth ones (e.g., dashed, Figure $11 b$ ) thereby permitting both the longterm simple shear and extension to be continuous throughout the basin. A smooth approach of long-term shear strain to discontinuous strike-slip displacement on the faults at $\mathrm{P}$ and $Q$ would imply tangency of the basin boundary with the master faults there, thereby suggesting the sigmoidal boundary form shown (see also Mann et al. [1983]). We shall use the sigmoidal form as a stylized means of representing this case of distributed long-term extension and shear (i.e., pure shear in vertical planes and simple shear and extension in horizontal planes) parallel to the master transforms.

The observation that earthquakes on faults parallel to the plate boundary generally have a right-lateral sense of motion [Lommitz et al., 1970; Elders et al., 1972] implies the condition

$$
\partial v / \partial x \geqq 0
$$

or, equivalently, that the velocity curves for larger $x$ lie above (or on) those for smaller $x$ for any number of strips in plots like Figures $10 a$ or $11 a$. This condition is assured in the model of Figure 10 if all of the transform offsets step forward as in
Figure 12a, not backward (Figure 12b). The backward step produces left-lateral faults and increases the length of plate boundary; this probably decreases the energy efficiency of plate motion and explains why it is not generally observed. The model of Figure $11 b$ satisfies (1) provided both basin boundaries have the forward stepping form or a smoothed equivalent (e.g., the sigmoidal form shown).

Exterior to the basin, the models of Figures $10 \mathrm{~b}$ and $11 \mathrm{~b}$ behave the same; particles on the boundary of the basin move in the NW or SE direction as the basin grows at rate $2 v_{0}$, its long axis PQ rotated (clockwise) from the growth direction. Within the basin, however, the consequences for the thermal and mechanical evolution of the crust may be very different for the two models. In the case of distributed deformation (Figure 11), lateral extension causes uniform thinning of the original crust and continuous distributed upwelling of dense mantle and/or basalt which underplates (Figure 11c) or intrudes (Figure 11d) the crust, while according to our assumption, isostatic subsidence leads to distributed sedimentation at the rate necessary to maintain the surface near sea level. The rates of sedimentation and intrusion are governed by the extensional strain rate (slope of curves in Figure 11a) and the thermal state depends upon these rates. In the case of localized deformation (Figure 10c), entirely new crust is formed by a narrow throughgoing dike at the "spreading center," and the local sedimentation rate must be very great there to compensate for the local separation of sediments and avoid the formation of a deep topographic basin. Crustal evolution (including deposition of the sedimentary column) is essentially completed

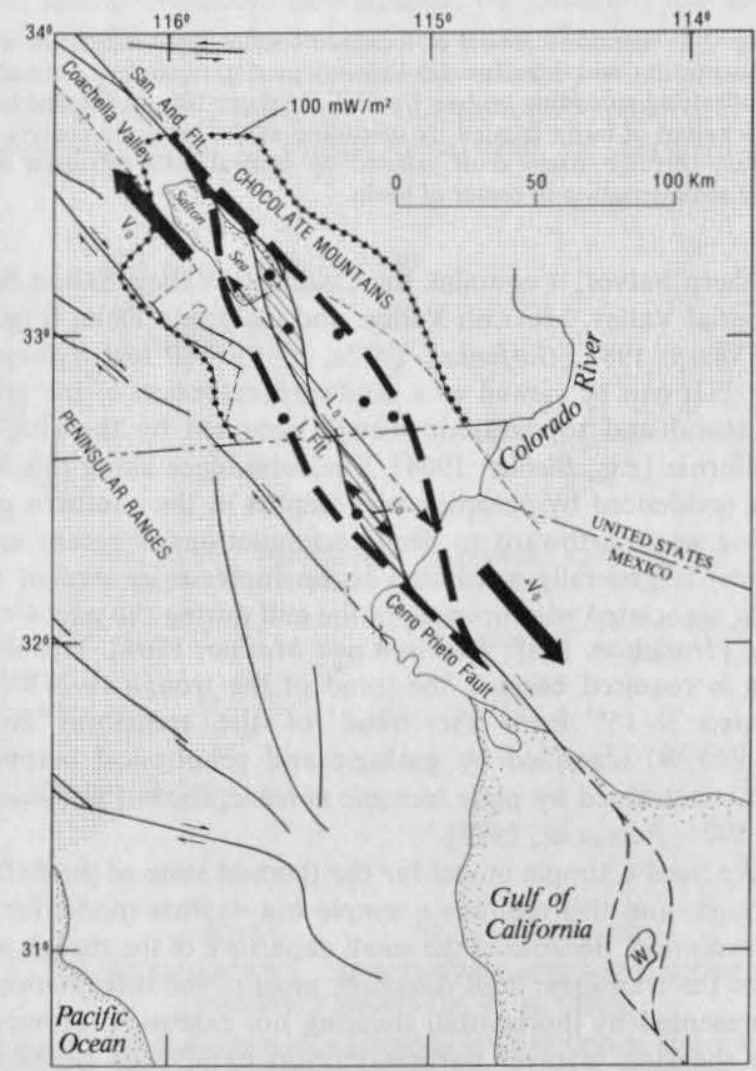

Fig. 13. Idealized model adapted from Figure $11 \mathrm{~b}$ for extension of Salton Trough. Region with scale length $L_{0}$ (to be determined) enclosed by dashed curves stretches uniformly in direction of heavy arrows. Crosshatched regions with scale length $L_{0}{ }^{\prime}$ indicate location of intense modern seismicity (modified from Fuis et al. [1982]). Abbreviations are I. Flt., Imperial fault; San. And. Flt., San Andreas fault; W, Wagner Basin. 
a

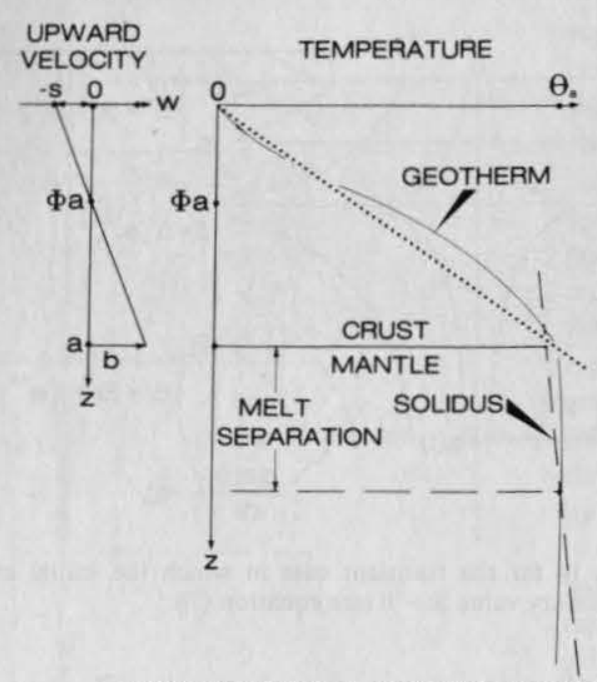

C

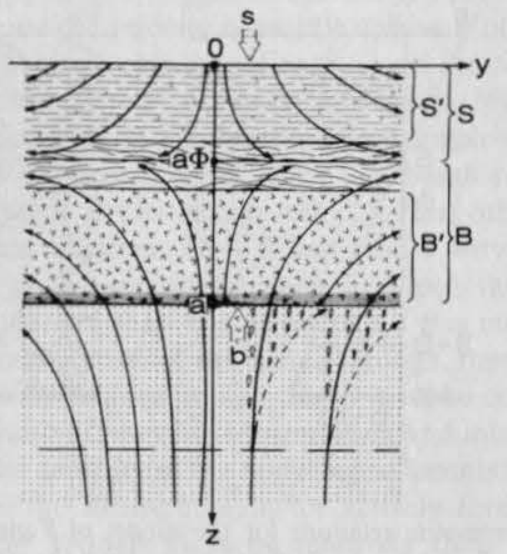

EXTENSION WITH SEDIMENTATION \& CRUSTAL UNDERPLATING

Fig. 14. Simple model for homogeneous crustal extension in the $y$ direction; thinning is compensated by underplating and sedimentation. (a) Vertical velocity distribution for a uniform horizontal extensional strain rate $\gamma($ equation $(9 b)) ;(b)$ steady state geothermal model; and (c) kinematic model; solid arrows represent average particle trajectories, dashed arrows represent refractory depleted mantle, and tear drops represent separated basaltic melt which rises and freezes to crust at rate $b$. Latent heat is liberated at base of crust $z=a$. Subsidence is compensated by distributed sedimentation at rate $s . S^{\prime}$ and $B^{\prime}$ are transient thicknesses of sediment and mantle-derived crystalline rock, respectively; their steady state thicknesses are $S$ and $B$. Illustrated for a crust whose total thickness is equal to stationary value. The $\phi$ is dimensionless sedimentation rate (equation (17)).

at the "spreading center" except for the relatively slow sedimentation associated with thermal subsidence as the crust and upper mantle cool and contract when they move away from the central intrusive heat source. Thus in the localized oceantype model the basin crust is all new, and the initial width of the basin is zero. Presumably this is the model implied by the view that the basin consists of sediment lying directly on "oceanic crust." The anomalous rates of heat supply, subsidence, and sedimentation are localized at the spreading center. In the model of distributed deformation the basin may have a finite initial width; the intrusion, heat supply, and sedimentation rates are distributed more uniformly; and significant amounts of prebasin crust might be present, depending on the accumulated strain. The resulting crust need not bear any close resemblance to oceanic crust. Unfortunately, the quality and distribution of the heat flow data and the thermal effects of plausible variants of these two models preclude a distinction between them on the basis of their predicted heat flows. We shall attempt to make the distinction in another way.

Two simple options for the distributed models are seen by comparing Figure $11 c$ with $11 e$ (see also England [1983]). The sharp boundaries of the basin in Figure $11 c$ imply that as the basin extended at constant (approximately plate) velocity $2 v_{0}$, the length of the extending region $L(t)$ grew at the same rate, in which case its average extensional strain rate $\left(2 v_{0} / L(t)\right)$ must have diminished. Figure $11 e$ illustrates the corresponding case in which the locus of extension $\left(L_{0}\right)$ remains fixed in time and space so that this active portion of the basin extends at constant strain rate as the basin lengthens with constant velocity $\left(2 v_{0}\right)$. The portions in the periphery where the sediments and magmatic additions are thinner are no longer extending because they have drifted out of the active region. This model is simpler mathematically, and it is probably more consistent with seismic refraction and gravity evidence [Fuis et al., 1982, Figure 17a; Biehler et al., 1964, Figure 6]. As the ocean-type model (Figure $10 c$ ) has a constant width intrusion zone, it can be viewed as a limit for small $L_{0}$ of these distributed constant strain rate models.

In Figure 13 the dashed heavy curves show the outline of a somewhat arbitrary region of scale length $L_{0}$ within which we shall assume extension like that shown in Figure $11 e$ (or its intrusive equivalent not illustrated) has, in some average sense, been operating over the past 4 or 5 m.y. to form the Salton Trough. The deformation within the dashed region may represent any combination of normal and strike-slip faulting, ductile flow, and extension failure [see e.g., Hill, 1977; Crowell, $1974 b]$, and these modes may vary in intensity and move about in time and space as long as the gross effect can be viewed as approximately uniform areal dilation on a time scale shorter than the appropriate thermal time constant, probably of the order of $1 \mathrm{~m}$.y., the value for the upper crustal region of seismogenic faulting [Lachenbruch and Sass, 1978]. We have drawn $L_{0}$ large relative to crustal thickness; the dimensions of the geothermal anomaly (see $100 \mathrm{~mW} \mathrm{~m}^{-2}$ contour, Figure 13) and the distribution of geothermal areas (dots, Figure 13) are consistent with the extension, on the average, occurring over a broad zone of this sort (see also Elders et al. [1972] and Garfunkel [1972a]). However, much of the present deformation is probably taking place in narrow seismically active "spreading centers" joining the major active strike-slip faults; they are represented in Figure 13 by the small crosshatched sigmoidal regions generalized from Fuis et al. [1982], Johnson and Hill [1982], and Johnson and Hutton [1982]. These regions also contain the two geothermal areas (CP and SS, Figure 2) associated with surface manifestation of volcanism. The width of these seismic regions $L_{0}{ }^{\prime}$ is generally less than a crustal thickness, and if the Salton Trough formed from extension confined exclusively to this narrow region, the ocean-type model of origin (Figure $10 c$ ) would be a reasonable one. We shall attempt to evaluate $L_{0}$ from kinematic and thermal implications of the model to see whether local, ocean- 
a
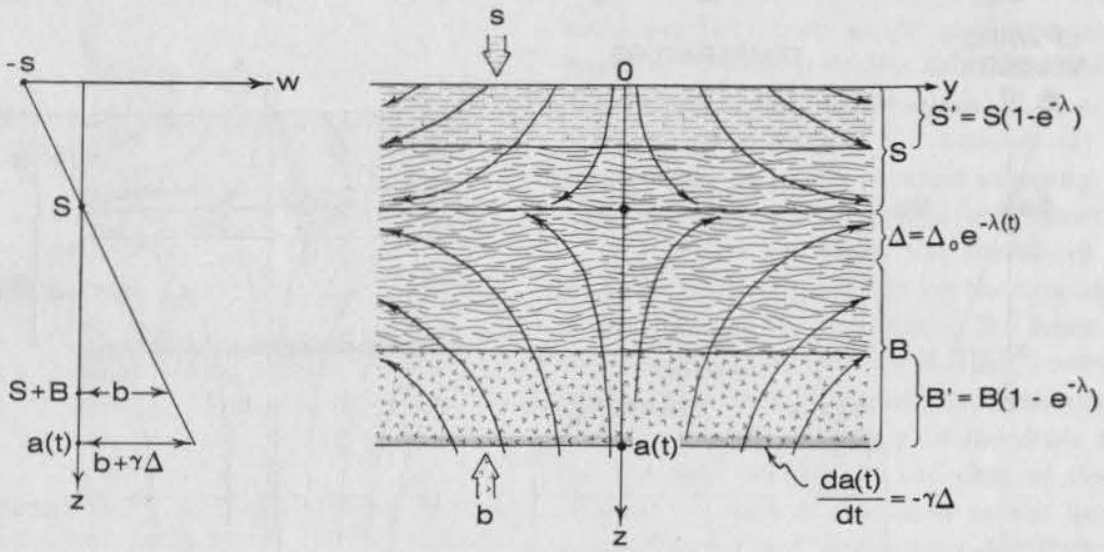

Fig. 15. Geometric relations for the model of Figure 14 for the transient case in which the initial crustal thickness differed by $\Delta_{0}$ from the stationary value $S+B$ (see equation (7)).

type, or distributed extension was responsible for formation of the Salton Trough.

\section{Kinematics of an Extending Crust WITH INTRUSION AND SEDIMENTATION}

We now investigate the motion of crustal material during distributed extension of the type depicted in the cartoon of Figure 11e. We imagine this extension to be taking place in the direction of the arrows throughout the region of length $L_{0}$ enclosed by the dashed lines in Figure 13. Explicit expressions for the vertical velocity of sediments, basalt, and original crustal material will be needed to compare the consequences of the extension models with the present composition and thermal state of the crust.

We consider the one-dimensional problem of an incompressible crust of thickness $a$ extending homogeneously in the horizontal $y$ direction with strain rate $\gamma$ independent of depth and time (e.g., Figure $14 c$ ). The crust receives sediment at its surface at rate $s(\mathrm{~km} / \mathrm{m} . \mathrm{y} . \equiv \mathrm{mm} / \mathrm{yr})$ and basaltic magma through its base at the rate $b$. The crustal thickness satisfies the differential equation

$$
d a / d t=-\gamma a+s+b
$$

The first term on the right is the rate of crustal thinning caused by extension and the second and third terms are the rates of thickening by sedimentation and intrusion, respectively.

For the stationary condition ( $a$ independent of time), this reduces to

$$
a=S+B
$$

where

$$
\begin{aligned}
& S=s / \gamma \\
& B=b / \gamma
\end{aligned}
$$

$S$ can be viewed as the portion of the crust whose thinning is compensated by sedimentation, and $B$ is the portion whose thinning is compensated by intrusion (Figure 14c). Even if extensional strain rate $\gamma$ varies with time and horizontal position, $S$ and $B$ will remain constant as long as the accumulation rates remain proportional to strain rate (equations (4)). A physical rationale for assuming the constancy of $S$ and $B$ is discussed in section 6 .

The total accumulated strain $\lambda(t)$ may be used as the independent variable, i.e.,

$$
\lambda(t)=\int_{0}^{t} \gamma\left(t^{\prime}\right) d t^{\prime}
$$

and ( 2 ) becomes

$$
d a / d \lambda=-a+S+B
$$

Any crust extending subject to the proportionality condition (i.e., $S, B$ constant) will eventually approach the stationary thickness (3). Thus according to (6) a crust whose initial thickness was $\Delta_{0}+S+B$ would at time $t$ have thickness $a(t)$ given by

$$
a(t)=\Delta+S+B
$$

where

$$
\Delta=\Delta_{0} e^{-\lambda(t)}
$$

and $\Delta_{0}$ can be positive or negative (see Figure 15 ). Thus the initial thickness would soon adjust to the stationary value $(S+B)$ in rapid extension if the two values were not very different initially. In much of what follows, we shall assume that the present-day crustal thickness inferred from geophysical data is indeed a reasonable approximation to $S+B$.

We let $v$ denote horizontal velocity (in the positive $y$ direction) and $w$ the upward velocity (in the negative $z$ direction). From the definition of $\gamma$ and the condition of continuity we obtain

$$
\partial w / \partial z=\partial v / \partial y \equiv \gamma
$$

As $\gamma$ is assumed to be independent of depth, integration of (8) yields

$$
\begin{gathered}
v(y)=\gamma y \\
w(z)=\gamma z-s=\gamma(z-S)
\end{gathered}
$$

where $(9 b)$ has been adjusted to the condition that $w(0)=-s$, the sedimentation rate, at $z=0$.

The instantaneous thickness of sediments $S^{\prime}(t)$ at any time $t$ is governed by

$$
d S^{\prime} / d t=-w\left(z=S^{\prime}\right)
$$

Substituting $(9 b)$ and $(5)$ and integrating, we obtain

$$
S^{\prime}(t)=S\left(1-e^{-\lambda(t)}\right)
$$




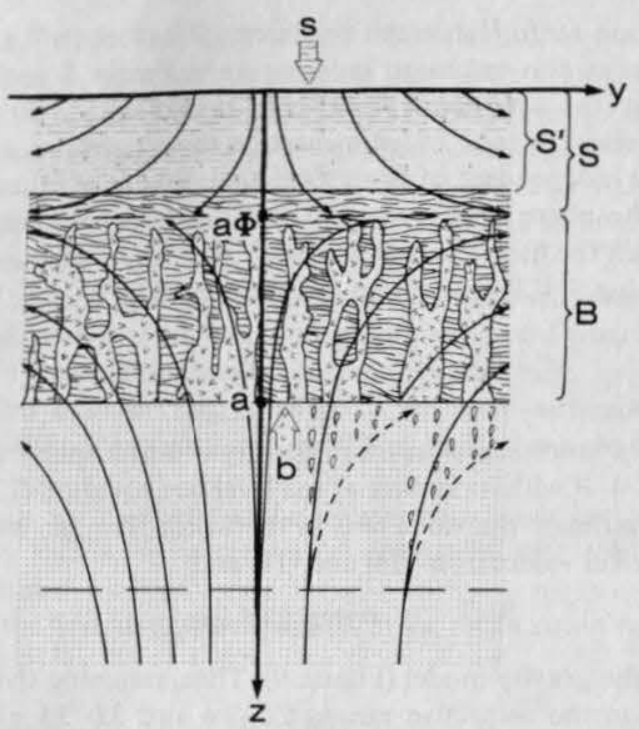

Fig. 16. Intrusive model of crustal extension in which thinning is compensated by distributed lower crustal intrusion of dikes and sills from below and sedimentation from above. Other conventions as in Figure $14 c$.

If we assume that the basalt accumulates at the base of the crust as a thickening layer of underplating sills, the transient thickness $B^{\prime}(t)$ of that layer is, by a similar argument,

$$
B^{\prime}(t)=B\left(1-e^{-\lambda(t)}\right)
$$

The geometry of this situation is illustrated for the case of stationary crustal thickness in Figure $14 c$ (the transient condition (7) is illustrated in Figure 15). Thinning due to stretching is compensated in the upper layer of thickness $S$ by sediment supplied from above and in the lower layer of thickness $B$ by basalt supplied from below. Equation $(9 b)$ shows that advection of heat and mass is downward in layer $S$ and upward in the underlying layer $B$ (Figure 14a). Equation (11a) shows that for large strain the sediment accumulating at rate $s$, approaches a maximum thickness $s / \gamma(=S)$ at which depth the horizontal removal of mass by stretching just balances the rate of supply at the surface. Similarly, the thickness of basalt approaches the limiting value $b / \gamma(=B)$ with increasing strain (equation (11b)).

A second model in which the basalt is supplied to layer $B$ by randomly distributed intrusion of pervasive dikes and/or sills is shown in Figure 16. For this case the long-term average particle trajectories are the same as in the underplating sill model and are given by equations (9). In this case, however, $B^{\prime}(t)$ does not represent a layer thickness, but as in underplating, the fraction of basalt in layer $B$ at any time is $B^{\prime}(t) / B$. Thermal aspects of these models have been discussed in detail elsewhere [Lachenbruch and Sass, 1978; Lachenbruch, 1978].

\section{An Isostatic Constraint}

It is clear that temperatures in the models of Figures 14 and 16 will be dominated by effects of advection of heat for large strain rates and that the thermal results will be very sensitive to the relative widths of the zones of downward movement $(S)$ and upward movement $(B)$ or, equivalently, to the relative rates of sedimentation $(s)$ and basalt intrusion $(b)$. In general, these rates are not mutually independent because of the tendency of the lithosphere to maintain isostatic balance.

It has been shown that a steady crustal thickness is approached if intrusion and sedimentation rates are each proportional to strain rate, (i.e., if $S$ and $B$ are constant (equations
(4)). Proportionality between the rates of extension and basalt supply is, of course, not necessary, but it is not unreasonable because the velocity of mantle upflow is proportional to extensional strain rate (equation (9)), and the rate of basalt melting should be proportional to the velocity of upflow, other things being equal. In the best known example of crustal extension, seafloor spreading, we know that basalt supply is indeed proportional to extension velocity, for otherwise the oceanic crustal thickness $(B \sim 5 \mathrm{~km})$ would vary with the extension rate of the spreading center at which the oceanic crust was created. We shall now show that if $B$ is indeed constant in the extending crust of the Salton Trough, then the requirement of isostatic balance implies that $S$ must be constant too and that the ratio of rates of sedimentation and intrusion are then fixed by the densities of the accreting sediments and basalt.

As the lithosphere in an actively forming basin like the Salton Trough must be relatively thin, hot, and weak, we represent it to be in a local state of floating equilibrium. Consider a lithosphere of thickness $R$ and mean density $\bar{\rho}$ floating in a sea of asthenosphere whose surface is free of normal stress and whose density is $\rho_{a}$ (Figure 17). If we denote the height of the earth's surface above sea level by $\varepsilon$ and above the free asthenosphere surface by $\varepsilon+H_{0}$, then mass balance requires

$$
\rho_{a}\left(\varepsilon+H_{0}\right)=\left(\rho_{a}-\tilde{\rho}\right) R \quad \varepsilon \geqq 0
$$

and the mean lithosphere density is given by

$$
\bar{\rho}=\rho_{a}\left(1-\frac{\varepsilon+H_{0}}{R}\right)
$$

For generality in (12) we regard any seawater that might be present as an upper layer of the asthenosphere.

The constant $H_{0}$ is most easily evaluated at an ocean ridge (see, e.g., Le Pichon and Sibuet [1981]) where about $2.5 \mathrm{~km}$ of seawater overlies about $5.5 \mathrm{~km}$ of solid lithosphere $(\rho \sim 2.8$ $\left.\mathrm{g} / \mathrm{cm}^{3}\right)$ to give $R \sim 8 \mathrm{~km}, \bar{\rho} \sim(2.5 \times 1+5.5 \times 2.8) / 8$. Taking $\rho_{a} \sim 3.2 \mathrm{~g} / \mathrm{cm}^{3}$ and setting $\varepsilon=0$, we obtain from $(12 a)$

$$
H_{0} \sim 2.4 \mathrm{~km}
$$

(It will be noted that $H_{0}$ is the height of sea level above the static level of asthenosphere with a free surface; it is less than the depth $d_{m}$ of "mantle geoid" defined by Turcotte et al.

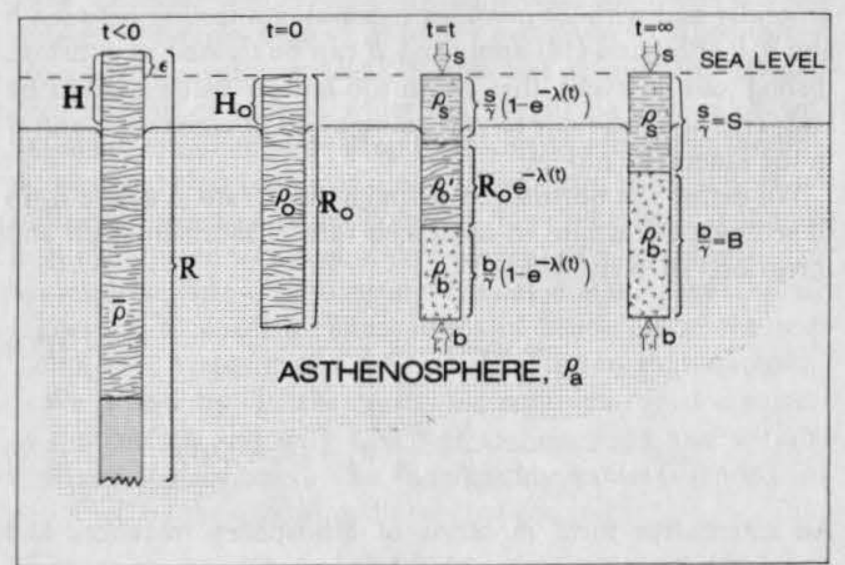

Fig. 17. Mass balance relations for a lithosphere originally $(t<0)$ of density $\bar{\rho}$, thickness $R$, and surface elevation $\varepsilon$, thinned to the crust with density $\rho_{0}$, thickness $R_{0}$, and surface at sea level at $t=0$, and subsequently $(t=t)$ extended horizontally by pure shear to a total strain $\lambda(t)$. Basaltic material of density $\rho_{b}$ is supplied from below at rate $b$ and sediment of density $\rho$, is supplied from above at the rate $s$ necessary to keep surface at sea level. $H_{0}$ is the buoyant height of sea level above a sea of asthenosphere (with a free surface) of density $\rho_{\alpha}$. 
[1977] by the factor $\rho_{a} /\left(\rho_{a}-\rho_{w}\right)$ because the latter is the corresponding height above an asthenosphere loaded to sea level by water of density $\rho_{w^{*}}$ )

Before applying (12) to the Salton Trough, we note that the trough's proximity to the sea on one side and to a prolific source of sediments from the Colorado River on another resulted in sedimentation which generally kept the subsiding trough filled approximately to sea level [Lucchita, 1972; Merriam and Bandy, 1965; Muffler and Doe, 1968]. Thus the trough probably evolved under the condition

$$
\varepsilon \cong 0
$$

The right side of $(12 a)$ is the buoyancy of the lithosphere, which according to (13) and (14) remained constant as the trough evolved and the thickness and composition of its lithosphere changed. Thus if $R_{0}, \rho_{0}$ characterize the trough's lithosphere at any early stage, then after extensional strain of the amount $\lambda$ in the mode of section 5 , we should have (see equation (12a) and Figure 17)

$$
\begin{gathered}
\rho_{a}\left(\varepsilon+H_{0}\right)=\left(\rho_{a}-\rho_{0}\right) R_{0} \\
\rho_{a}\left(\varepsilon+H_{0}\right)=\left(\rho_{a}-\rho_{0}\right) R_{0} e^{-\lambda}+\left(\rho_{a}-\rho_{s}\right) \frac{s}{\gamma}\left(1-e^{-\lambda}\right) \\
+\left(\rho_{a}-\rho_{b}\right) \frac{s}{\gamma}\left(1-e^{-\lambda}\right)
\end{gathered}
$$

The $\varepsilon$, understood to be constant, is retained for generality. The three terms on the right in (15b) are, from left to right, contributions to buoyancy of the extended lithosphere from the thinned original material (assumed to have unchanged density $\rho_{0}$ ), from sediments of density $\rho_{s}$ accumulating at rate $s$, and from basalt of density $\rho_{b}$ accumulating at rate $b$ (see equations (4), (7), and (11)). Dependence on the initial state $\left(R_{0}, \rho_{0}\right)$ may be eliminated with $(15 a)$ to yield

$$
\left(\rho_{a}-\rho_{b}\right) \frac{b}{\gamma}+\left(\rho_{a}-\rho_{s}\right) \frac{s}{\gamma}=\rho_{a}\left(\varepsilon+H_{0}\right)
$$

Note that the right side of (16) is a constant. If the basalt intrusion rate is proportional to spreading rate, as it probably is in the ocean at least, then $b / \gamma=B$ is constant, and according to (16) this requires that sedimentation rate also be proportional to extension rate (i.e., $s / \gamma=S$ is constant). Or more generally and without invoking a causal connection between $b$ and $\gamma$, if $(12 a)$ and (14) apply and $B$ can be treated as constant throughout an event, then $S$ can too and its value is given by (16). This is a rationale for the assumption of constant $S$ and $B$ in the kinematic model.

We define the normalized sedimentation rate $\phi$ as the ratio of sedimentation rate to combined rate of sedimentation and intrusion. Then (16) yields

$$
\begin{gathered}
\phi \equiv \frac{s}{s+b}=\frac{S}{S+B} \\
\phi=\frac{1}{\rho_{b}-\rho_{s}}\left\{\frac{H_{0}+\varepsilon}{S+B} \rho_{a}-\left(\rho_{a}-\rho_{b}\right)\right\}
\end{gathered}
$$

An alternative form in terms of lithosphere thickness and mean density is obtained with $(12 a)$ :

$$
\phi=\frac{1}{\rho_{b}-\rho_{s}}\left\{\frac{R}{S+B}\left(\rho_{a}-\bar{\rho}\right)-\left(\rho_{a}-\rho_{b}\right)\right\}
$$

Thus if $B$ is constant, the relative rates of sedimentation and intrusion (i.e., $\phi$ ) are held constant (see equation (17b)) by isostasy even though the thickness $R$ and mean density $\bar{\rho}$ of the lithosphere (and even the strain rate $\gamma$ ) may be changing (equation (18)). Hence the parameter $B$ can control the kinematics of this extension process; it determines $S$ and consequently the long-term lithosphere thickness $(S+B)$, and it establishes the ratio of sedimentation rate $s$ to intrusion rate $b$, a ratio independent of strain rate, that obtains whether or not the lithosphere has approached this long-term thickness.

When the lithosphere thickness $R$ does approach its stationary value $S+B$, then $\phi$ can be represented by

$$
\phi=\frac{\rho_{b}-\bar{\rho}^{*}}{\rho_{b}-\rho_{s}} \quad R=S+B
$$

where $\bar{\rho}^{*}$ represents the mean density of a lithosphere of thickness $S+B$ with its surface at sea level (see equation (12b)).

To estimate the value of $\phi$ in the Salton Trough, we use the numerical values from (13) and (14) and

$$
S+B \cong 23.5 \mathrm{~km}
$$

from the gravity model (Figure 9). Then assuming that $\rho_{3}$ and $\rho_{b}$ lie in the respective ranges $2.5-2.6$ and $3.0-3.1 \mathrm{~g} / \mathrm{cm}^{3}$, we obtain a likely range of $\phi$ from $(17 b)$ :

$$
\frac{1}{4} \lesssim \phi \lesssim \frac{1}{2}
$$

The value selected for $\rho_{s}$ must, of course, represent an average for the sediments in various stages of compaction and metamorphism. (From (17b) note that $S$ and $\phi$ will generally increase from early to later stages if $\rho_{s}$ does.)

\section{Matching the Geophysical Model AND THE Kinematic Model.}

The kinematic model described in sections 5 and 6 was suggested by the relation between light sediments and dense subbasement in the "geophysical model" (Figure 9) derived from seismic and gravity data. We shall now consider the parameter values suggested by matching the two models and their implications for a thermal model to be presented in the next section.

The kinematic models are characterized mainly by four parameters: (1) steady state crustal thickness $S+B$, (2) total extensional strain $\lambda$, (3) average extensional strain rate $\gamma$, and (4) ratio of sedimentation rate to combined rate of sedimentation and intrusion $(\phi)$.

We take the crustal thickness from the geophysical model (23.5 km, Figure 9) and assume that it is close to the steady state value $S+B$ as in (20). To estimate $\lambda$, we compare Figure 9 with Figure 14 and note that the thickness $B^{\prime}$ of accumulated "gabbroic" subbasement is $\sim 50 \%$ of the crustal thickness $(S+B)$. Over much of the Imperial Valley the accumulated sediments $S^{\prime}$ account for at least $20 \%$ of the present crust and possibly quite a bit more if much of the intermediate basement layer represents such sediments metamorphosed to grecnschist facies [Fuis et al., 1982]. According to this view, at least $70 \%$ of the present crust has been emplaced since the stretching began. Thus from equations (11), total strain $\lambda$ satisfics

$$
\begin{gathered}
\frac{S^{\prime}+B^{\prime}}{S+B} \sim\left(1-e^{-\lambda}\right) \geq 70 \% \\
\lambda \geq 1.2
\end{gathered}
$$

(In the notation of McKenzie [1978] this is equivalent to a stretching factor " $\beta$ " $\geq 2.2$.) The assumption of section 6 (equation (20)) that the present crustal thickness is close to steady state is justified in part by the large total strain implied by (22) (see equation (7)). 
In the Salton Trough, evidence for the simultaneous rapid accumulation of modern sediments and deep crustal basalt, the high heat flow, and the likelihood that these anomalous conditions are associated with an extensional regime that accompanied the opening of the Gulf of California over the past $5 \mathrm{~m} . \mathrm{y}$. or so suggests the following assumptions (equivalent to assumptions 3 and 4 of section 1):

1. The large amounts of upper crustal sediment and lower crustal gabbro that constitute much of the present crust (equation (22)) accumulated largely during the last $5 \mathrm{~m} . \mathrm{y}$.

2. The base of the crust is at or near asthenosphere (basalt-solidus) temperatures and has been throughout this period.

Though not compelling, the assumptions seem reasonable, and they lead to a simple model consistent with the major observations.

With the first assumption and $(22 b)$ the mean strain rate $\gamma$ is limited by

$$
\gamma \geq 25 \% / \text { m.y. }
$$

In view of the rapid supply of basalt to the base of the crust implied by (23), the second assumption seems consistent with the first (and we shall show later that it is). It defines a needed boundary condition at the base of the crust and a time frame, $\sim 5$ m.y., which is of the order of the appropriate thermal time constant for the thin model crust [Lachenbruch and Sass, 1978, p. 225; Jartis and McKenzie, 1980, Appendix]. On this basis we shall assume a steady state with constant (solidus) temperature boundary conditions in most thermal models of section 8. It will be noted that these assumptions imply that the lithosphere mantle was missing or at least thermally decoupled from the crust by sill intrusion throughout much of the stretching episode. We shall not consider this matter further except to note that by sharply reducing lithosphere strength, such conditions would greatly facilitate the rapid extension implied by (23).

If the entire intermediate basement layer (Figure 9) represents metamorphosed recent sediments, then the crust is composed of about equal parts of material of sedimentary and igneous origin in which case $S^{\prime} \sim B^{\prime}$. If, on the other hand, the intermediate layer represents attenuated original crust, then $S^{\prime} \sim 0.4 B^{\prime}$. The two cases suggest a range of plausible values for $\phi$ (equations (11) and (17a)):

$$
0.3 \leqslant \phi \leqslant 0.5
$$

This range of $\phi$ is quite consistent with the range suggested by the isostatic constraint applied to the kinematic model in section 6 (equation (21)). However, an additional source of uncertainty in this comparison is that $\phi$ estimated from (21) represents relative accumulation rates when the surface is at sea level. Removal of cold mantle as implied by the second assumption would generally result in uplift with details depending upon history prior to $t=0$. Karig and Jensky [1972] suggest that in Miocene time the gulf region was occupied by Basin and Range type terrane of high-temperature mantle which later served as a locus of weakness for the intracontinental plate boundary that opened the gulf and presumably extended the Salton Trough. If the lithosphere mantle in this Miocene terrain were say $\sim 40 \mathrm{~km}$ thick, removing it would cause an uplift of $500 \mathrm{~m}$ or so, a change that would be nullified by crustal thinning of perhaps $4 \mathrm{~km}$. Thus if the surface were above sea level at $t=0$, the basalt accumulation could have had a several kilometer head start on sedimentation.

The width of the Imperial Valley is $\sim 2-3$ times the thickness of the model crust, and little is known about three- dimensional details of crustal structure and temperature; even the model crustal thickness has not been confirmed seismically. Until more is known, only the simplest one-dimensional thermal models seem warranted. However, it is worth noting that heat flow close to the basin average has been measured in bordering crystalline rocks (particularly in the western Chocolate Mountains, Figure 3) where large extension rates (equation (23)) are most unlikely. This suggests that a subcrustal asthenosphere (assumption 2, above) might extend more widely than the locus of rapid extension (equation (23)). It will be shown that this condition is compatible with thermal models based on the temperature boundary condition (assumption 2) and constrained by (21); for them, heat flow is insensitive to extension rate. Thermal conditions at the periphery of the trough raise additional questions related to uplift history which are beyond the scope of this analysis.

\section{Thermal Models}

As we now have an explicit, if simplified, mechanical model, we can return to the question of the significance of high heat flow in the Salton Trough.

In this one-dimensional model, advection of heat in the crust is governed by the vertical velocity field (equation (9b)) which can be written

$$
w=\gamma(z-a \phi) \quad 0 \leqq z \leqq a=23.5 \mathrm{~km}
$$

We consider the crustal thickness $a$ to be known and equal to the stationary value, $S+B$ (equation (20)), the dimensionless parameter $\phi$ to be limited to a reasonably narrow range by the isostatic constraint (21), and the strain rate $\gamma$ to be a free parameter whose physical consequences are to be investigated and compared to the constraint imposed by (23). We shall solve the steady state heat equation for the underplating and intrusion cases illustrated respectively in Figures 14 and 16 and address the following questions: (1) What range of extensional strain rates leads to surface heat flows consistent with those observed in the Imperial Valley and (2) what strain rates are required by these models to satisfy heat balance at the base of the crust?

Temperatures for the two models are obtained by modification (for effects of sedimentation) of solutions applied to a similar problem in the Great Basin [Lachenbruch and Sass, 1978; Lachenbruch, 1978]. Only the needed equations and definitions are given below; solutions are given in Appendix B. Note that the velocity field (25) does not account for independent motion of ground water that might be associated with sediment compaction or deep hydrologic circulation. We have pointed out that unlike at ocean ridges, such motion does not influence estimates of surface heat flow; whether it enhances heat transfer on a crustal scale remains to be determined. Our assumption below of constant crustal conductivity actually allows for a $30-50 \%$ enhancement of heat flow in the sediments, as it overestimates their conductivity by that amount.

We denote by $O(z)$ the crustal temperature adjusted to zero at the surface and with effects of radioactivity and variable conductivity neglected. The underplating model (Figure 14) is described by the following differential equation:

$$
K \frac{d^{2} \theta}{d z^{2}}+w \rho c \frac{d \theta}{d z}=0 \quad 0<z<a
$$

Most of the discussion will be based on the solution for constant boundary temperature:

$$
\theta=\theta_{a} \quad z=a
$$

where according to assumption 2 of section $7, \theta_{a}$ is the adjusted basalt solidus temperature $\left(\theta_{m}(a)\right)$, defined below. We shall 
also use results for a heat balance boundary condition that allows us to specify the conductive flux $q_{n}$ from the mantle

$$
K \frac{d \theta}{d z}=q_{n}+w \rho c\left[\theta_{i}-\theta\right] \quad z=a
$$

where $\theta_{i}$ is the adjusted intrusion temperature defined below. The second term on the right is the rate at which heat is given up at the base of the crust by underplating magma; it is a plane source associated with a conductive heat flow discontinuity.

The intrusion model of Figure 16 is described by a different differential equation in the portion of the crust $(z>a \phi)$ in which intrusion takes place. For this case the governing equations are

$$
\begin{array}{rl}
K \frac{d^{2} \theta}{d z^{2}}+w \rho c \frac{d \theta}{d z}=0 & 0<z<a \phi \\
K \frac{d^{2} \theta}{d z^{2}}+\gamma \rho c\left[\theta_{i}-\theta\right]+w \rho c \frac{d 0_{i}}{d z}=0 & a \phi<z<a
\end{array}
$$

Equations (28) are subject to the conditions that $\theta$ and its derivative be continuous at the interface $z=a \phi$. They will be solved subject to boundary condition $(27 a)$ and for the heat balance boundary condition, which for this case is simply

$$
K \frac{d \theta}{d z}=q_{n} \quad z=a
$$

The second term in (28b), including the brackets, is heat given up by cooling magma in place, and the third term represents heat lost by the magma during its rise. The quantity $\theta_{i}(z)$ is the temperature at which material is intruded at depth $z$, adjusted for the temperature equivalent of its latent heat of crystallization. Thus

$$
\begin{aligned}
& \theta_{i}(z)=\theta_{m}(z)+f \frac{L}{c} \\
& \theta_{i}(z)=\theta_{m}(0)+G_{m} z+f \frac{L}{c}
\end{aligned}
$$

where $\theta_{m}(z)$ is the solidus temperature (adjusted downward like 0 by about $50^{\circ} \mathrm{C}$ for effects of surface temperature and radioactivity, see Appendix $B$ ). We use the values

Adjusted basalt solidus temperature at $x=0$

$$
\theta_{m}(0)=1010^{\circ} \mathrm{C}
$$

Gradient of solidus

$$
G_{m}=3^{\circ} \mathrm{C} \mathrm{km}^{-1}
$$

Ratio of latent heat to specific heat

$$
L / c=320^{\circ} \mathrm{C}
$$

Melt fraction at time of intrusion

$$
f=\text { constant }
$$

Analytical solutions to the foregoing differential equations (26) and (28), with both temperature (27a) and heat balance (27h) or (29) boundary conditions are presented in Appendix B. They are most easily expressed in terms of the Peclet number which we denote by $P^{2}$; it is a measure of the importance of advective heat transfer relative to conductive transfer. It is given by

$$
p^{2}=\frac{a^{2}}{\alpha} \gamma
$$

$$
P^{2} \cong 0.2 \gamma
$$

where the numerical value (with $y$ in percent per million years) is based on the assumption that $a$ is fixed (25) and that the thermal diffusivity $x$ has the value

$$
x=28 \mathrm{~km}^{2} / \mathrm{m} . \mathrm{y} .\left(\cong 9 \times 10^{-3} \mathrm{~cm}^{2} / \mathrm{s}\right)
$$

\section{Extension Rate, Sedimentation Rate, and SURface Heat Flow}

We shall now consider the effects of crustal extension and sedimentation on surface heat flow for a crust whose basal temperature $\theta_{\mathrm{a}}$ is held at the (adjusted) basalt solidus $\theta_{m}(a)$. Thus we use

Crustal thickness

$$
a=23.5 \mathrm{~km}
$$

Adjusted temperature at base of crust

$$
\theta_{a}=1080^{\circ}
$$

Average crustal gradient

$$
G^{*}=\theta_{a} / a=46^{\circ} \mathrm{C} / \mathrm{km}
$$

The quantity $G^{*}$ is the gradient that would obtain throughout a stationary homogeneous crust if there were no extension (and consequently no subsidence, sedimentation, or intrusion).

Crustal geotherms for the underplating model of the Salton Trough are illustrated for extensiona! strain rates from 1 to $100 \% / \mathrm{m}$.y. $\left(3 \times 10^{-16}\right.$ to $\left.3 \times 10^{-14} \mathrm{~s}^{-1}\right)$ and four values of $\phi$ in Figure 18; they were calculated from equation (B11). A similar representation for the intrusive model, calculated from equations (B19), is presented in Figure 19. In Figures $18 a$ and $19 a$ there is no sedimentation $(\phi=0)$, and basaltic material is being underplated at the base of the crust (Figure 18a) or intruded throughout the crust (Figure 19a) at the rate necessary to compensate for extensional thinning and maintain the stationary crustal thickness $a$. Advection of heat is upward and temperature profiles are convex throughout the crust. In Figures $18 b$ and $19 b$ and $18 c$ and $19 c$ stretching of the upper 40 or $60 \%$ of the crust, respectively is compensated by sedimentation, and in these regions, advection is downward, and geotherms are concave. In Figures $18 d$ and $19 d(\phi=1)$, extensional thinning is compensated entirely by sedimentation, there are no basaltic additions, and the two models are identical, with downward advection and concave profiles throughout the crust.

Where the temperatures (shown dashed) in Figures 18 and 19 (and similar curves to follow) exceed the basalt solidus, they are, of course, fictional, as the analytical results are not valid there. For intuitive purposes it is useful, though wrong in detail, to consider such regions to contain a melt fraction that generally increases with the indicated temperature excess (see equations (30) and (31c)).

It is seen from Figures 18 and 19 that for extensional strain rates $\gamma \leqslant 1 \% / \mathrm{m}$.y. the geotherm is nearly a straight line with gradient $G^{*}$ (equation $(34 c)$ ), as expected in a static conductive regime $(\gamma=0)$. For the reasonable mean value for crustal conductivity,

$$
K \cong 2.72 \mathrm{w} / \mathrm{m}^{\circ} \mathrm{K} \cong 6.5 \mathrm{mcal} / \mathrm{cm} \mathrm{s}^{\circ} \mathrm{C}
$$

the reduced heat flow $q^{*}$ for the static case should be (equation $(34 c)$ )

$$
\begin{aligned}
& q^{*}=K G^{*} \\
& q^{*} \cong 125 \mathrm{mw} / \mathrm{m}^{2} \cong 3 \mathrm{HFU}
\end{aligned}
$$




\section{$\theta / \theta_{0}$}
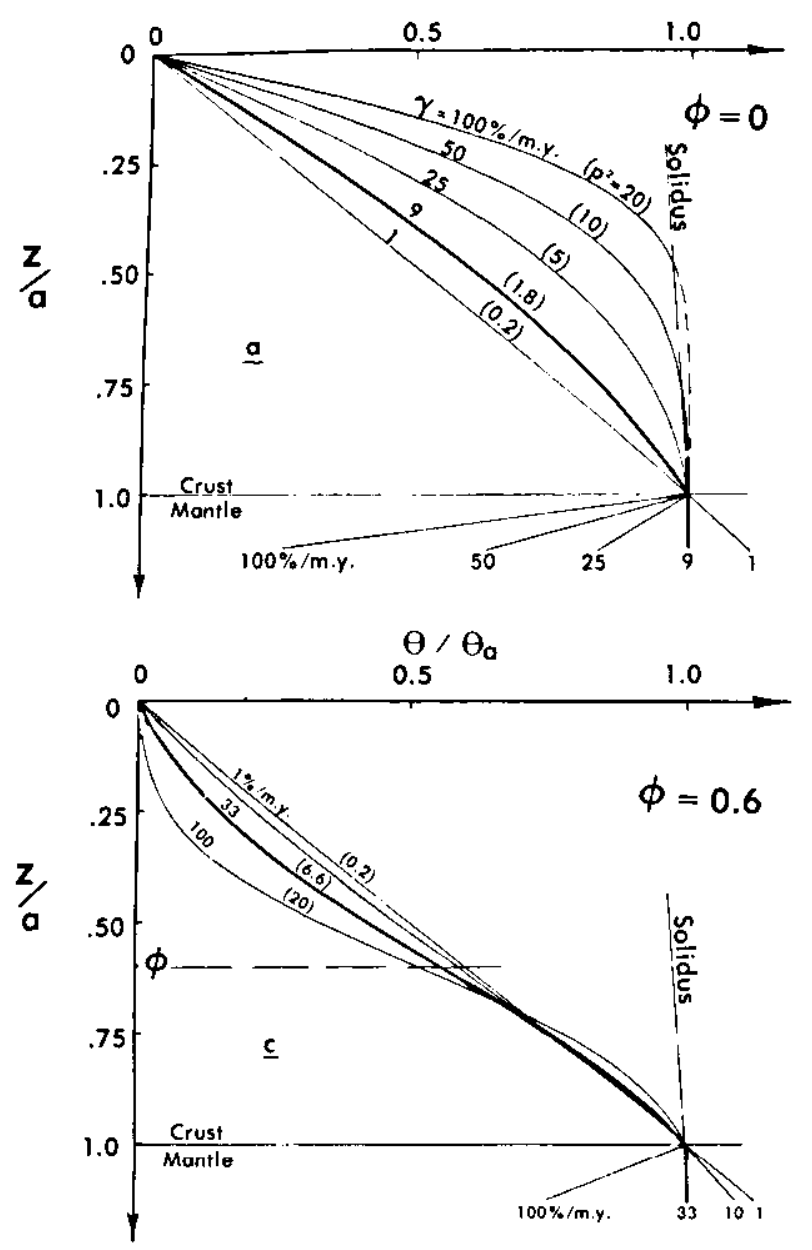

$\theta / \theta_{a}$
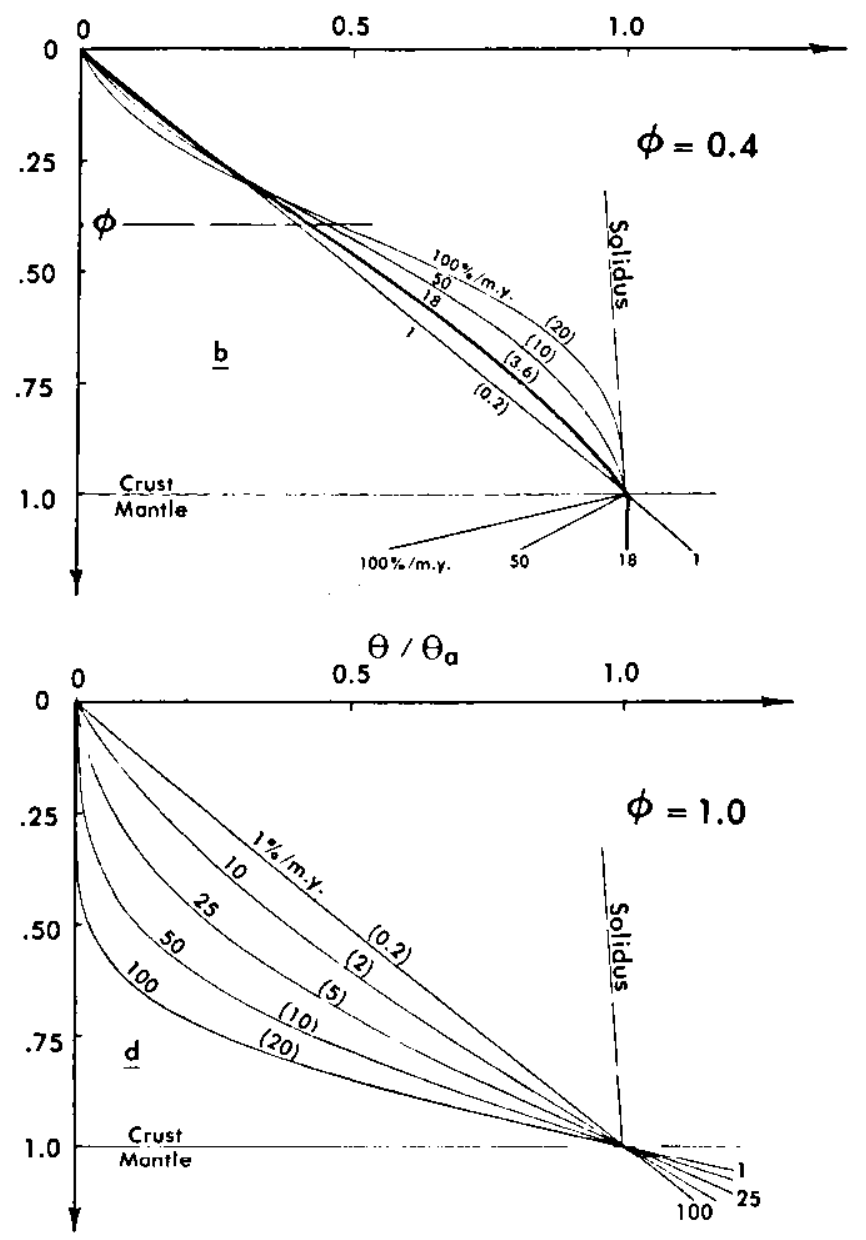

Fig. 18. Geotherms for the underplating model with base of crust maintained at solidus temperature $\theta_{a}$, for four different values of dimensionless sedimentation rate $\phi$. Numbers on curves are extension rate $\gamma$ in percent per million years and Peclet number $P^{2}$ in parentheses. Scale factors are $\theta_{a}=1080^{\circ} \mathrm{C}, a=23.5 \mathrm{~km}$ for Salton Trough. The basalt solidus is shown for these dimensional values. Dark curves in Figures $17 a, 17 b$, and $17 c$ satisfy heat balance condition (see equation (43)).

But this static conductive value is the same as the mean reduced heat flow observed in the Imperial Valley (see section 2). This is quite surprising, as it suggests that rapid sedimentation, crustal extension, and intrusion that have obviously been going on there are not affecting the heat flow. The paradox is explained by noting that for $\phi=0.4$ (Figures $18 b$ and $19 b$ ) the near-surface geothermal gradients, and hence heat flows, are about the same for extension at any reasonable rate and that $\phi=0.4$ is in the range of values we expect from the isostatic constraint (equation (21)). This effect of $\phi$ on the relation between heat flow and extension rate is illustrated more clearly by the solid curves representing heat flow for selected extension rates in Figure 23 for the underplating model (equation (B12)), and Figure 24 for the intrusive model (equation B20a). Each family of curves has a broad range within the interval $\$ \lessgtr \phi \lesssim \frac{1}{2}$ (equation (21)) where heat flow is insensitive to extension rate $\gamma$. For such ranges of $\phi$ the increased heat supply caused by more rapid intrusion at larger strain rate is compensated by the increased heat absorption by more rapidly accumulating sediments, and the surface heat flow is affected little.

Thus this simple model provides a rather robust answer to the question "Why is the heat flow high $\left(\sim 125 \mathrm{~mW} / \mathrm{m}^{2}\right)$ in the
Salton Trough?" and, indeed, to why it is not higher or lower. It could also explain why heat flow is about the same in the bordering crystalline rocks (where there was little or no sedimentation or extension) if the subcrustal asthenosphere should extend out beneath this border.

\section{Extension Rate, Heat Balance, and Size OF THE EXTENDING REGION}

We have shown that with the lower boundary temperature at the solidus, our model adequately "predicts" the observed surface heat flow but a knowledge of the heat flow does not discriminate from among a broad range of extension rates. To learn more about extension rate, we must examine heat transfer across the base of the crust, which, though less observable than surface heat flow, is not subject to the same limitation.

In section 7 we judged that the massive accumulation of lower crustal gabbro over the past $5 \mathrm{~m} . \mathrm{y}$. implies that the base of the crust was close to the basalt solidus and noted that the present crustal composition implies an average distributed extension rate $\sim 25 \% /$ m.y. or greater over that period. In this section we use thermal models to show that for distributed extension the $25 \% / \mathrm{m} . y$. rate is consistent with the subcrustal melting condition assumed but that much greater strain rates, 

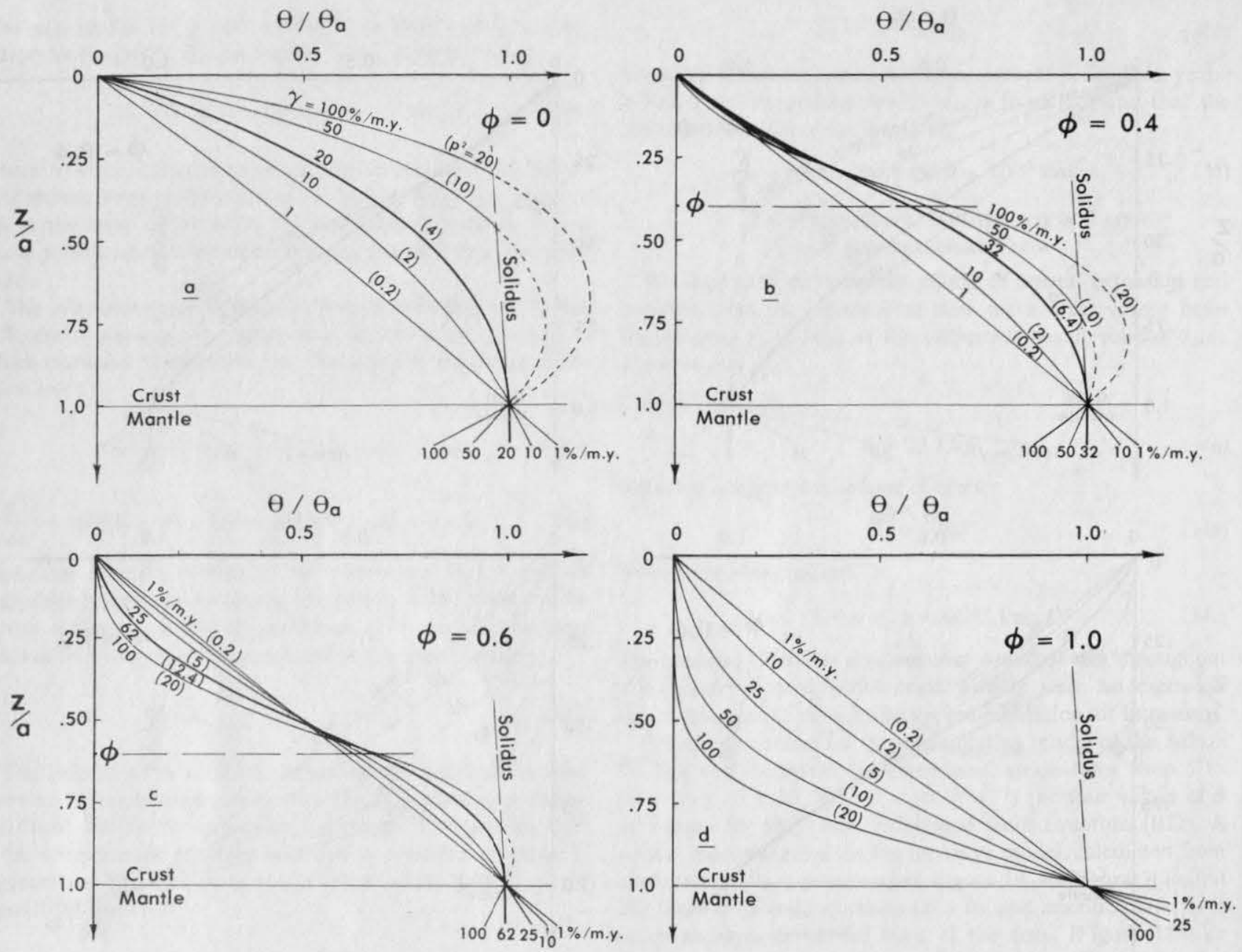

Fig. 19. Geotherms for conditions similar to Figure 18 except that magmatic additions are by pervasive intrusion of the lower crust. Dark curves in Figures 19a,19b, and 19c satisfy heat balance condition (see equation (43)).

such as those required by local ocean-type models, would generally lead to massive crustal melting.

In our model the region enclosed by the dashed curves in Figure 13 extends with constant velocity $2 v_{0}$ and with constant strain rate $\gamma$ over the length $L_{0}$ in the extension direction. Hence

$$
L_{0}=2 v_{0} / \gamma
$$

The relative velocity of the Pacific and North American plates during the past $5 \mathrm{~m} . \mathrm{y}$. has been $\sim 5.6 \mathrm{~cm} / \mathrm{yr}$ [Minister and Jordan, 1978] and $2 v_{0}$ may have been somewhat less because of motion taken up on subsidiary faults [e.g., King and Savage, 1983; Lomnitz et al., 1970]. If, for example, we take $2 v_{0}$ to be $4.5 \mathrm{~cm} / \mathrm{yr}(45 \mathrm{~km} / \mathrm{m} . \mathrm{y}$.) and $\gamma$ to be the minimum value $(25 \% / \mathrm{m} . \mathrm{y}$.) suggested by crustal composition (23), then from (37), long-term extension would be distributed over a length $L_{0}$ of about $180 \mathrm{~km}$. If, on the other hand, the locus of extension for the past $5 \mathrm{~m} . \mathrm{y}$. remained in the narrow seismic zones where much of it probably is today, $L_{0}$ would be an order of magnitude smaller $\left(L_{0}^{\prime} \sim 15-20 \mathrm{~km}\right.$, Figure 13$)$ and $\gamma$ an order of magnitude larger $(\sim 250 \% / \mathrm{m} . \mathrm{y}$.). The different thermal consequences of such alternatives can be visualized with the aid of Figures 20 and 21, although they represent onedimensional conditions and hence cannot illustrate the extreme case $L_{0}=L_{0}{ }^{\prime}(\gamma \sim 250 \% /$ m.y. $)$.
Figure 20 shows the steady state crustal geotherms required to accommodate heat given up by underplating basalt for selected extension rates with no contribution from mantle conduction (i.e., with $q_{n}=0$ in (27b)). The corresponding geotherms required in the intrusion model $\left(q_{n}=0\right.$ in (29)) are shown in Figure 21. The curves were calculated from equations (B15) and (B21), respectively. Before discussing details, we note that for extension rates in the neighborhood of $25 \% / \mathrm{m} . y$., in Figures 20 and 21 the temperature at the base of the crust is close to the solidus and the crust is mostly (or all) subsolidus. According to (37) and the foregoing example, this corresponds to having the long-term extension distributed over $\sim 180 \mathrm{~km}$. By contrast, for extension at rates of $100 \% / \mathrm{m} . y_{\text {, }}$, the temperature of most of the lower crust is above the solidus, suggesting massive crustal melting. According to (34) this case corresponds to extension distributed over a region $\left(L_{0}\right)$ only about $45 \mathrm{~km}$ wide, but still 2 or 3 times the size of the zone of active modern seismicity. The application of our one-dimensional steady state models is probably not unreasonable for this case: $L_{0} \sim 45 \mathrm{~km}$ means that the width of the spreading region is twice the crustal thickness and $\gamma \sim 100 \% /$ m.y. means that enough latent heat is advected into the lower crust (of thickness $B=a(1-\phi) \sim 14 \mathrm{~km}$ ) every million years to melt it all. As the width of the seismic zone is even narrower than in this example, for an ocean-type model 
Adjusted temperature, $\theta,\left({ }^{\circ} \mathrm{C}\right)$

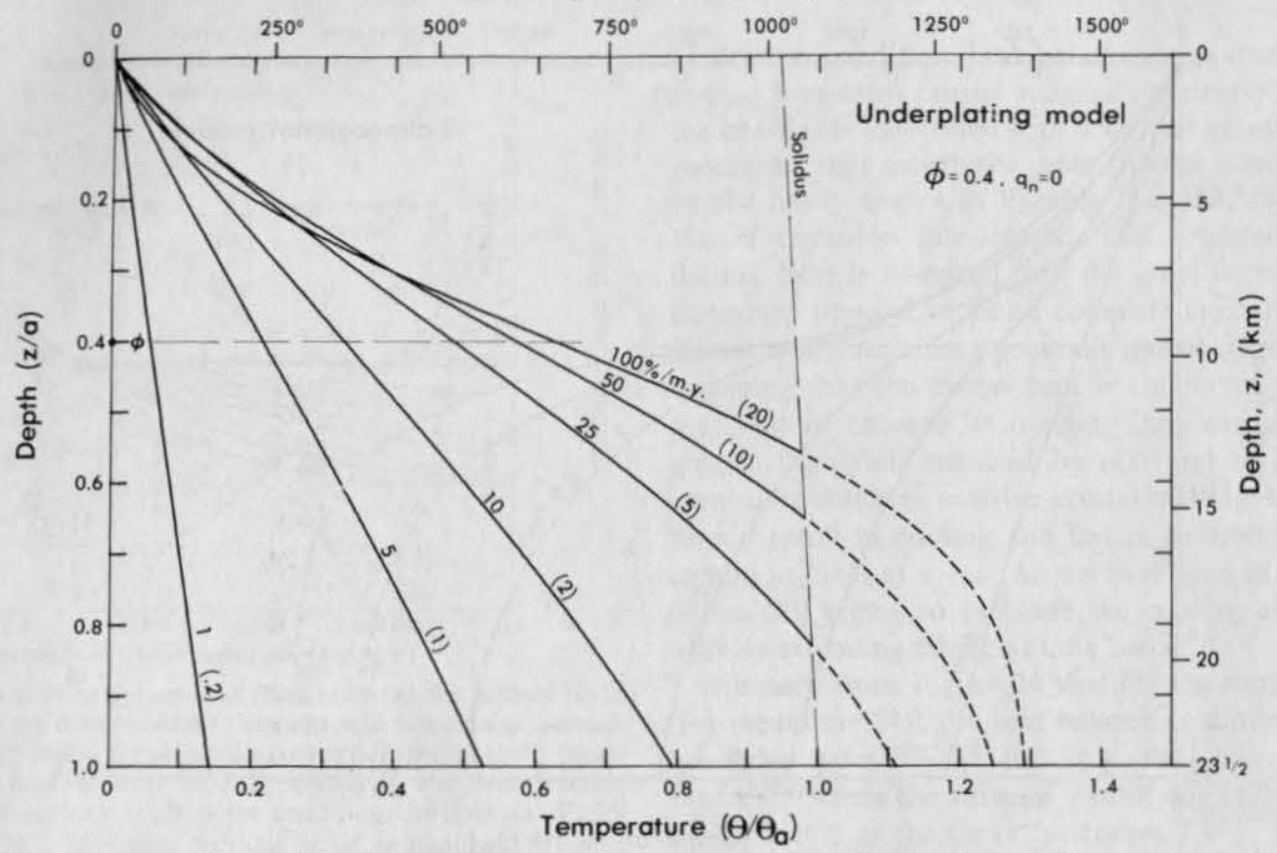

Fig. 20. Geotherms for a uniformly extending crust with sedimentation and underplating and no conductive heat flow from the mantle. The $\theta_{a}$ is the adjusted solidus temperature at base of crust; $a$ is crustal thickness. Numbers on curves are extensional strain rate; Peclet numbers (equation (32)) are in parentheses. Illustrated for completely molten magmatic additions $(f=1)$ and dimensionless sedimentation rate $\phi=0.4$. Dimensional coordinates on top and right refer to Salton Trough model.

(Figure 10) with spreading confined to that zone, we should expect still higher temperatures and even greater amounts of lower crustal melting.

One problem with the foregoing argument is that lateral heat loss is neglected. For a fixed plate separation velocity $2 v_{0}$, increasing of the strain rate $\gamma$ implies narrowing of the spreading interval; although the crustal temperature will always in- crease with $\gamma$, it will not do so as fast for $\gamma \gtrsim 100 \% /$ m.y., as is indicated by the one-dimensional models, because heat loss to the walls becomes important as the width of the spreading region $\left(L_{0}\right)$ approaches crustal thickness $a$.

To investigate spreading rates required to cause lower crustal melting for thin spreading centers, we can use the twodimensional model of Sleep [1975]. It is the analog of our

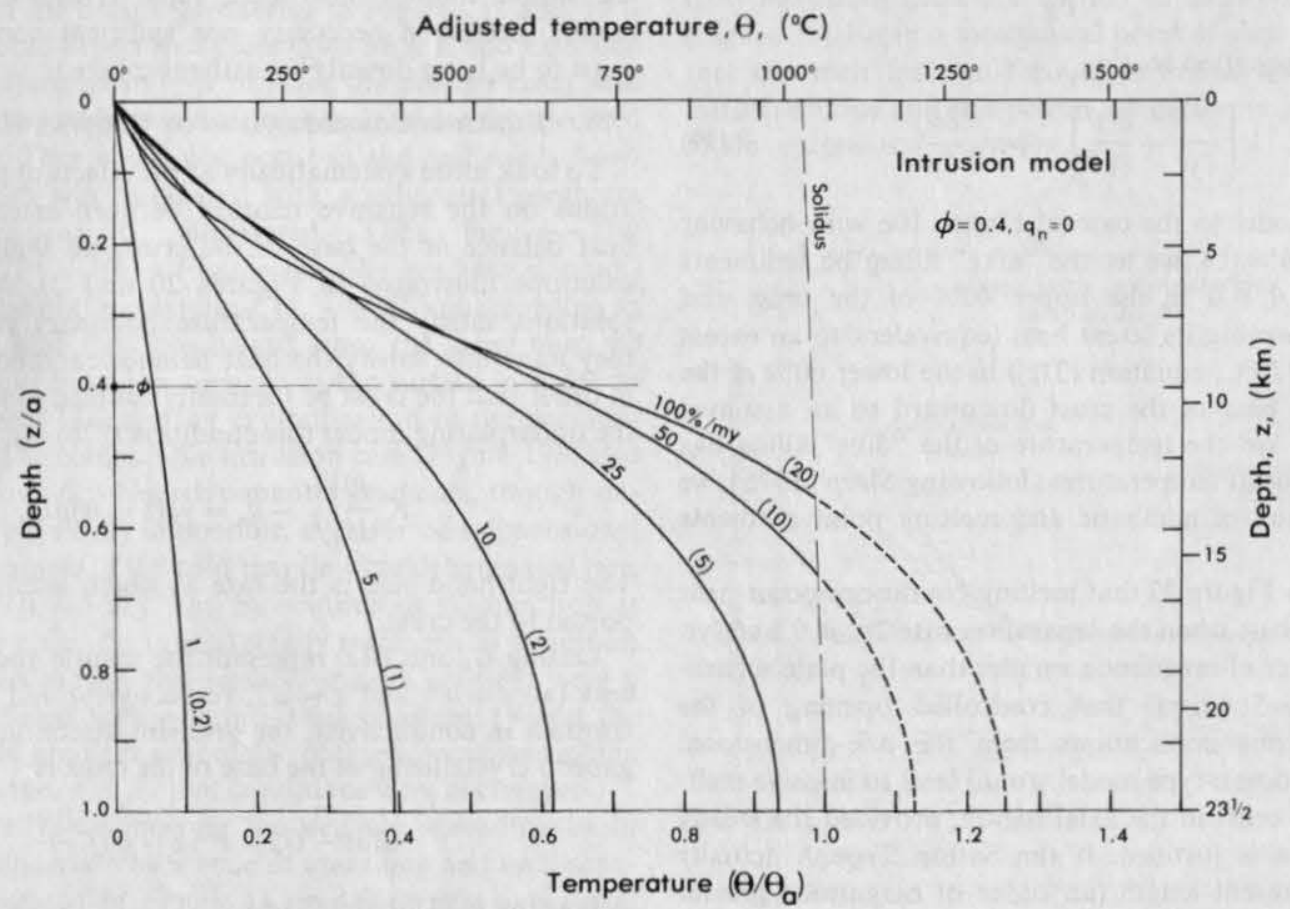

Fig. 21. Geotherms for conditions similar to Figure 22 except that magmatic additions are by pervasive intrusion of the lower crust. 


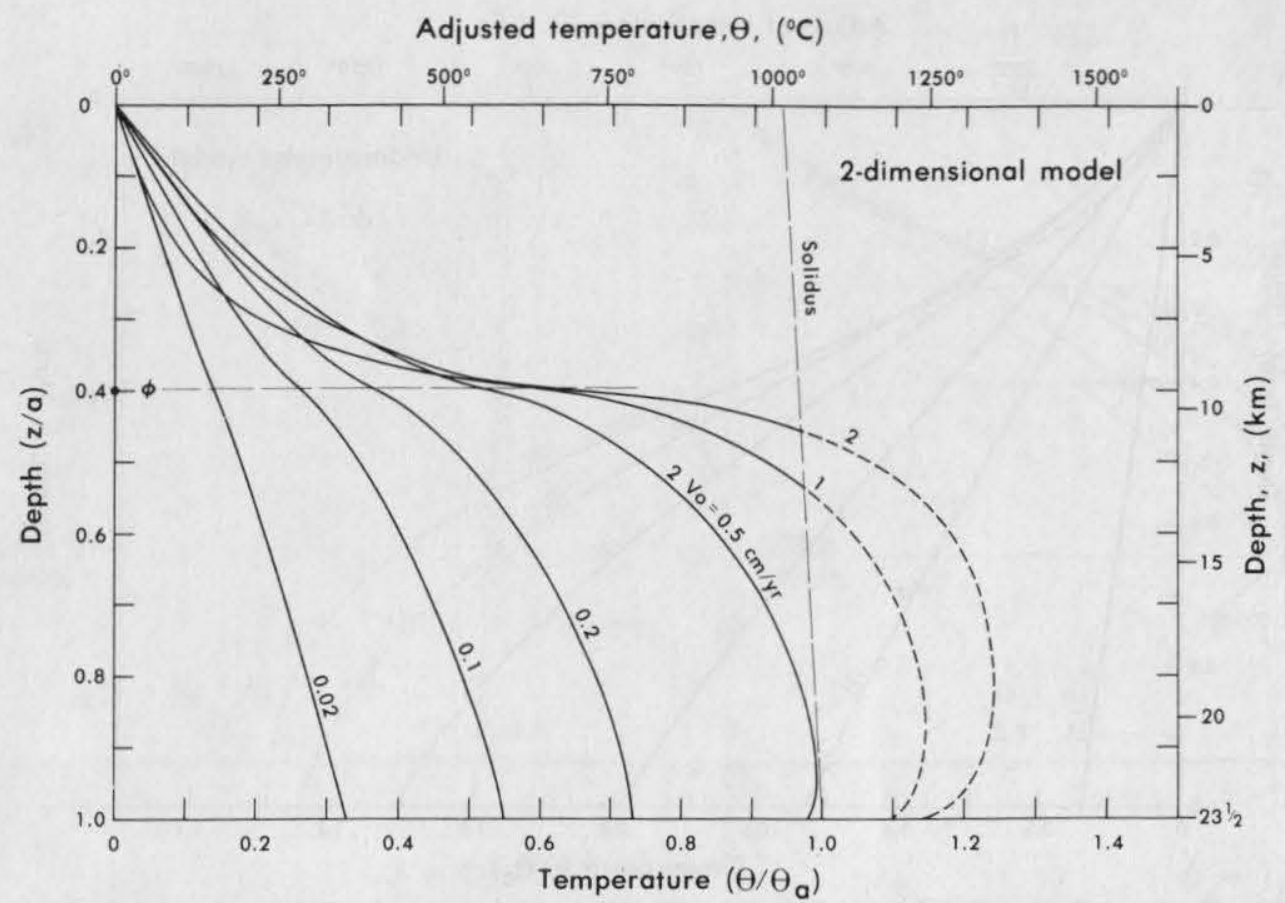

Fig. 22. Axial geotherms for crustal spreading at a zero-width dike which opens at rate $2 v_{0}$. Upper $40 \%$ of crust is produced by filling "dike" with sediments from above, lower $60 \%$ with basalt from below. Dimensional quantities are for the Salton Trough model.

intrusive model (Figure 14) for a spreading axial region of zero width. A "dike" opening at average rate $2 v_{0}$ penetrates the entire lithosphere, and heat balance is maintained by the heat absorbed or liberated by material that fills the dike at intrusion temperature $\theta_{i}(z)$ (see equation (30)), i.e., the lateral heat flow $q_{y}$ at the axis, $y=0$, is

$$
\begin{aligned}
& q_{y}=\rho c v_{0} \theta_{i}(z) \\
& q_{y}=\rho c \theta v_{0}-k \frac{\partial \theta}{\partial y} \quad y=0
\end{aligned}
$$

The differential equation is

$$
k\left[\frac{\partial^{2} \theta}{\partial y^{2}}+\frac{\partial^{2} \theta}{\partial z^{2}}\right]=\rho c v_{0} \frac{\partial \theta}{\partial y}
$$

To adapt the model to the case of Figure $10 c$ with behavior comparable to $\phi=0.4$, we let the "dike" filling be sediments at temperature $\theta_{i}=0$ in the upper $40 \%$ of the crust and molten basalt carrying its latent heat (equivalent to an excess temperature of $320^{\circ} \mathrm{C}$, equation $(31 \mathrm{c})$ ) in the lower $60 \%$ of the crust. From the base of the crust downward to an assumed isotherm at $100 \mathrm{~km}$ the temperature of the "dike" filling has little effect on crustal temperatures; following Sleep [1975], we use a combination of adiabatic and melting point gradients there.

It is seen from Figure 22 that melting conditions occur near the base of the crust when the separation rate $2 v_{0}$ is $0.5 \mathrm{~cm} / \mathrm{yr}$. As this is an order of magnitude smaller than the plate separation velocity $(\sim 5 \mathrm{~cm} / \mathrm{yr})$ that controlled opening of the trough, it confirms implications from the one-dimensional models that the ocean-type model would lead to massive melting of the lower crust in the axial region, provided the steady state assumption is justified. If the Salton Trough actually opened to its present length (an order of magnitude greater than crustal thickness) by this local process, a close approach to the thermal steady state near the axis would be expected.

We have noted that Figures 20 and 21 demonstrate that minimum extension rates $(25 \% /$ m.y.) suggested by crustal composition are compatible with the assumption of a nearsolidus basal temperature; for larger extension rates the temperature will not be much higher because of the narrow melting interval for basalt. Hence results of this section and section 9 both support the validity of the solidus-temperature boundary condition; it is the condition implied by the representation of the subcrust as asthenosphere in Figures 9 and 14. (Because of possible transient and three-dimensional departures from the simple models illustrated, rapid crustal extension is, of course, neither a necessary nor sufficient condition for the crust to be lying directly on asthenosphere.)

\section{Further Consideration of Crustal heat Balance}

To look more systematically at the effects of parameter variations on the sensitive relation between extension rate and heat balance at the base of the crust, we shall return to the solutions illustrated in Figures 20 and 21. Although these solutions satisfy the temperature boundary condition (27a), they must also satisfy the heat balance condition (27b) or (29) in order that the crust be thermally coupled to the mantle. For the underplating model this condition $(27 b)$ can be written

$$
\left.K \frac{d \theta}{d z}\right|_{a^{-}}-q_{n}=\gamma a(1-\phi) \rho L f
$$

The right-hand side is the rate at which latent heat is transported to the crust.

Letting $G_{n}$ and $G(a)$ represent the mantle and crustal gradients (at $z=a^{+}$and $z=a^{-}$, respectively) and neglecting the contrast in conductivity, the gradient discontinuity caused by gabbro crystallizing at the base of the crust is

$$
G(a)-G_{n}=P^{2}(1-\phi) f \frac{L / c}{a}
$$

According to (31c) and (34a),

$$
\frac{L / c}{a} \cong 14^{\circ} \mathrm{C} / \mathrm{km}
$$




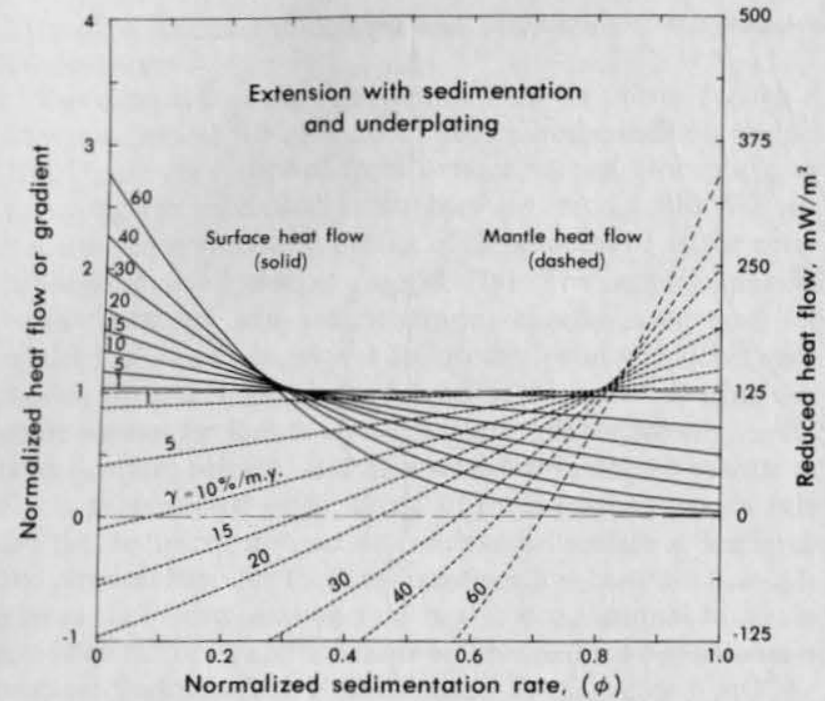

Fig. 23. Heat flow in the underplating mode at the surface (solid curves) and from the mantle (dashed curves) as a function of normalized sedimentation rate $\phi$ for selected extensional strain rates $\gamma$ (numbers on curves). Base of crust held at solidus $\theta_{a}$ and melt fraction $f=1$. Right-hand ordinate scale is for conditions in Imperial Valley (equations $(31)-(36))$; left-hand ordinate scale normalized to static value (at $\gamma=0$ ).

For the intrusion model, latent heat is transported through the base of the crust at the same rate but no discontinuity results (29). Hence

$$
G_{n}-G(a)=0
$$

The mantle gradients $G_{n}$ required for heat balance by (41a) and (42) are illustrated by the slopes of the mantle portions of the curves in Figures 18 and 19 and by the families of dashed curves in Figures 23 and 24 . In these relations, $G(a)$ has been calculated for the underplating model from (B12) and for the intrusion model from (B2Ob); the case $f=1$ is illustrated.

Thus each of the crustal geotherms in Figures 18 and 19 is the one we should expect in a solid crust after it had extended for a time constant or so ( $\sim 4 \mathrm{~m} . \mathrm{y}$. for the present case) with its base in contact with near-melting basalt under the specified extension rate. They could not occur in the real earth, however, unless each was associated with a subcrustal geotherm with the gradient $G_{n}$ illustrated. Thus for $\phi=0.4$, $\gamma=50 \% / \mathrm{m} . \mathrm{y} .\left(P^{2}=10\right)$ in Figure $18 b$, the gradient discontinuity at the base of the crust must be $\sim 84^{\circ} \mathrm{C} / \mathrm{km}$ according to (41), implying heat flow downward from the crust must be about as great as heat flow upward at the surface in order to dissipate the heat liberated by crystallization of the accumulating basalt. (The comparable intrusion case (Figure 19b) also indicates negative $G_{n}$.) Negative mantle gradients, though unlikely, are not physically impossible, even for one-dimensional models. For example, if the cold mantle were delaminated (see, e.g., Bird [1979]) 5 m.y. ago by continuous sill injection at the base of the crust, the (quasi) steady state crustal condition could exist even though the negative mantle gradient were a transient associated with a longer time constant. (When the negative mantle gradient eventually decayed, massive melting would occur in the crust if other conditions were unchanged.)

More generally, we imagine the actively spreading basin interior to be underlain by a zone of upwelling and melt separation, as illustrated in Figure 14, in which case subcrustal gradients $G_{n}$ would probably be negligible, of the order of the solidus gradient, $G_{m} \sim 3^{\circ} \mathrm{C} / \mathrm{km}$ or less (see, e.g., Ahern and Turcotte [1979]). We represent this condition by

$$
G_{n} / G^{*} \sim 0
$$

Under this condition, heat balance (with crust base at solidus but no long-term crustal magma chambers) would occur for the strain rate associated with a vertical mantle geotherm. The geotherms that satisfy this heat balance condition are shown by the heavy curves in Figures $18 a, 18 b, 18 c, 19 a, 19 b$, and $19 c$. If extension rate exceeds that required for these geotherms, heat is advected into the crust faster than it can be dissipated upward to cause complete crystallization, and the formal model requires a generally unrealistic negative gradient signifying that the excess heat is conducted downward from the crust to balance its budget. Thus extension rates much greater than that required by (43) and (41) or (42) should eventually result in massive crustal melting, and smaller ones should result in cooling and failure to meet the temperature condition $(34 b)$ at $z=a$. As we have seen in section 10, condition (23) seems to preclude the cooling alternative in the actively extending portion of the basin.

It is seen from Figure 24 that for the range of $\phi$ expected $\left(\frac{1}{4} \frac{1}{2}\right.$, equation (21)), the heat balance condition (43) is satisfied for strain rates $\gamma \sim 25-40 \% / \mathrm{m}$.y. This can be seen also in Figure 25 where the value of $\gamma$ satisfying (42) and (43) is plotted against $\phi$ as the curve "intrusion, $f=1$ " for conditions in Figure 24. From Figure 23 the case "underplating, $f=1$," the values of $\gamma$ required to satisfy heat balance (41) and (43) are about half as great $(\sim 13-23 \%)$ as in the comparable intrusion case; this is seen also in the corresponding curves in Figure 25. (The solid curves in Figure 25 represent $G_{n}=0$ and the dashed curves $G_{n}=G_{m}=3^{\circ} \mathrm{C} / \mathrm{km}$.) Shown also in Figure 25 are results for the case "underplating, $f=\frac{1}{2}$," which represents the accumulation of a half-molten crystalline mush at the base of the crust; such low melt fractions may be consistent with the high compressional wave velocity and density $\left(v_{p} \cong 7.2\right.$ $\mathrm{km} / \mathrm{s}, \rho \sim 3.1 \mathrm{~g} / \mathrm{cm}^{3}$, Figure 9) suggested by Fuis et al. [1982] for this material when fully crystallized. For $f=\frac{1}{2}$ the latent heat per unit volume is reduced, and hence greater extension (and intrusion) rates are needed to satisfy the heat balance (Figure 25). From a mechanical point of view it seems unlikely that the melt fraction $f$ could be much less than 1 in the intrusive mode and still permit the pervasive intrusion that the mode represents.

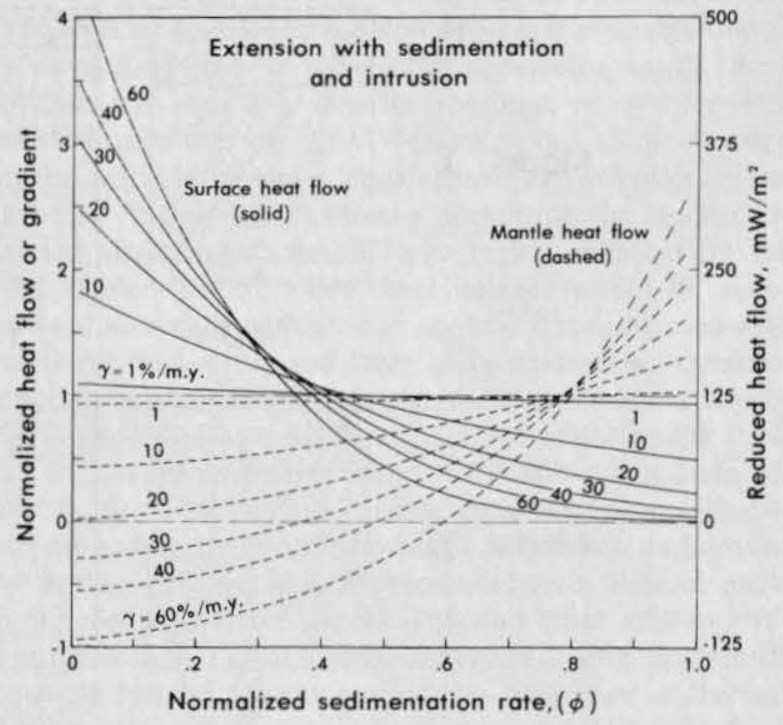

Fig. 24. Heat flow in the intrusion mode for conditions similar to Figure 22. 


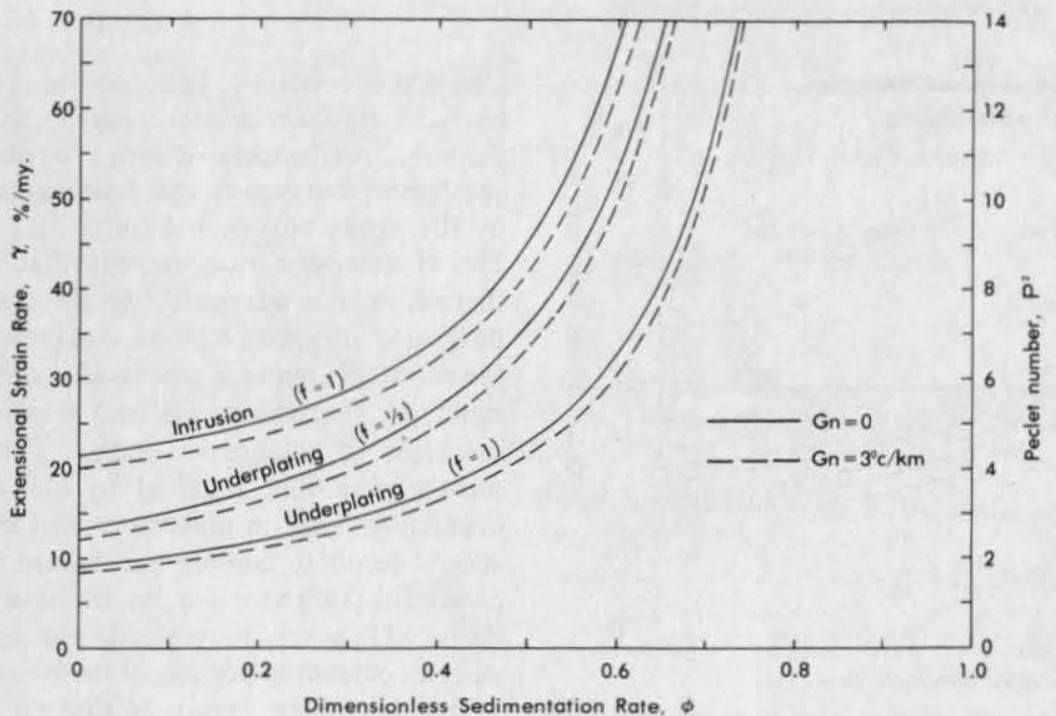

Fig. 25. Extension rate required for heat balance (when unmelted crust has its base at solidus) as a function of dimensionless sedimentation rate. Solid curves are for an upper mantle gradient $G_{n}=0$; dashed curves are $G_{n}=3^{\circ} \mathrm{C} / \mathrm{km}$. Underplating mode is illustrated for melt fraction $f=1$ (lower curves) and $\frac{1}{2}$ (middle curves). Upper curves are for the pervasive intrusion mode with $f=1$. Peclet number $P^{2}$, shown on the right-hand ordinate scale, includes the most important dimensional dependence (equation (32)).

Intuitively, it seems reasonable to expect that mantle material might invade the crust in some combination of the intrusive mode with $f \sim 1$ and the underplating mode with $f$ perhaps somewhat less. In any case, the results suggest that if extension over the last 5 m.y. can be represented as being more or less uniformly distributed over a finite region (of length $L_{0}$, Figures $11 e$ and 13) and the basal temperature of the crust has been near the solidus but the crust is not being extensively melted, then the trough has probably extended at average rates of perhaps $15-45 \% / \mathrm{m} . y$., i.e., of the order of a few tens of percent per million years or $\sim 10^{-14} \mathrm{~s}^{-1}$. For the reasonable values $2 v_{0} \sim 4.5 \mathrm{~cm} / \mathrm{yr}, \gamma \sim 30 \% / \mathrm{m} . \mathrm{y}$., equation (37) yields $L_{0} \sim 150 \mathrm{~km}$, the case illustrated in Figure 13. These results are, as we have mentioned previously, consistent with the minimum extension rate (23) suggested by present crustal composition.

\section{Discussion}

As much of the recent work on basin formation is based on the model of McKenzie [1978], it is worth putting this study in the context of that model which is represented as model I, Figure 26. Instantaneous homogeneous extension increases the area of the basin and the thermal gradient by some factor $\beta>1$ and thins the lithosphere and crust by $\beta^{-1}$. This generally involves a loss in buoyancy of the lithosphere and subsidence which we represent in Figure 26, model Ib by an initial increment of deposited sediments. The second stage of subsidence and sedimentation (models Ib-Id, Figure 26) is caused a

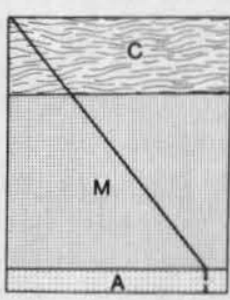

$t<0$

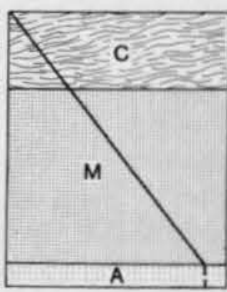

a b

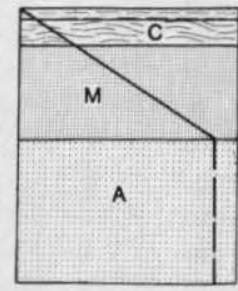

$t=0$

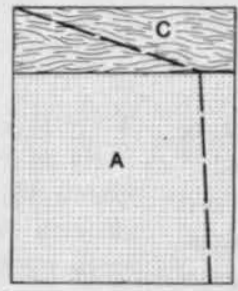

b d

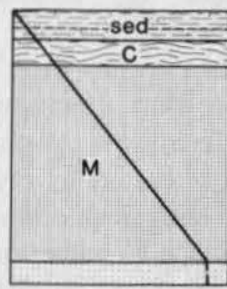

$t=t$

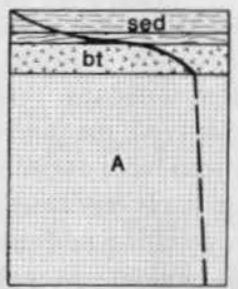

C $t=\infty$

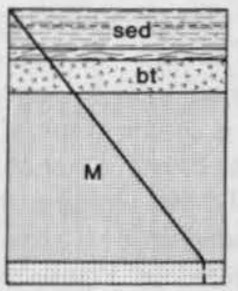

d

Fig. 26. Relationship of the present model (model II) to the McKenzie [1978] model (model I); see text. Abbreviations are C, crust; M, cold mantle; A, asthenosphere; sed, sediments; bt, basalt or gabbro. Heavy lines represent idealized geotherms. 
by passive conductive cooling and thickening of the inactive lithosphere.

For comparison, our representation of the Salton Trough is shown as model II in Figure 26. Our initial condition (model IIb, Figure 26) is derived from a more normal lithosphere by removing the subcrustal lithosphere (M, model IIa). We are not now concerned with details of the process or of the prior lithosphere configuration (model IIa). The active stage of basin formation and sedimentation, already completed for model I in Figure 26, model Ib, occurs for model II between models IIb and IIc and is the subject of this paper. During this phase we assume that the crust extends homogeneously, maintains isostatic balance, and receives basalt from the mantle at a rate proportional (with factor $B$ ) to extensional strain rate and that sedimentation maintains the solid surface at sea level. The physical basis for these assumptions has been discussed. It follows that sedimentation rate is also proportional to strain rate (with factor $S$ ) and for large strain the crust approaches a constant thickness $(B+S)$ determined by the factor $B$ and the density of the sedimentary and basaltic additions. The fraction of the crust occupied by these additions gives an estimate of total strain (22); in the notation of McKenzie [1978] we obtained a stretching factor of $\beta \geq 2.2$. Evidence that this extension occurred during the opening of the Gulf of California provides a short time frame for the massive accumulation of basalt, and this in turn suggests that the crust base temperature was near basalt melting, providing a boundary condition for thermal models. This implies that the lithosphere has been thinned to the crust by some "dismantling" process (three have been discussed: delamination of the cold mantle, warming the cold mantle from below, or stretching it until it disappears, see e.g., Bird [1979], Spohn and Schubert [1983], Turcotte and Emerman [1983], Morgan and Baker [1983], Morgan [1983], Sclater et al. [1980]). A condition of this sort was recently invoked to explain data from the Pannonian Basin in a comprehensive modeling effort by Royden et al. [1983]. Geologic evidence for thinning and warming of the lithosphere prior to opening of the Gulf has been presented by Karig and Jensky [1972] (see also Dokka and Merriam [1982]).

Thermal models suggest that unless there is extensive melting of the lower crust, extension was distributed over a distance $L_{0} \sim 150 \mathrm{~km}$ with average strain rates of the order of a few tens of percent per million years (i.e., $\sim 10^{-14} \mathrm{~s}^{-1}$ ). This is one to two orders of magnitude greater than average rates suggested by similar models for the Great Basin [Lachenbruch and Sass, 1978] or rates generally estimated for continental rifts and basins [e.g., Le Pichon et al., 1982]. It is of the same order as values suggested for some bimodal volcanic centers [Lachenbruch et al., 1976; Lachenbruch, 1978] and one to two orders of magnitude less than likely values for oceanic ridges (e.g., 1-10 cm/yr distributed over a horizontal distance of the order of crustal thickness).

If much larger extension rates prevailed in the Imperial Valley, they must have been associated with much smaller $L_{0}$, e.g., $10-20 \mathrm{~km}$ for local ocean-ridge-type models ( $L_{0} \lesssim$ crustal thickness, Figure 10a) which could represent extension confined for millions of years to the present narrow zones of active seismicity (crosshatched regions, Figure 13). Calculations with our one-dimensional models and a limiting twodimensional case suggest that this would lead to extensive lower crustal melting.

Because crustal heat balance in a spreading ocean has received more attention than that in a spreading continent, it is worth scaling our one-dimensional results to the ocean to underscore the important role played by crustal thickness. We use the intrusive model with magma completely molten $(f=1)$ and negligible sedimentation $(\phi=0)$, as expected at an ocean ridge; the important scaling parameter is $P^{2} \sim 4$ (Figure 25), and the appropriate geotherm is the heavy curve in Figure 19a. (For a different application of a related model to ridges, see Jarvis [1983].) If the crustal thickness $a$ is reduced from $23.5 \mathrm{~km}$ for the Imperial Valley to $5 \mathrm{~km}$ for oceanic crust, the extension rate for heat balance increases by the factor $(23.5 \div 5)^{2} \sim 20$; i.e., from $20 \% /$ m.y. for the Salton Trough to $400 \% / \mathrm{m} . y$. for ocean ridges. This corresponds to oceanic spreading half rates of $1 \mathrm{~cm} / \mathrm{yr}$ distributed over a plausible zone of extension a crustal thickness $(5 \mathrm{~km})$ wide. This result is in surprisingly good agreement with a calculation based on a two-dimensional model of localized spreading at an ocean ridge by Sleep [1975]. He calculated heat balance (i.e., crust base at solidus but no crustal magma chambers in a $5-\mathrm{km}$ crust) when the spreading half rate was $\sim 1 \mathrm{~cm} / \mathrm{yr}$. These results suggest that in order to avoid (massive) lower crustal melting, extension must be distributed over a distance $\sim 20$ times wider in the Salton Trough $(\sim 10$ times when sedimentation is considered, Figure 25) than in the oceanic southern gulf for the same plate separation rate. No evidence for such melting is shown in the Imperial Valley where the seismic refraction profile of Fuis et al. [1982, Figure 17a] crosses the locus of modern seismicity in the Brawley "spreading center" region. Like our earlier calculations, this suggests that the models of distributed extension (Figure 11) might be more appropriate than the localized ones (Figure 10) for the relatively thick crust of the Salton Trough. (Note that sedimentation ( $\phi>0$, heavy curves in Figure 19) is qualitatively similar to the effects of hydrothermal circulation at an ocean ridge; cold material travels downward through the upper crust (to depth $\phi a$ ), and it decreases surface heat flow and increases the extension rate required for crustal melting.)

We have shown that the geometric and gravity relations in a simple crustal spreading model are consistent with geophysical observations and crustal heat balance if the crust base has been maintained near the solidus temperature and most of the lower crust is unmelted. Under these conditions the model yields an extensional strain rate that depends largely on crustal thickness $\left(\sim 10^{-14} \mathrm{~s}^{-1}\right.$ for the Imperial Valley). We have not specified what sort of physical process in the subcrustal region might be compatible with distributed extension of a thick crust under these simple conditions (i.e., how dbes the crust know to adopt a strain rate that will keep its base melted and its interior solid). The simplest process is probably that of melt rising to the base of the crust or uppermost mantle where it spreads out until it covers an area large enough for it to freeze as fast as it is supplied. Weakening due to the elevated temperature in this region could cause the extension to be distributed throughout it, thereby permitting the modest extensional strain rates over a large region required by the model. Under this condition, heat balance would be maintained automatically with little or no crustal melting even with a relatively thick crust and large plate separation velocities; relatively rapid sedimentation (large $S$ ) and magma supply (large $B$ ) would, of course, be required to maintain the thick crust. In a more realistic refinement the sills might form beneath the rising base of the original crust (and ultimately beneath the sediments) where the basalt might lose its buoyant drive in the lighter rocks and produce viscous siliceous melts that impede its vertical progress. This and other options leading to the observed crustal structure are probably represented adequately for the present purpose by the range of thermal and kinematic models that we have presented. However, for a better understanding of the physics of the spreading process in the Salton Trough, further investigations are needed of the 
physical state of the lower crust and of the age, distribution, and structure of sediments in the basin. It is also desirable to test the foregoing conclusions with more complete models accounting for transient and two-dimensional heat flow and possible hydrologic effects.

An additional question of general interest related to this study is the significance of large $B$. It will be recalled that $B$ $\left(=b / \gamma=b L_{0} / 2 v_{0}\right)$ is the thickness of the lithosphere layer whose extensional thinning is compensated by magnatic additions from the mantle; if constant, it is the limiting thickness approached for large strain, of the layer of magmatic origin Physically, $B$ can have any value whatsoever because lithosphere extension $(\gamma>0)$ is not necessary for intrusion $(b>0)$ and conversely [Lachenbruch and Sass, 1978, p. 241; McKenzie, 1984]. However, in models of sustained spreading accompanied in some degree by magmatic additions to the lithosphere, $B$ is a useful descriptive parameter whether it represents a causal relation between $b$ and $\gamma$ or a fortuitous juxtaposition of magmatic and extensional events. For the oceanic crust (where a causal relation is not in question), $B$ is rather constant at $\sim 5 \mathrm{~km}$, leading to the expectation that magmatic contributions probably would not compensate for more than this amount during extension of continental crust (e.g., $M c$ Kenzie [1978]; see also McKenzie [1984]). However, in our model of the Salton Trough, $B$ must be $\sim 12-15 \mathrm{~km}$ to account for the seismic refraction results of Fuis et al. [1982]. It is seen that $B$ is the ratio of how fast melt is delivered by the asthenosphere $(b)$ to how fast the lithosphere can spread it out $(\gamma)$. The $b$ depends upon the temperature, composition, and velocity distribution in the asthenosphere. The anomalously large $B$ in the Salton Trough might be caused in part by the incorporation of a large refractory crystalline fraction in the crustal additions or by a large melt fraction generated by the upwelling of anomalous mantle. It could also result from the extensional strain rate $\gamma$ in the lithosphere bcing smaller than in the underlying asthenosphere. In this case, the corresponding mismatch in horizontal velocity (equation (9a)) would cause spreading tractions to be exerted by the asthenosphere on the base of the lithosphere, and large $B$ could be an indicator of this important (active) dynamic condition. In any case the data from the Salton Trough are interesting because they suggest that there are continental spreading processes in which substantial amounts of crustal thinning can be compensated by coeval magmatic additions, and this has important implications for the relations among crustal extension, crustal thinning, and subsidence. Such thermal models (with large $B$ ) have been suggested for the Great Basin [e.g., Lachenbruch, 1978], where there is little evidence that subsidence was associated with extension.

\section{Summary}

Heat flow in southernmost California is relatively high in the major valleys (the Salton Trough) and low in the surrounding mountains. This is consistent with the geometric effects of horizontal compressional deformation accompanying rapid uplift of the mountains and extensional deformation accompanying rapid subsidence of the basins in the trough. For a better understanding of the thermal regime in the trough and of the active tectonic stage of basin formation taking place there, we attempt to explain why the heat flow is high in the trough in terms of a simple model consistent with other observations. This requires an explicit mechanical model for evolution of the basin to specify the velocity field governing advection and to identify heat sources and physically plausible boundary conditions.
Measurements of gravity and crustal seismic velocity inc cate that the upper crust is composed largely of recent sec ments and the lower crust of gabbroic material from $t$ ] mantle and that they are in isostatic balance with the surfa at sea level. These observations suggest a simple mechanic model wherein an extending crust is intruded or underplate by gabbroic magma from the mantle, while subsidence is a companied by rapid sedimentation that keeps the surface sea level and isostatic balance is maintained.

The Salton Trough is a pull-apart basin between righ stepping plate boundary faults extending southward from t? San Andreas fault to the Gulf of California; it is believed 1 have formed over the last 4 or $5 \mathrm{~m}$.y. with the opening of th gulf. We assume that over this time the basin can be viewed having undergone distributed extension at a uniform averas rate $\gamma$. It is shown that if the basalt supply can also be cor sidered uniform (or more generally, if it is proportional to th spreading rate as it is at ocean ridges), the crustal thickne will approach a stationary value at which intrusion and sed mentation will compensate for thinning by extension and the relative rates will be determined by isostasy. Under these cor ditions the velocity field is determined. It remains to specil the mode of intrusion to characterize the distribution of he: sources. We consider two different modes; one in which th intrusive material is underplated on the crust as sills, the othe in which it is intruded randomly as dikes and/or sills through out the lower crust. The boundary condition that the base $c$ the crust is at or near the basalt solidus temperature the permits a complete analytical solution for temperature of th crust and hence for heat flow in terms of extension rate.

The important result is that for the ratio of sedimentatio to intrusion required by isostatic balance in the Salto Trough, increasing the extension rate has little effect on hea flow because it increases effects of the heating by intrusion an cooling by sedimentation in a compensating manner. Thus fo a wide range of extension rates the heat flow is close to th static value (with crust base at the solidus), and this explain why that is the value we measured in spite of evidence fo rapid extension.

Extension rate can be estimated by applying a seconc boundary condition at the base of the crust, namely, that th conductive heat flow there be negligible. Physically, this expected if the uppermost mantle is a zone of melt separation where the gradient is buffered by latent heat. On the basis o this criterion we expect an average extension rate in the Salto Trough of a few tens of percent per million years $\left(\sim 10^{-1}\right.$ $s^{-1}$ ). If it were faster, the latent heat of intrusion could not $b$ dissipated, and massive melting would occur in the crust; if $i$ were slower, the present composition of the crust could not $b$ accounted for in terms of igneous and sedimentary contri butions accumulating since the Gulf of California started to open.

With the extensional strain rates suggested by heat balanc and total pull-apart velocities approaching the Pacific America relative plate velocity, the length of the actively ex tending region of the basin would be $\sim 150 \mathrm{~km}$, an order 0 magnitude larger than the present zone of active seismicity This suggests that the seismic pattern may be ephemeral or the evolutionary time scale for the trough. Extension of this large region during the opening of the Gulf of California with sedimentary and magmatic additions as described by ou idealized models can account for formation of the deep sedi mentary basin observed and for the major findings from grav ity, seismic refraction, heat flow, and plate tectonics in the Salton Trough region. The models underscore the need for 
information on crustal structure, heat flow, sedimentary stratigraphy, and hydrology throughout a larger portion of the Salton Trough, so that this simplified view can be revised to give a more complete understanding of the evolution of this important region.

\section{Appendix A: Data AcQuisition}

All except two of the new sites in crystalline rocks (Tables 1 and 2 and Figures 6 and 7) were drilled specifically for heat flow. Consequently, they are situated in topographic settings selected to minimize the effects of topography on the nearsurface thermal regime. They were also completed with grout surrounding the casing in the lowermost 50-80 m [Moses and Sass, 1979] to prevent any vertical movement of water in the annulus between casing and borehole wall.

Temperature logs were obtained within 72 hours of completion and at intervals of weeks to months for at least a year postdrilling. Temperatures were obtained using the hoist units and thermistor transducers described by Sass et al. [1971b] but with a modernized digital system for measuring resistances and, in the logging truck mode, real-time data processing, plotting, and magnetic tape storage of temperaturedepth data. For the latest temperature $\log$, temperatures were measured at $0.3-\mathrm{m}$ intervals in water and at $8-\mathrm{m}$ intervals in air.

All of the new data from the unconsolidated sediments of the Imperial Valley were obtained using an in situ technique [Sass et al., 1981] during drilling. In some holes where the in situ technique did not yield sufficient information (usually because the sediments were too stiff to allow penetration of the downhole heat flow probe) the wells were cased in the conventional manner, and temperature profiles were obtained as described above for crystalline rocks.

All holes in crystalline rocks were drilled using the rotary percussion (downhole hammer) technique [see Moses and Sass, 1979]. For the early wells, cores were also obtained for comparison with measurements of thermal conductivity and radioelement abundances on chips and outcrop samples. The coring operation proved to be prohibitively expensive, however, and as soon as we established that there were no obvious systematic effects associated with the use of drill cuttings, we discontinued coring.

Thermal conductivities were measured on cuttings using the technique described by Sass et al. [1971a]. Cuttings samples were collected during drilling at intervals of $6 \mathrm{~m}$. Conductivities usually were measured on a split of each of these samples below $30 \mathrm{~m}$ with the result that between eight and 12 thermal conductivities were obtained from each well. For granitic rocks the standard deviation of a single value is typically between 10 and $20 \%$, so that this sampling density is suflicient to produce an acceptable statistical uncertainty (usually $\pm 5 \%$ or better) in the mean conductivity (Tables 1 and 2).

The abundances of uranium, thorium, and potassium were determined by A. R. Smith at the Lawrence Berkeley Laboratory, University of California, using $\gamma$ ray spectrometry. Radiation counting was continued for periods sufficiently long that checks for disequilibrium could be made and internally consistent values of radioelement abundances accurate to $\pm 5 \%$ could be obtained. Initial comparisons between cores and contiguous samples of cuttings established that no serious systematic errors were involved in using drill cuttings. Between four and six composite samples of cuttings were used for each well.

In most instances (Tables 1 and 2), topographic effects were minor or negligibly small. For those sites near which there was a substantial amount of relief, corrections for steady state topography were made using a three-dimensional Birch [1950] type correction or two-dimensional Lees hills, valleys, or monoclines [Jaeger and Sass, 1963], depending on the topographic configuration.

The heat flow $q$ was determined by combining the corrected temperature gradient $\Gamma_{c}$ (Tables 1 and 2 ) and the harmonic mean thermal conductivity $\langle K\rangle$ according to

$$
q=\langle K\rangle \Gamma_{c}
$$

for the depth range specified in Tables 1 and 2 .

\section{APPENDix B: ANAlytical Results for the Thermal MODELS}

\section{Assumptions and Notation}

We represent the crustal temperature $T(z)$ as follows:

$$
T(z)=\theta(z)+T(0)+T_{r}(z)
$$

where $T_{r}(z)$ is the contribution of crustal radioactivity and $T(O)$ is the mean temperature at the earth's surface; in the Imperial Valley its value is

$$
T(0) \cong 25^{\circ} \mathrm{C} \quad z=0
$$

In the present model the radioactivity of the lower crust is probably negligible. Radiogenic sources of uniform strength $H$ in the upper crustal layer of thickness $S$ would, in the static case, cause a temperature increase $T_{r}(z)$ given by

$$
\begin{array}{ll}
T_{r}(z)=\frac{H S^{2}}{K}\left[\frac{z}{S}-\frac{1}{2}\left(\frac{z}{S}\right)^{2}\right] & 0<z<S \\
T_{r}(z)=\frac{H S^{2}}{2 K} \sim 25^{\circ} \mathrm{C} & z \geqq S
\end{array}
$$

where $K$ is thermal conductivity and the numerical value in (B3b) is obtained from the following choice of parameters:

$$
\begin{gathered}
S \sim 10 \mathrm{~km} \\
K \sim 6.5 \mathrm{mcal} / \mathrm{cm} \mathrm{s}^{\circ} \mathrm{C}\left(=2.72 \mathrm{~W} / \mathrm{m}^{\circ} \mathrm{K}\right) \\
H \sim 3.5 \times 10^{-13} \mathrm{cal} / \mathrm{cm}^{3} \mathrm{~s}\left(=1.5 \times 10^{-6} \mathrm{~W} / \mathrm{m}^{3}\right)
\end{gathered}
$$

The value in $(\mathrm{B} 4 \mathrm{c})$ is the mean of measured values from borehole samples in the Imperial Valley [Sass et al., 1984]. As the radioactive contribution is relatively small, departures from (B3) due to advection will not be considered, and the contribution $T$, will be treated as an additive correction.

We shall analyze only the nonradiogenic part, $\theta(z)$, of $T(z)$; it is subject to the boundary condition

$$
\theta(z)=0 \quad z=0
$$

and either a temperature (equation (27a)) or heat balance (equation $(27 b)$ or $(29)$ ) boundary condition at the base of the crust $z=a$.

The solidus temperature $T_{m}(z)$ is represented by

$$
T_{m}(z)=T_{m}(0)+m z
$$

where

$$
\begin{gathered}
T_{m}(0)=1060^{\circ} \mathrm{C} \\
m=3^{\circ} \mathrm{C} / \mathrm{km}
\end{gathered}
$$


We define an adjusted solidus $\theta_{m}(z)$ by subtracting from (B6a) the additive effects of mean surface temperature (B2) and deep crustal radioactivity (B3b), i.e.,

$$
\begin{gathered}
\theta_{m}(z) \equiv T_{m}(z)-T(0)-T_{r}(a) \\
\theta_{m}\left[{ }^{\circ} \mathrm{C}\right]=1010+3 x[\mathrm{~km}]
\end{gathered}
$$

Hence at the base of a crust of thickness $23.5 \mathrm{~km}$ we use

$$
\theta_{m}(a)=1080^{\circ} \mathrm{C}
$$

The analysis for temperature in the underplating and intrusive models will differ from those presented by Lachenbruch and Sass [1978] only by the introduction of the parameter $\phi$ to account for sedimentation. Equations and results are summarized below.

\section{The Underplating Model}

Introducing the dimensionless independent variable

$$
\xi=z / a
$$

and using (25) and (32a), we can write the differential equation (26) as follows:

$$
\frac{d^{2} \theta}{d \xi^{2}}+P^{2}(\xi-\phi) \frac{d \theta}{d \xi}=0 \quad 0<\xi \leqq 1
$$

For the constant temperature boundary condition (27a) the solution is

$$
\frac{\theta}{\theta_{a}}=\frac{\operatorname{erf}(P / \sqrt{2})(\xi-\phi)+\operatorname{erf}(P / \sqrt{2}) \phi}{\operatorname{erf}(P / \sqrt{2})(1-\phi)+\operatorname{erf}(P / \sqrt{2}) \phi}
$$

The normalized thermal gradient at depth $z$ is obtained by differentiation of (B11):

$$
\frac{a}{\theta_{a}} \frac{d \theta}{d z}=\frac{1}{P}\left(\frac{\pi}{2}\right)^{1 / 2} e^{(P / 2)(\xi-\phi) 2}\left[\operatorname{erf} \frac{P}{\sqrt{2}}(1-\phi)+\operatorname{erf} \frac{P}{\sqrt{2}} \phi\right]^{-1}
$$

The heat balance boundary condition $(27 b)$ can be written (with (25) and (32a))

$$
\frac{d \theta}{d z}=\frac{q_{n}}{K}+\frac{P^{2}(1-\phi)}{a}\left[\theta_{i}-\theta\right] \quad z=a
$$

For solution of $(\mathrm{B} 10)$ it is convenient to put this in the form of the so-called radiation boundary condition [e.g., Carslaw and Jacyer, 1959, p. 18]

$$
\frac{d \theta}{d \xi}=P^{2}(1-\phi)\left[\theta_{0}-\theta\right] \quad \xi=1
$$

where (see (30))

$$
0_{0}=0_{m}(a)+f \frac{L}{C}+\frac{a q_{n}}{K} \frac{1}{P^{2}(1-\phi)}
$$

The solution of (B10) subject to (B14) is

$$
\begin{aligned}
\frac{\theta}{\theta_{0}}= & \left(\frac{\pi}{2}\right)^{1 / 2}\left[\operatorname{erf} \frac{P}{\sqrt{2}}(\xi-\phi)+\operatorname{erf} \frac{P}{\sqrt{2}} \phi\right] \\
& \cdot\left\{\left(\frac{\pi}{2}\right)^{1 / 2}\left[\operatorname{erf} \frac{P}{\sqrt{2}}(1-\phi)+\operatorname{erf} \frac{P}{\sqrt{2}} \phi\right]+\frac{1}{P(1-\phi)}\right. \\
& \left.\cdot e^{-(P 2 / 2)(1-\phi)^{2}}\right\}^{-1}
\end{aligned}
$$

\section{The Intrusite Model}

Equations (28a) and (28b) are, in the present notation,

$$
\begin{array}{cc}
\frac{d^{2} \theta}{d \xi^{2}}+P^{2}(\xi-\phi) \frac{d \theta}{d \xi}=0 & 0<\xi<\phi \\
\frac{d^{2} \theta}{d \xi^{2}}+P^{2}\left(\theta_{i}-\theta\right)+P^{2}(\xi-\phi) \frac{d \theta_{i}}{d \xi}=0 & \phi<\xi<1
\end{array}
$$

(B16a

$(\mathrm{B} 16 b$

Equations (B16) are subject to the requirement that $\theta$ and its derivative be continuous at $\xi=\phi$. If we denote by $\theta_{i}(\phi)$, the value of $\theta_{i}$ at $\xi=\phi$, then according to (30),

$$
\theta_{i}(\phi) \equiv \theta_{m}(a \phi)+f \frac{L}{C}
$$

and

$$
0_{i}=\theta_{i}(\phi)+G_{m} a(\xi-\phi)
$$

Introducing (B17) into (B16b) results in a slight simplication:

$$
\frac{d^{2} \theta}{d \xi^{2}}+P^{2}\left(\theta_{i}(\phi)-\theta\right)+2 P^{2} G_{m} a(\xi-\phi)=0 \quad \phi<\xi<1
$$

The solution to these equations, subject to the constant temperature boundary condition $(27 a)$, is

$$
\begin{aligned}
\theta(\xi)= & \theta(\phi)\left\{1+\frac{\operatorname{erf}(P / \sqrt{2})(\xi-\phi)}{\operatorname{erf}(P / \sqrt{2}) \phi}\right\} \quad 0<\xi<\phi \\
\theta(\xi)= & \theta(\phi)+\left[\theta_{i}(\phi)-\theta(\phi)\right]\left\{1-\frac{\cosh P(1-\xi)}{\cosh P(1-\phi)}\right. \\
& \left.-\frac{\sinh P(\xi-\phi)}{\sinh P(1-\phi)}[1-\operatorname{sech} P(1-\phi)]\right\} \\
& +\frac{\sinh P(\xi-\phi)}{\sinh P(1-\phi)}\left[\theta_{a}-\theta(\phi)-2 a G_{m}(1-\phi)\right] \\
& +2 a G_{m}(\xi-\phi) \quad \phi<\xi<a
\end{aligned}
$$

and the interface temperature $\theta(\phi)$ at $\xi=\phi$ is given by

$$
\begin{aligned}
O(\phi)= & \left(\frac{\pi}{2}\right)^{1 / 2} \operatorname{erf}\left(\frac{P}{\sqrt{2}} \phi\right) \tanh P(1-\phi) \\
& \cdot\left\{\tanh P(1-\phi)+\left(\frac{\pi}{2}\right)^{1 / 2} \operatorname{erf} \frac{P}{\sqrt{2}} \phi\right\}^{-1} \\
& \cdot\left\{\theta_{i}(\phi)\left[\frac{\cosh P(1-\phi)-1}{\sinh P(1-\phi)}\right]+\frac{1}{\sinh P(1-\phi)}\right. \\
& \left.\cdot\left[\theta_{a}-2 a G_{m}(1-\phi)\right]+\frac{2 a G_{m}}{P}\right\}
\end{aligned}
$$

Differentiation of (B19a) yields the gradient at the surface.

$$
\left.\frac{d \theta}{d z}\right|_{z=0}=\frac{\theta(\phi)}{a}\left\{\frac{1}{P}\left(\frac{\pi}{2}\right)^{1 / 2} e^{(P 2 / 2) \phi^{2}} \operatorname{erf} \frac{P}{\sqrt{2}} \phi\right\}^{-1}
$$

The gradient at the base of the crust obtained from (B19b) is

$$
\begin{aligned}
\left.\frac{d \theta}{d z}\right|_{z=a}= & \frac{\theta_{i}(\phi)-\theta(\phi)}{a}\{P \operatorname{coth} P(1-\phi)[\operatorname{sech} P(1-\phi)-1]\} \\
& +\left\{\frac{\theta_{a}-\theta(\phi)}{a}-2 G_{m}(1-\phi)\right\} P \operatorname{sech} P(1-\phi)+2 G_{m}
\end{aligned}
$$


For the intrusion model with the heat balance boundary condition (29) the temperature is given by

$$
\begin{gathered}
\theta(\xi)=\theta(\phi)\left\{1-\frac{\operatorname{erf}(P / \sqrt{2})(\xi-\phi)}{\operatorname{erf}(P / \sqrt{2}) \phi}\right\} \quad 0<\xi<\phi \quad \text { (B21a) } \\
\theta(\xi)=\theta(\phi)+\left[\theta_{i}(\phi)-\theta(\phi)\right]\left\{1-\frac{\cosh P(1-\xi)}{\cosh P(1-\phi)}\right\} \\
+\frac{a}{P}\left[\frac{q_{n}}{K}-2 G_{m}\right] \frac{\sinh P(\xi-\phi)}{\cosh P(1-\phi)}+2 G_{m} a(\xi-\phi) \\
\phi<\xi<1 \quad(\mathrm{~B} 21 b)
\end{gathered}
$$

where the interface temperature $O(\phi)$ at $\xi=\phi$ is given by

$$
\begin{aligned}
\theta(\phi)= & \frac{(\pi / 2)^{1 / 2} \operatorname{erf}(P / \sqrt{2}) \phi}{1+(\pi / 2)^{1 / 2} \operatorname{erf}(P / \sqrt{2}) \phi \tanh P(1-\phi)} \\
& \cdot\left\{\theta_{i}(\phi) \tanh P(1-\phi)+\operatorname{sech} P(1-\phi)\right. \\
& \left.\cdot\left[\frac{q_{n}}{K}-2 G_{m}\right] \frac{a}{P}+2 G_{m} \frac{a}{P}\right\}
\end{aligned}
$$

Acknowledgments. We are grateful to our colleague B. V. Marshall for assistance with numerical computations and computer graphics. We thank Robert W. Rex, Republic Geothermal, for sharing his unpublished geothermal gradient data from the Imperial Valley and Frank Wyatt, University of California, San Diego, for assistance in obtaining data from the Pinyon Flat Observatory. We also thank the following people for their helpful comments on our manuscript: Paul Morgan, Gary Fuis, Walter Mooney, James C. Savage, Warren Hamilton, Marcus Langseth, Thomas C. Hanks, Norman Sleep, Paul Kasameyer, L. Younker, Peter Ward, Robert DeRito, T. C. Lee, and Dan McKenzie.

\section{REFERENCES}

Ahern, J. L., and D. L. Turcotte, Magma migration beneath an ocean ridge, Earth Planet. Sci. Lett., 45, 115-122, 1979.

Atwater, T., Implications of plate tectonics for the Cenozoic tectonic evolution of western North America, Geol. Soc. Am. Bull., 81, 3513$3536,1970$.

Aydin, A., and A. Nur, Evolution of pull-apart basins and their scale independence, Tectonics, I, 91-105, 1982.

Biehler, S., Geophysical study of the Salton Trough of southern California, Ph.D. thesis, Calif. Inst. of Technol., Pasadena, 1964.

Biehler, S., R. L. Kovach, and C. R. Allen, Geophysical framework of northern end of Gulf of California structural province, in Marine Geology of the Gulf of California, AAPG Mem. 3, edited by T. H. van Andel and G. G. Shor, Jr., pp. 126-143, American Association of Petroleum Geologists. Tulsa, Okla., 1964.

Birch, F., Flow of heat in the Front Range, Colorado, Geol. Soc. Am. Bull., 6I, 567-630, 1950

Bird, P., Continental delamination and the Colorado Plateau, J. Geophys. Res., 84, 7561-7571, 1979.

Carslaw, H. S., and J. C. Jaeger, Conduction of Heat in Solids, 386 pp., Oxford University Press, New York, 1959.

Crowell, J. C., Sedimentation along the San Andreas fault, California, in Modern and Ancient Geosynclinal Sedimentation, Spec. Publ. 19, edited by R. H. Dott, Jr., and R. H. Shaver, pp. 292-303, Society of Economic Paleontologists and Mineralogists, Tulsa, Okla., 1974a.

Crowell, J. C., Origin of late Cenozoic basins in southern California, in Tectonics and Sedimentation, Spec. Publ. 22, edited by W. R. Dickinson, pp. 190-204, Society of Economic Paleontologists and Mineralogists, Tulsa, Okla., $1947 b$.

Crowell, J. C., and A. G. Sylvester, Introduction to the San AndreasSalton Trough Juncture, in Tectonics of the Juncture Between the San Andreas Fault System and the Salton Trough, Southeastern California, edited by J. C. Crowell and A. G. Sylvester, pp. 1-13, Department of Geological Sciences, University of California, Santa Barbara, 1979.

Dokka, R. K., and R. H. Merriam, Late Cenozoic extension of northeastern Baja California, Mexico, Geol. Soc. Am. Bull., 93, 371-378, 1982.

Elders, W. A., R. W. Rex, T. Meidav, P. T. Robinson, and S. Biehler, Crustal spreading in southern California, Science, 178, 15-24, 1972.
England, P., Constraints on extension of continental lithosphere, $J$. Geophys. Res., 88, 1145-1152, 1983.

Fenneman, N. M., Physical divisions of the United States, report, U.S. Dep. of the Inter., Washington, D. C., 1946.

Fuis, G. S., W. D. Mooney, J. H. Healy, G. A. McMechan, and W. J. Lutter, Crustal structure of the Imperial Valley region, U.S. Geol. Surr. Prof. Pap., 1254, 25-49, 1982.

Fuis, G. S., W. D. Mooney, J. H. Healy, G. A. McMechan, and W. J. Lutter, A seismic refraction survey of the Imperial Valley region, California, J. Geophys. Res., 89, 1165-1189, 1984.

Garfunkel, Z., The tectonics of the Salton Trough, southern California and Mexico and their relation to plate tectonics, in Cooperative Investigation of Geothermal Resources in the Imperial Valley Area and their Potential Value for Desalting of Water and Other Purposes, pp. H-1-H-33, Education Research Service, University of California, Riverside, $1972 a$.

Garfunkel, Z., The structure of the Salton Trough in southern California, in Cooperative Intestigation of Geothermal Resources in the Imperial Valley Area and their Potential Value for Desalting of Water and Other Purposes, pp. I-1-I-57, Education Research Service, University of California, Riverside, $1972 b$.

Hadley, D., and H. Kanamori, Seismic structure of the Transverse Ranges, California, Geol. Soc. Am. Bull., 88, 1469-1478, 1977.

Hamilton, W., Origin of the Gulf of California, Geol. Soc. Am. Bull, $72,1307-1318,1961$.

Harrison, J. C., and S. P. Mathur, Gravity anomalies in Gulf of California, in Marine Geology' of the Gulf of California, AAPG Mem. 3, edited by T. H. van Andel and G. G. Shor, Jr., pp. 76-89, American Association of Petroleum Geologists, Tulsa. Okla., 1964.

Henyey, T. L., and J. L. Bischoff, Tectonic elements of the northern part of the Gulf of California, Geol. Soc. Am. Bull., 84, 315-330, 1973.

Hill, D. P., A model of earthquake swarms, J. Geophys. Res., 82, $1347-1352,1977$.

Jaeger, J. C., and J. H. Sass, Lees's topographic correction in heat flow and the geothermal hux in Tasmania, Geofis. Pura Appl., 54 $53-63,1963$.

Jarvis, G. T., Submarine rifting at mid-ocean ridges, Tertonophysics, 94, 109-122, 1983.

Jarvis. G. T., and D. P. McKenzie, Sedimentary basin formation with finite extension rates, Earth Planct. Sci. Lett., 48, 42-52, 1980.

Johnson, C. E., and D. P. Hill, Seismicity of the Imperial Valley, U.S. Geol. Surv. Prof. Pap., 1254, 15-24, 1982.

Johnson, C. E., and L. K. Hutton, Aftershocks and preearthquake scismicity, U.S. Geol. Surv. Prof. Pap., 1254, 59-76, 1982.

Karig. D. E., and W. Jensky, The proto-Gulf of California, Earth Planet. Sci. Lett., 17, 169-174, 1972.

King, N. E., and J. C. Savage, Strain rate profile across the Elsinore, San Jacinto, and San Andreas faults near Palm Springs, California, 1973-81, Geophys. Res. Lett., 10, 55-57, 1983.

Kovach, R. L., C. R. Allen, and F. Press, Geophysical investigations in the Colorado delta region, J. Geophys. Res., 67, 2845-2871, 1962.

Lachenbruch, A. H., Preliminary geothermal model of the Sierra Nevada, J. Geophys. Res., 73, 6977-6989, 1968.

Lachenbruch, A. H., Heat flow in the Basin and Range province and thermal effects of tectonic extension, Pure Appl. Geophys., 117, $34-50,1978$.

Lachenbruch, A. H., and J. H. Sass, Heat flow in the United States and the thermal regime of the crust, in The Earth's Crust, Geophys. Monogr. Ser., vol. 20, edited by J. G. Heacock, pp. 626-675, AGU, Washington, D. C., 1977.

Lachenbruch, A. H., and J. H. Sass, Models of an extending lithosphere and heat flow in the Basin and Range province, Geol. Soc. Am. Mem., 152, 209-250, 1978.

Lachenbruch, A. H., and J. H. Sass, Heat flow and energetics of the San Andreas fault zone, J. Geophys. Res., 85, 6185-6223, 1980.

Lachenbruch, A. H., and J. H. Sass, Corrections to "Heat flow and energetics of the San Andreas fault zone" and some additional comments on the relation between fault friction and observed heat flow, J. Geophys. Res., 86, 7171-7172, 1981.

Lachenbruch, A. H., J. H. Sass, R. J. Munroe, and T. H. Moses, Jr., Geothermal setting and simple heat conduction models for the Long Valley Caldera, J. Geophys. Res., 81, 769-784, 1976.

Larson, R. L., H. W. Menard, and S. M. Smith, Gulf of California: A result of ocean-floor spreading and transform faulting. Science, $16 I$, 781-784, 1968.

Lawver, L. A., and D. L. Williams, Heat flow in the central Gulf of California, J. Geophys. Res., 84, 3465-3478, 1979.

Lee, T.-C., Heat flow through the San Jacinto fault zone, southern California, Geophy's. J. R. Astron. Soc., 72, 721-731, 1983. 
Le Pichon, X., and J.-C. Sibuet, Passive margins: A model of formation, J. Geophys. Res., 86, 3708-3720, 1981.

Le Pichon, X., J. Angelier, and J.-C. Sibuet, Subsidence and stretching, in Studies in Continental Margin Geology, AAPG Mem. 34, edited by J. S. Watkins and C. L. Drake, pp. 731-741, American Association of Petroleum Geologists, Tulsa, Okla., 1982.

Lomnitz, C., F. Mooser, C. R. Allen, J. N. Brune, and W. Thatcher, Seismicity and tectonics of the northern Gulf of California region, Mexico: Preliminary results, Geofis. Jnt., 10, 37-48, 1970.

Lucchitta, I., Early history of the Colorado River in the Basin and Range province, Geol. Soc. Am. Bull., 83, 1933-1948, 1972.

McKenzie, D., Some remarks on the development of sedimentary basins, Earth Planet. Sci. Lett., 40, 25-32, 1978.

McKenzie, D., A possible mechanism for epeirogenic uplift, Nature, 307, 616-618, 1984.

Mann, P., M. R. Hempton, D. C. Bradley, and K. Burke, Development of pull-apart basins, J. Geol., 91, 529-554, 1983.

Mase, C. W., J. H. Sass, C. A. Brook, and R. J. Munroe, Shallow hydrothermal regime of the East Brawley and Glamis KGRA's, Salton Trough, California, U.S. Geol. Surv. Open File Rep., 81-834, 57 p., 1981.

Merriam, R., and O. L. Bandy, Source of upper Cenozoic sediments in Colorado delta region, J. Sediment. Petrol. 35, 911-916, 1965.

Minster, J. B., and T. H. Jordan, Present-day plate motions, J. Geophys. Res., 83, 5331-5354, 1978.

Morgan, P., Constraints on rift thermal processes from heat flow and uplift, Tectonophysics, 94, 277-298, 1983.

Morgan, P., and B. H. Baker, Introduction-Processes of continental rifting, Tectonophysics, 94, 1-10, 1983.

Moses, T. H., Jr., and J. H. Sass, Drilling techniques presently in use by the Geothermal Studies Project, U.S. Geol. Surv. Open File Rep., $79.763,1979$.

Muffler, L. J. P., and B. R. Doe, Composition and mean age of detritus of the Colorado River Delta in the Salton Trough, southeastern California, J. Sediment. Petrol., 38, 384-399, 1968.

Muffler, L. J. P., and D. E. White, Active metamorphism of upper Cenozoic sediments in the Salton Sea geothermal field and the Salton Trough, southeastern California, Geol. Soc. Am. Bull., 80, 157-182, 1969.

Roy. R. F., D. D. Black well, and F. Birch, Heat generation of plutonic rocks and continental heat flow provinces, Earth Planet. Sci. Lett., $5,1-12,1968$.

Roy, R. F. D. D. Blackwell, and E. R. Decker, Continental heat flow, in The Nature of the Solid Earth, edited by E. C. Robertson, pp. 506-543, McGraw-Hill, New York, 1972.

Royden, L., F. Horvath, A. Nagymarosy, and L. Stegena, Evolution of the Pannonian basin system, 2, Subsidence and thermal history, Tectonics, 2, 91-137, 1983.

Sass, J. H., A. H. Lachenbruch, and R. J. Munroe, Thermal conductivity of rocks from measurements on fragments and its application to heat flow determinations, J. Geophys. Res., 76, 3391-3401, 1971 a.
Sass, J. H., A. H. Lachenbruch, R. J. Munroe, G. W. Greene, and I H. Moses, Jr., Heat flow in the western United States, J. Geophy Res., 76, 6376-6413, $1971 b$.

Sass, J. H., D. D. Blackwell, D. S. Chapman, J. K. Costain, E. R Decker, L. A. Lawver, and C. A. Swanberg, Heat flow from th crust of the United States, in Physical Properties of Rocks an Minerals, edited by Y. S. Touloukian, W. R. Judd, and R. F. Roy pp. 503-548, McGraw-Hill, New York, 1981.

Sass, J. H., S. P. Galanis, Jr., A. H. Lachenbruch, B. V. Marshall, an R. J. Munroe, Temperature, thermal conductivity, heat flow, an radiogenic heat production from unconsolidated sediments of th Imperial Valley, California, U.S. Geol. Surv. Open File Rep., 84-490 37 pp., 1984.

Sclater, J. G., L. Royden, F. Horvath, B. C. Burchfiel, S. Semken, an L. Stegena, The formation of the intra-Carpathian basins as deter mined from subsidence data, Earth Planet. Sci. Lett., SI, 139-162 1980.

Sharman, G. F., M. S. Reichle, and J. N. Brune, Detailed study o relative plate motion in the Gulf of California, Geology, 4, 206-210 1976.

Sharp, R. V., Tectonic setting of the Imperial Valley region, U.S. Geo Surv. Prof. Pap., 1254, 5-14, 1982.

Sleep, N. H., Formation of oceanic crust: Some thermal constraints J. Geophys. Res., 80, 4037-4042, 1975.

Smith, D. L., C. E. Nuckels, R. L. Jones, and G. A. Cook, Distri bution of heat flow and radioactive heat generation in norther Mexico, J. Geophys. Res., 84, 2371-2379, 1979.

Spohn, T., and G. Schubert, Convective thinning of the lithosphere: mechanism for rifting and mid-plate volcanism on Earth, Venus and Mars, Tectonophysics, 94, 67-90, 1983.

Swanberg, C. A., Heat flow and geothermal potential of the Eas Mesa KGRA, Imperial Valley, California, in Proceedings, Confer ence on Research for the Development of Geothermal Energy Re sources, p. 85, California Institute of Technology, Pasadena, 1974.

Turcotte, D. L., and S. H. Emerman, Mechanisms of active and pas sive rifting, Tectonophysics, 94, 39-50, 1983.

Turcotte, D. L., W. F. Haxby, and J. R. Ockendon, Lithospheri instabilities, in Island Arcs, Deep Sea Trenches and Back-Arc Basins, Maurice Ewing Ser., vol. 1, edited by M. Talwani, and W. C. Pitman 1II, pp. 63-69, AGU, Washington, D. C., 1977.

Von Herzen, R. P., Geothermal heat flow in the Gulfs of California and Aden, Science, 140, 1207-1208, 1963.

S. P. Galanis, Jr., A. H. Lachenbruch, and J. H. Sass, U.S. Geologi cal Survey, Geothermal Studies Project, 345 Middlefield Road MS/923, Menlo Park, CA 94025.

(Received July 12, 1984; revised February 27, 1985; accepted February 27, 1985.) 